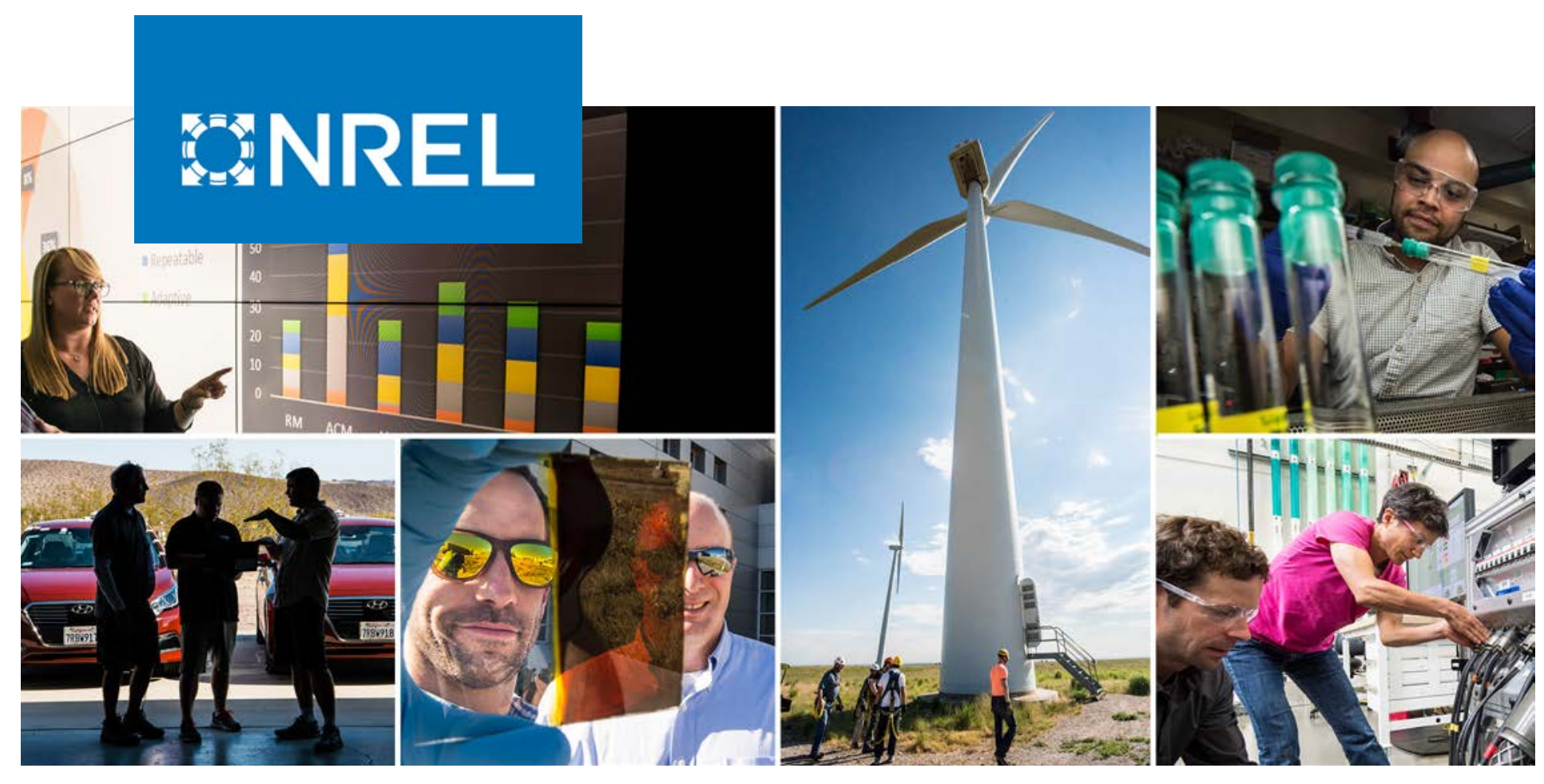

\title{
2018 Cost of Wind Energy Review
}

\section{Tyler Stehly and Philipp Beiter}

National Renewable Energy Laboratory

NREL is a national laboratory of the U.S. Department of Energy Office of Energy Efficiency \& Renewable Energy Operated by the Alliance for Sustainable Energy, LLC

This report is available at no cost from the National Renewable Energy Laboratory (NREL) at www.nrel.gov/publications.
Technical Report

NREL/TP-5000-74598

December 2019 


\title{
GANEL
}

\section{Cost of Wind Energy Review}

\author{
Tyler Stehly and Philipp Beiter
}

National Renewable Energy Laboratory

\section{Suggested Citation}

Stehly, Tyler, and Philipp Beiter. 2020. 2018 Cost of Wind Energy Review. Golden, CO:

National Renewable Energy Laboratory. NREL/TP-5000-74598.

https://www.nrel.gov/docs/fy20osti/74598.pdf.

NREL is a national laboratory of the U.S. Department of Energy Office of Energy Efficiency \& Renewable Energy Operated by the Alliance for Sustainable Energy, LLC

This report is available at no cost from the National Renewable Energy Laboratory (NREL) at www.nrel.gov/publications.

Contract No. DE-AC36-08GO28308
Technical Report

NREL/TP-5000-74598

December 2019

National Renewable Energy Laboratory 15013 Denver West Parkway Golden, CO 80401

303-275-3000 • www.nrel.gov 


\section{NOTICE}

This work was authored by the National Renewable Energy Laboratory, operated by Alliance for Sustainable Energy, LLC, for the U.S. Department of Energy (DOE) under Contract No. DE-AC3608G028308. Funding provided by the U.S. Department of Energy Office of Energy Efficiency and Renewable Energy Wind Energy Technologies Office. The views expressed herein do not necessarily represent the views of the DOE or the U.S. Government.

This report is available at no cost from the National

Renewable Energy Laboratory (NREL) at

www.nrel.gov/publications.

U.S. Department of Energy (DOE) reports produced

after 1991 and a growing number of pre-1991

documents are available

free via www.OSTI.gov.

Cover Photos by Dennis Schroeder: (clockwise, left to right) NREL 51934, NREL 45897, NREL 42160, NREL 45891, NREL 48097, NREL 46526.

NREL prints on paper that contains recycled content. 


\section{Acknowledgments}

This work was supported by the U.S. Department of Energy (DOE) under Contract No. DEAC36-08GO28308 with the National Renewable Energy Laboratory (NREL). Funding for the work was provided by the DOE Office of Energy Efficiency and Renewable Energy Wind Energy Technologies Office (WETO). The authors would like to thank Patrick Gilman (WETO) for supporting this research. Thanks also to Daniel Beals of Allegheny Science and Technology (contractor to WETO) for reviewing prior versions of this manuscript and Richard Tusing (NREL) for providing strategic guidance in the development of this work. Thank you to Ryan Wiser and Mark Bolinger (Lawrence Berkeley National Laboratory) for their analysis of wind project market data that informed this analysis and also to George Scott, Donna Heimiller, Nick Grue, and Katy Waechter (NREL) for their work to develop the national wind supply curves. Thanks also to Ben Maples (Mortenson Construction) for reviewing prior versions of this manuscript. Finally, thanks to Eric Lantz (NREL) for his technical guidance, contributions, and review of prior versions of this manuscript. Any remaining errors or omissions are the sole responsibility of the authors. 


\section{List of Acronyms}

\begin{tabular}{ll} 
AEP & annual energy production \\
ATB & Annual Technology Baseline \\
BOS & balance of system \\
capital expenditures \\
CapEx & capital recovery factor \\
CSM & Cost and Scaling Model \\
DOE & U.S. Department of Energy \\
FCR & fixed charge rate \\
GPRA & Government Performance and Results Act \\
GW & gigawatt \\
kW & kilowatt \\
LCOE & levelized cost of energy \\
m & meter \\
m/s & meters per second \\
MACRS & Modified Accelerated Cost Recovery System \\
MW & megawatt \\
MWh & megawatt-hour \\
NREL & National Renewable Energy Laboratory \\
O\&M & operation and maintenance \\
OpEx & operational expenditures \\
ORCA & Offshore Wind Regional Cost Analyzer \\
PTC & production tax credit \\
SAM & System Advisor Model \\
USD & U.S. dollars \\
WACC & weighted-average cost of capital \\
WETO & Wind Energy Technologies Office \\
yr & year \\
\hline
\end{tabular}




\section{Executive Summary}

This report uses representative utility-scale projects to estimate the levelized cost of energy (LCOE) for land-based and offshore wind power plants in the United States. Data and results detailed here are derived from 2018 commissioned plants. Analysis detailed here relies on recent market data and state-of-the-art modeling capabilities to maintain an up-to-date understanding of wind energy cost trends and drivers. This report represents the eighth annual installment and is intended to provide insight into current component-level costs as well as a basis for understanding variability in LCOE across the country.

The primary elements of this report include:

- Estimated LCOE for a representative, land-based wind project installed in a moderate wind resource in the United States in 2018

- Estimated LCOE for representative offshore, fixed-bottom, and floating projects, in the North Atlantic and Pacific Coast regions of the United States using National Renewable Energy Laboratory (NREL) models and a database informed by projects installed in Europe in 2018

- Sensitivity analyses showing the range of effects that basic LCOE variables could have on the cost of wind energy for land-based and offshore wind power plants

- Updated national supply curves for land-based and offshore wind based on geographically specific wind resource conditions paired with approximate wind turbine size characteristics

- Updated fiscal year 2019 values for land-based and offshore wind used for Government Performance and Results Act (GPRA) reporting as well as illustrated progress toward established GPRA targets.

\section{Key Inputs and Results}

Throughout this report, the representative land-based and offshore project types are referred to as "reference projects." Table ES1, Table ES2, and Table ES3 summarize the basic LCOE inputs and outputs for the reference land-based, fixed-bottom, and floating offshore wind projects, with some additional detail about project capital expenditures (CapEx) and the respective turbine capacity factor associated with the net annual energy production estimate. Unless specifically stated, all data and analysis in the report are in 2018 U.S. dollars. 
Table ES1. Summary of the Land-Based Reference Project using 2.4-megawatt (MW) Wind Turbines

\begin{tabular}{|c|c|c|}
\hline & $\begin{array}{l}\text { 2.4-MW Land-Based } \\
\text { Turbine } \\
\text { (\$/kilowatt [kW]) }\end{array}$ & $\begin{array}{l}\text { 2.4-MW Land-Based } \\
\text { Turbine } \\
\text { (\$/megawatt-hour } \\
\text { [MWh]) }\end{array}$ \\
\hline Turbine capital cost & 1,011 & 20.8 \\
\hline Balance of system & 332 & 6.8 \\
\hline Financial costs & 127 & 2.6 \\
\hline CapEx & 1,470 & 30.3 \\
\hline Operational expenditures (OpEx) (\$/kW/year [yr]) & 44 & 12.1 \\
\hline Fixed charge rate (real) [\%] & \multicolumn{2}{|c|}{$7.5 \%$} \\
\hline Net annual energy production (MWh/MW/yr) & \multicolumn{2}{|c|}{3,648} \\
\hline Net capacity factor $(\%)$ & \multicolumn{2}{|c|}{$41.5 \%$} \\
\hline TOTAL LCOE (\$/MWh) & \multicolumn{2}{|c|}{42} \\
\hline
\end{tabular}

Table ES2. Summary of the Fixed-Bottom Reference Project using 5.5-MW Wind Turbines

\begin{tabular}{|c|c|c|}
\hline & $\begin{array}{c}\text { 5.5-MW Fixed-Bottom } \\
\text { Turbine } \\
(\$ / k W)\end{array}$ & $\begin{array}{c}\text { 5.5-MW Fixed-Bottom } \\
\text { Turbine } \\
\text { (\$/MWh) }\end{array}$ \\
\hline Turbine capital cost & 1,301 & 17.2 \\
\hline Balance of system & 2,498 & 33.0 \\
\hline Financial costs & 645 & 8.5 \\
\hline CapEx & 4,444 & 58.8 \\
\hline OpEx (\$/kW/yr) & 129 & 30.3 \\
\hline Fixed charge rate (real) [\%] & \multicolumn{2}{|c|}{$5.6 \%$} \\
\hline Net annual energy production (MWh/MW/yr) & \multicolumn{2}{|c|}{4,257} \\
\hline Net capacity factor (\%) & \multicolumn{2}{|c|}{$48.6 \%$} \\
\hline Total LCOE (\$/MWh) & \multicolumn{2}{|c|}{89} \\
\hline
\end{tabular}


Table ES3. Summary of the Floating Offshore Reference Project using 5.5-MW Turbines

\begin{tabular}{|c|c|c|}
\hline & $\begin{array}{c}\text { 5.5-MW Floating } \\
\text { Offshore Turbine } \\
(\$ / \mathrm{kW})\end{array}$ & $\begin{array}{c}\text { 5.5-MW Floating } \\
\text { Offshore Turbine } \\
\text { (\$/MWh) }\end{array}$ \\
\hline Turbine capital cost & 1,301 & 22.0 \\
\hline Balance of system & 3,263 & 55.3 \\
\hline Financial costs & 790 & 13.4 \\
\hline CapEx & 5,355 & 90.7 \\
\hline OpEx (\$/kW/yr) & 137 & 41.2 \\
\hline Fixed charge rate (real) [\%] & \multicolumn{2}{|c|}{$5.6 \%$} \\
\hline Net annual energy production (MWh/MW/yr) & \multicolumn{2}{|c|}{3,324} \\
\hline Net capacity factor (\%) & \multicolumn{2}{|c|}{$37.9 \%$} \\
\hline Total LCOE (\$/MWh) & \multicolumn{2}{|c|}{132} \\
\hline
\end{tabular}

Note: GPRA values are not reported for floating technology.

In this report, 2018 installed land-based wind project data and costs are primarily obtained from Wiser and Bolinger (2019). These data are supplemented with outputs from NREL's cost models for wind turbine and balance-of-system detail. The authors included an additional analysis that models potential future turbine technologies in 2030 in this year's report to inform the 2019 Annual Technology Baseline (NREL's Annual Technology Baseline and Standard Scenarios web page: atb.nrel.gov); details presented in Appendix C. The offshore reference project data are estimated from installed 2018 global offshore projects, data collected from U.S.-proposed projects, and market data from the existing international offshore wind industry. The assumed wind resource regime and geospatial power plant characteristics (e.g., water depth and distance from shore) for the offshore reference plants are comparable to sites on the U.S. North Atlantic and Pacific Coast and are detailed in Appendix D.

The three major component LCOE categories and many subcategories including operations and maintenance (O\&M) are represented Figure ES1, Figure ES2, and Figure ES3. These figures include wind turbine (e.g., wind turbine components), balance of system (e.g., development, electrical infrastructure, assembly, and installation), and financial costs (e.g., insurance and construction financing). The majority of the land-based reference project LCOE $(49.2 \%)$ is in the turbine itself, whereas the balance of system is the major contributor for the fixed-bottom and floating offshore reference projects, making up $37.1 \%$ and $41.9 \%$, respectively. 


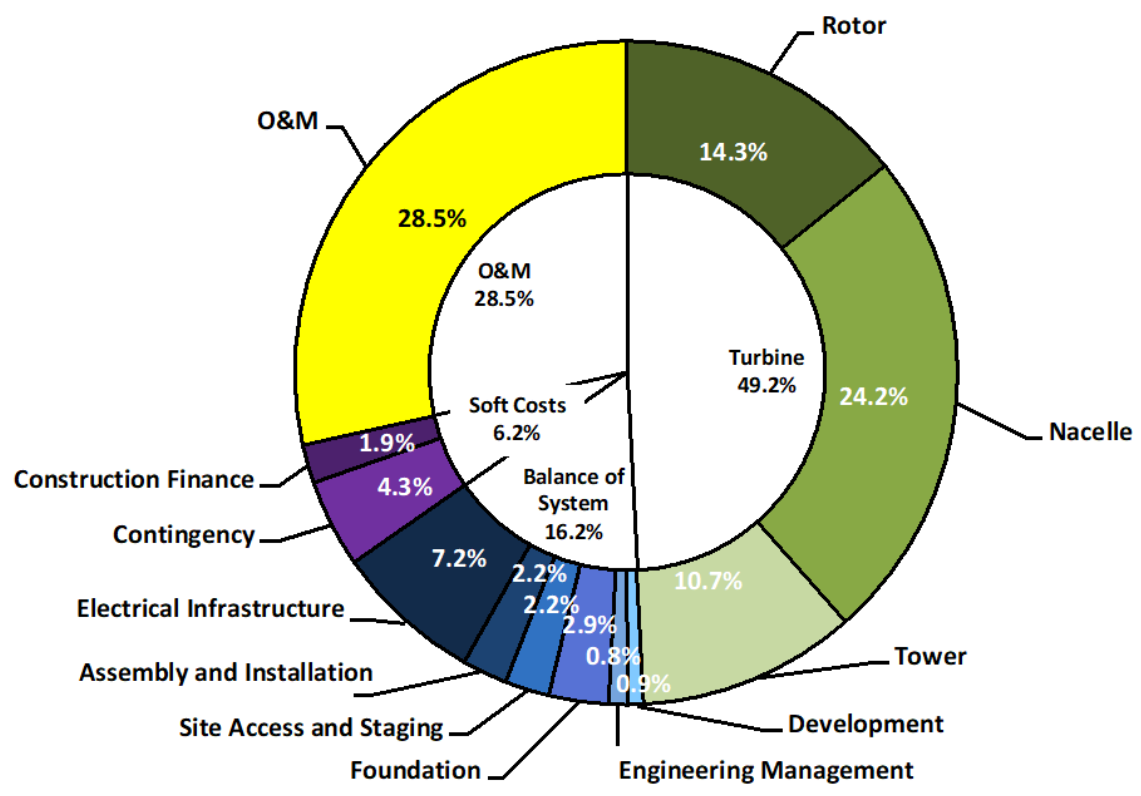

Figure ES1. Component-level LCOE contribution for the 2018 land-based wind reference project Note: O\&M represents operation and maintenance

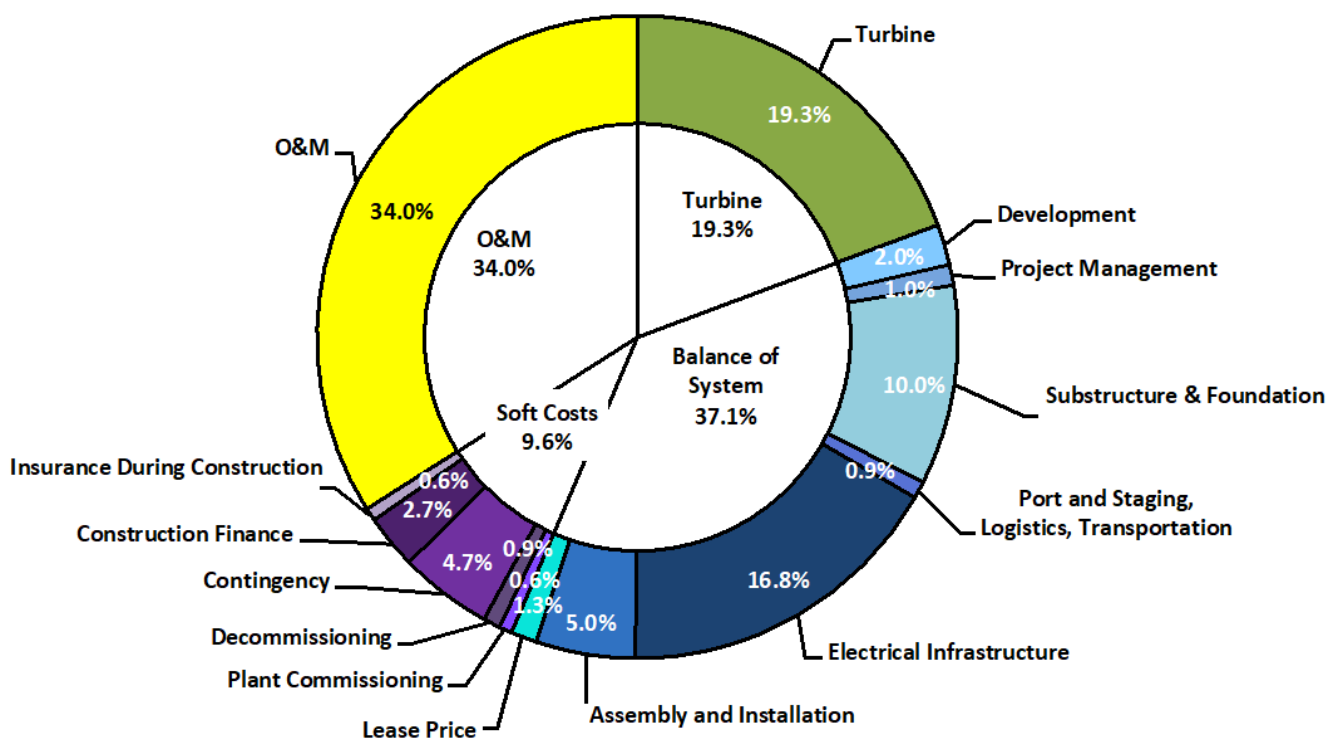

Figure ES2. Component-level LCOE contribution for the 2018 fixed-bottom offshore wind reference project 


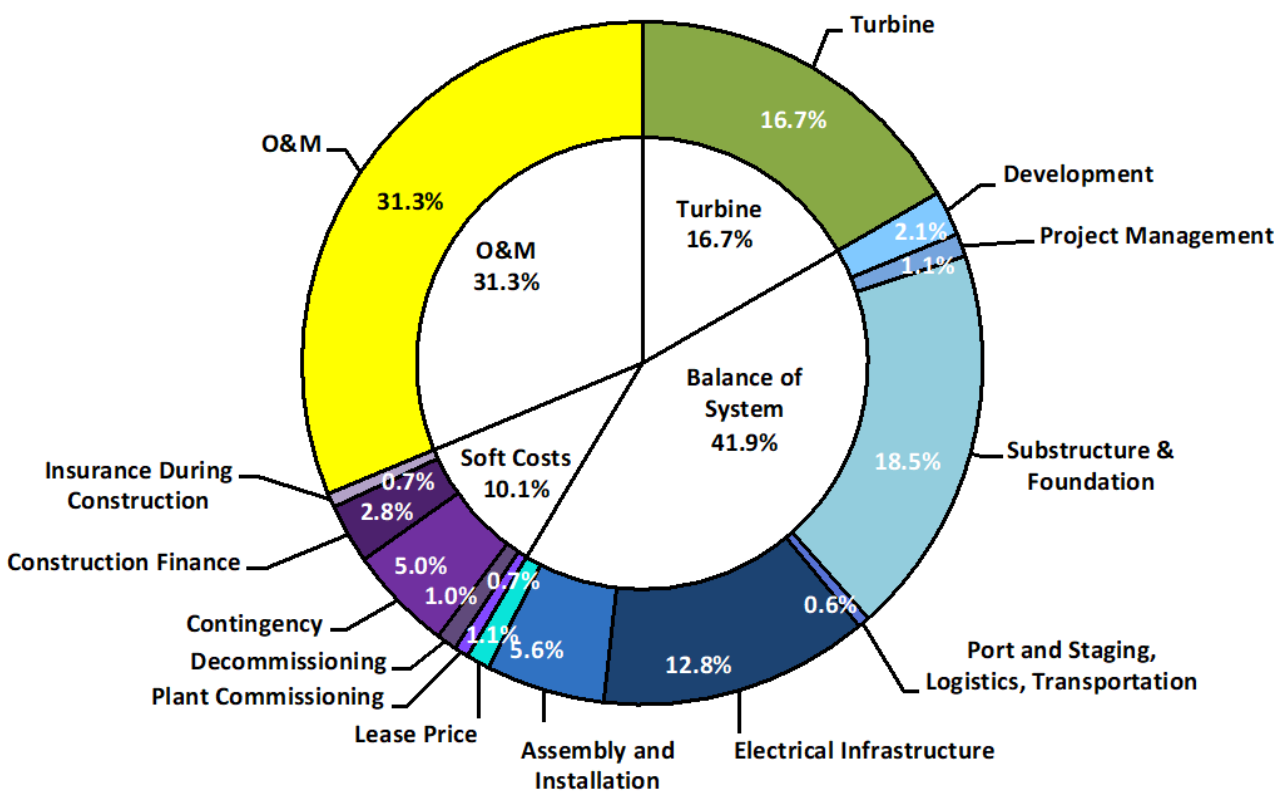

Figure ES3. Component-level LCOE contribution for the 2018 floating offshore wind reference project

Figure ES4, Figure ES5, and Figure ES6 illustrate the LCOE associated with the land-based and offshore reference power plants and provide a range of independent, single-variable sensitivities showing how these variables affect cost and performance. More specifically, these figures show the effect that CapEx, OpEx, net capacity factor, nominal discount rate, and project design life ${ }^{1}$ have on the LCOE for both land-based and offshore wind projects. Reference project values of \$42/MWh for land-based wind, \$89/MWh for fixed-bottom offshore wind, and \$132/MWh for floating offshore wind rely on inputs summarized in Table ES1 through Table ES3 and are identified by the vertical white line in those figures. The figures also show sensitivity ranges pulled from representative industry data contained in the "2018 Wind Technologies Market Report" (Wiser and Bolinger 2019) for the LCOE inputs and the resulting calculated impacts on LCOE for land-based wind. The sensitivity ranges for fixed-bottom and floating offshore are informed by the "2018 Offshore Wind Technologies Market Report" (Musial et al. 2019) and NREL's offshore wind database. The ranges for land-based and offshore wind LCOE inputs vary significantly (note the different axes in these figures). More detailed descriptions of the ranges and assumptions are included in Section 4.7 (land-based wind) and Section 5.7 (offshore wind).

\footnotetext{
${ }^{1}$ Project design life refers to the time in which the wind power plant is expected to operate (not referring to the turbine's design life for engineering or certification purposes).
} 


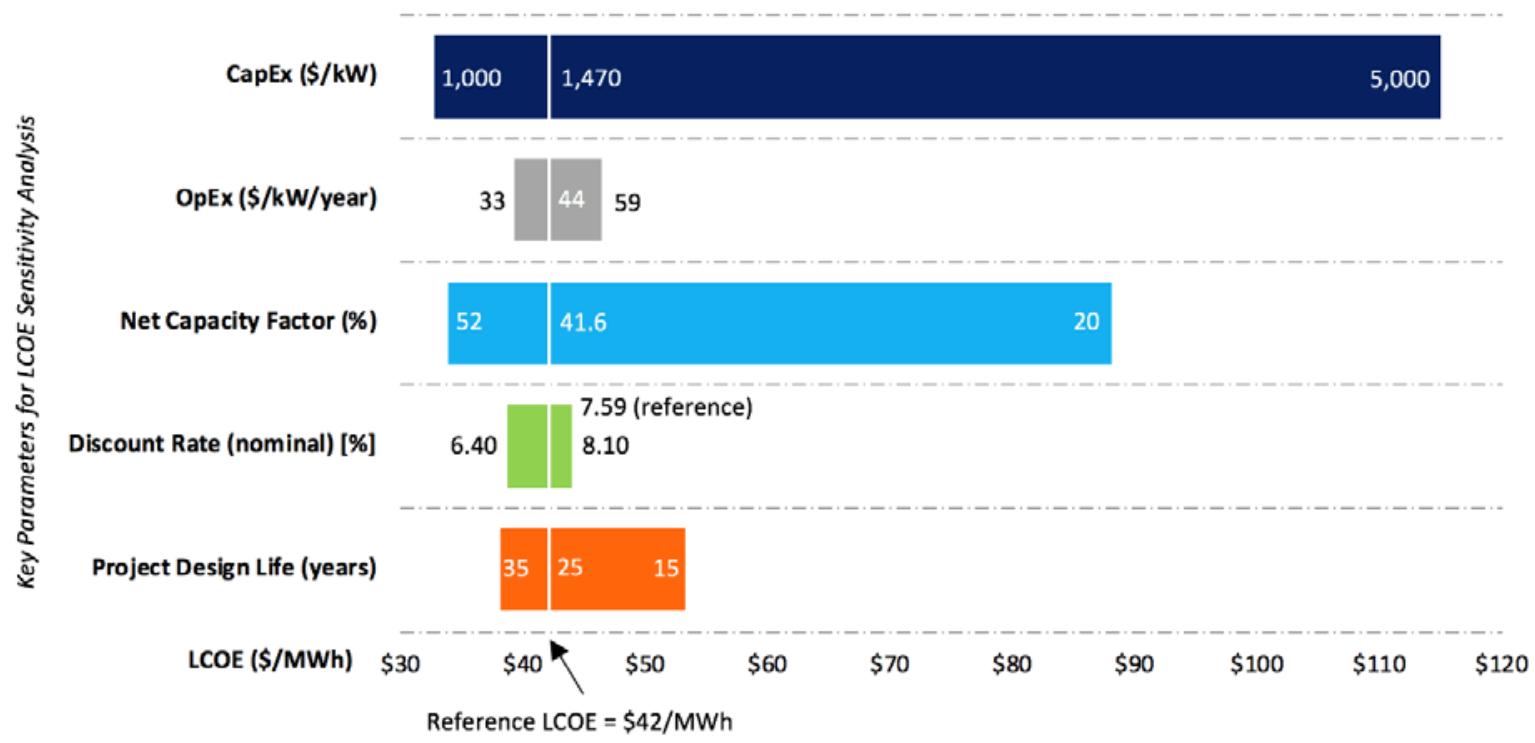

Figure ES4. Land-based wind power plant assumptions and ranges for key LCOE input parameters

Note: The reference LCOE represents the estimated LCOE for the NREL reference project. Changes in LCOE for a single variable can be understood by moving to the left or right along a specific variable. Values on the $\mathrm{x}$-axis indicate how the LCOE will change as a given variable is altered, assuming that all others are constant. For example, as capacity factor decreases toward $20 \%$, the LCOE shown on the $\mathrm{x}$-axis will increase accordingly to approximately $\$ 88 / \mathrm{MWh}$. Or, as the operational life for the reference project moves toward 35 years, the period in which a project achieves the requisite cash flow it needs to recover its initial CapEx and meet investors' internal rate of return threshold is assumed to be 35 years; therefore, the resulting LCOE decreases to nearly $\$ 38 / \mathrm{MWh}$.

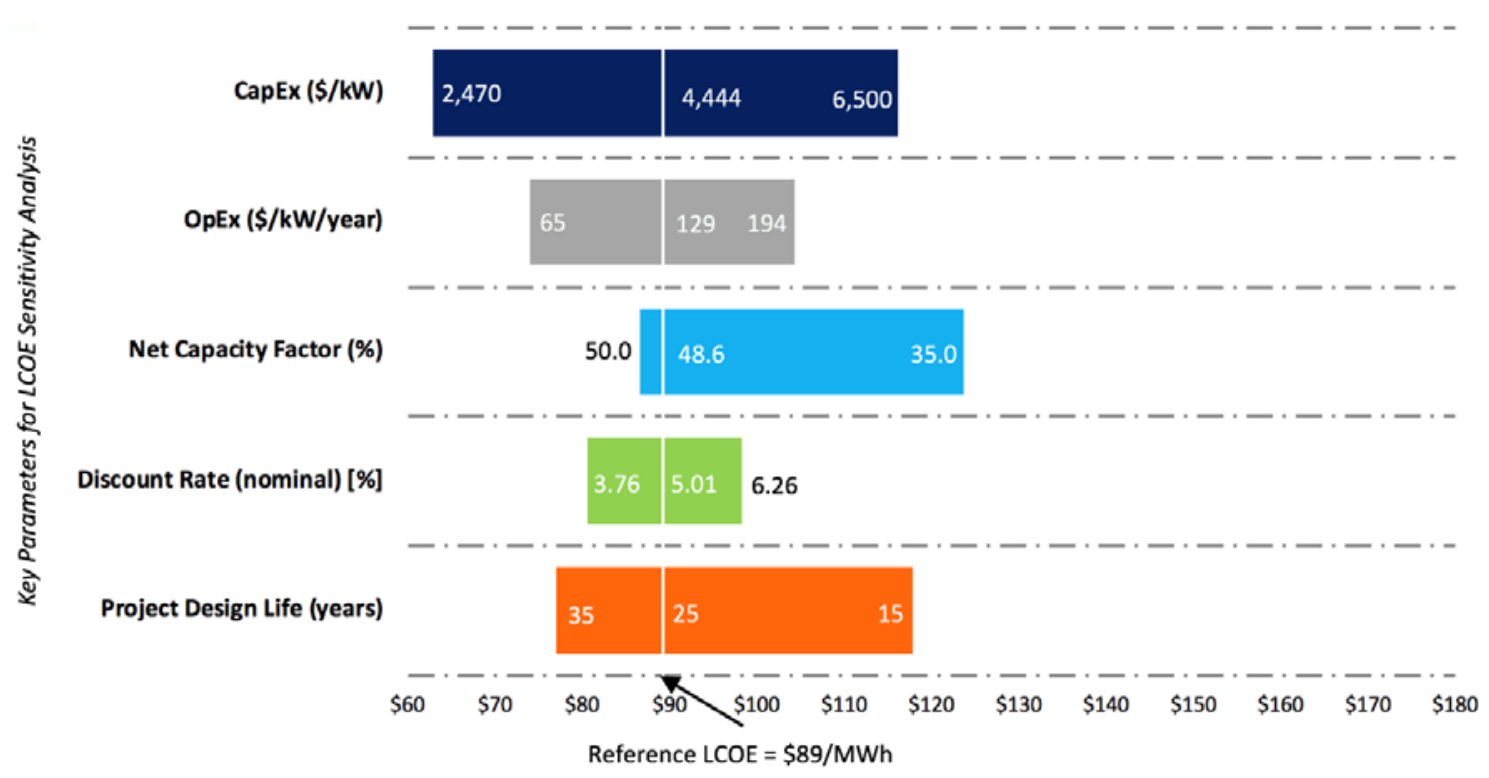

Figure ES5. Fixed-bottom offshore wind power plant assumption and ranges for key LCOE input parameters 


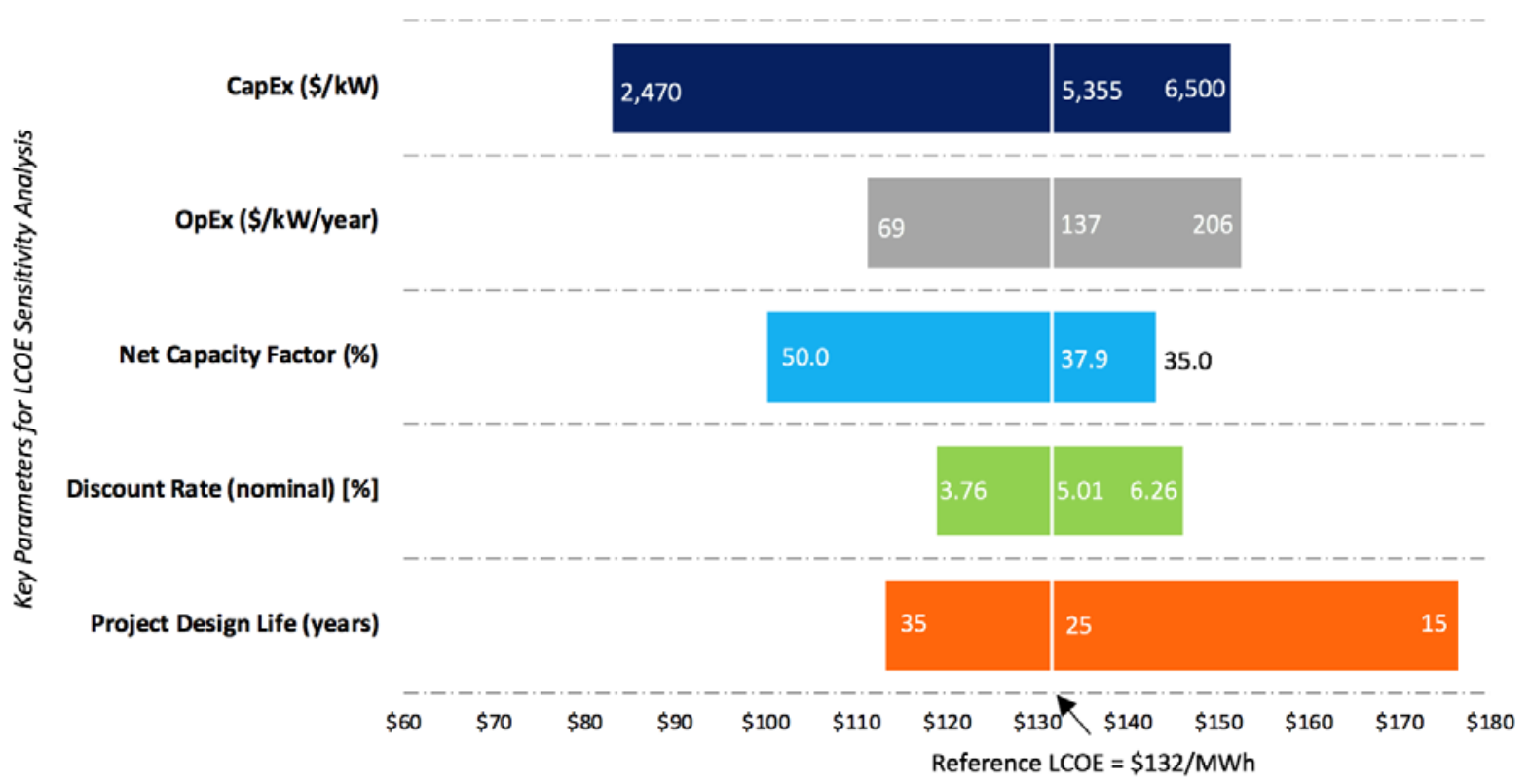

Figure ES6. Floating offshore wind power plant assumptions and ranges for key LCOE input parameters

From the data provided earlier as well as the full body of work detailed in this report, we derived the following key conclusions:

- Land-based wind power plant LCOE estimates continue to show a downward trend from the "2010 Cost of Wind Energy Review" (Tegen et al. 2012) to the 2018 review. The reference project LCOE for land-based installations was observed to be $\$ 42 / \mathrm{MWh},{ }^{2}$ with a range of land-based estimates from the single-variable sensitivity analysis covering $\$ 33-\$ 115 / \mathrm{MWh}^{3}$

- Offshore wind power plant LCOE estimates continue to decrease. The fixed-bottom reference project offshore estimate is $\$ 89 / \mathrm{MWh}$, and the floating substructure reference project estimate is $\$ 132 / \mathrm{MWh}$. These two reference projects give a single-variable sensitivity range of $\$ 63-\$ 176 / \mathrm{MWh}$. This range is primarily caused by the large variation in CapEx $(\$ 2,470-\$ 6,500 / \mathrm{kW})$, which is partially a function of water depth and distance from shore, reported by project developers. More recent European and U.S. auction bids suggest that costs for offshore wind could fall further in the coming years. ${ }^{4}$

- Sensitivity analyses show that LCOE can vary widely based on changes in any one of several key factors; however, the variable with the most dramatic effect on LCOE is CapEx, followed by net capacity factor, then project design life for land-based projects, and CapEx, followed by project design life, then net capacity factor for offshore projects.

\footnotetext{
${ }^{2}$ As the production tax credit ramps down and expires in 2020, it is likely that wind project weighted-average cost of capital or discount rate will be reduced as leverage increases and tax equity is replaced with cheaper debt. ${ }^{3} \mathrm{LCOE}$ estimates reflect a cost to a wind power plant developer and are not directly comparable with power purchase agreements that reflect the sale of electricity.

${ }^{4}$ Additional information on the recent European and U.S. auction bids can be found in the "2018 Offshore Wind Technologies Market Report” (Musial et al. 2019).
} 


\section{Table of Contents}

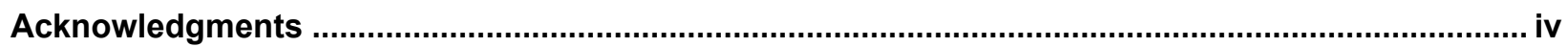

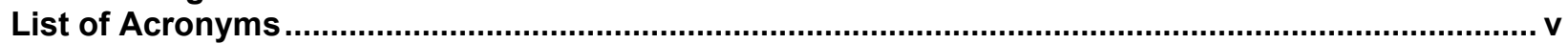

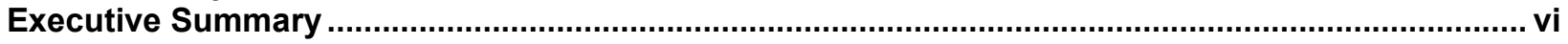

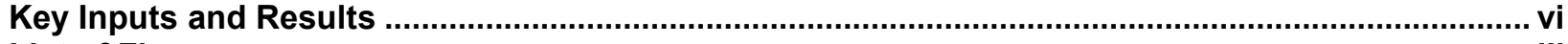

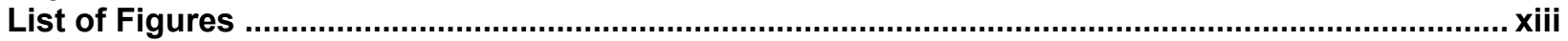

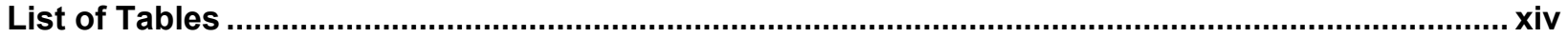

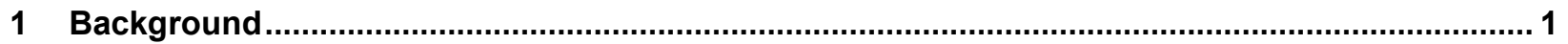

2 U.S. Department of Energy Goals and Reporting Requirements .............................................. 3

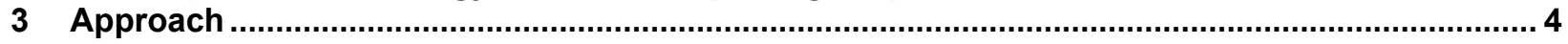

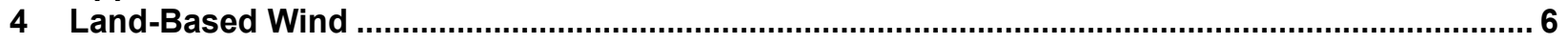

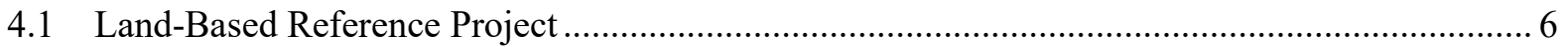

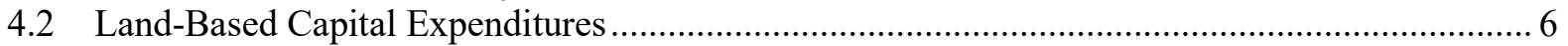

4.3 Land-Based Technology Characteristics and Annual Energy Production .................................. 9

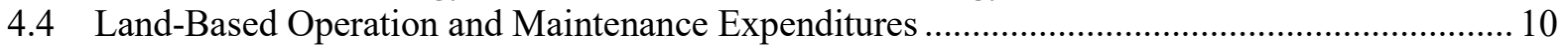

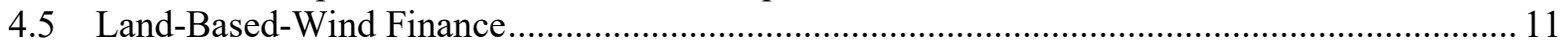

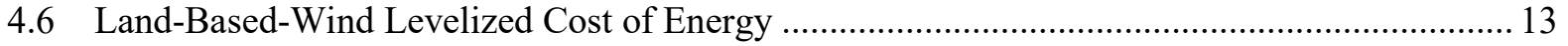

4.7 Land-Based-Wind Levelized Cost of Energy Sensitivities ..................................................... 15

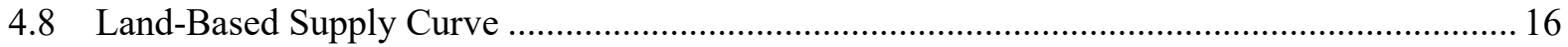

4.9 Land-Based-Wind Discussion of Results in Context of DOE Goals ..................................... 17

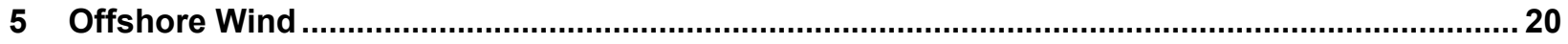

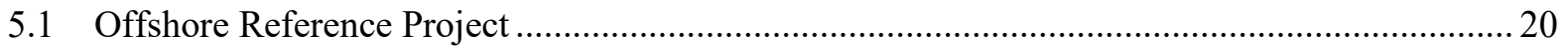

5.2 Offshore Capital Expenditures ......................................................................................... 21

5.3 Offshore Technology Characteristics and Annual Energy Production ..................................... 26

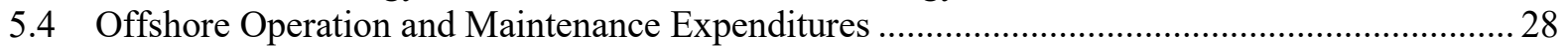

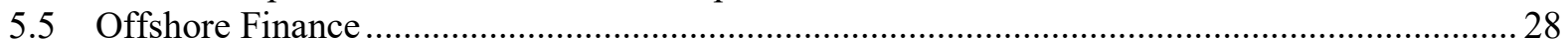

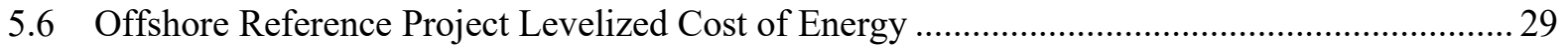

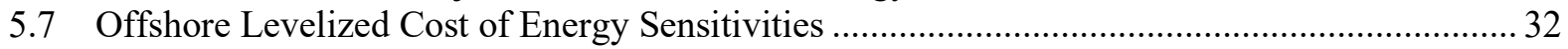

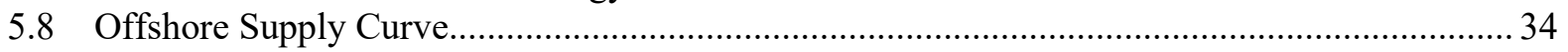

5.9 Offshore Discussion of Results in Context of DOE Goals...................................................... 35

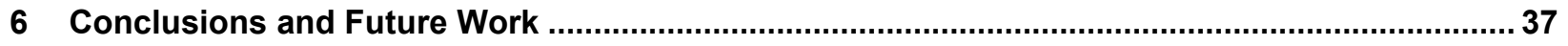

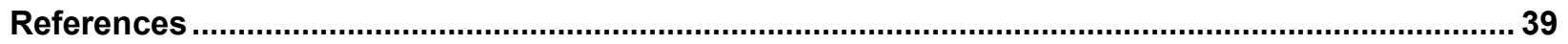

Appendix A. Land-Based Wind 30-Year Financial Life Sensitivity ................................................. 43

Appendix B. Offshore Wind 30-Year Financial Life Sensitivity .......................................................... 44

Appendix C. Land-Based Wind 2030 Turbine Technology Assessment............................................45

Appendix D. Offshore Wind Reference Site Development ............................................................. 48

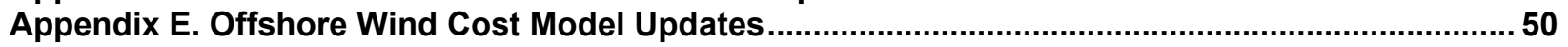

Appendix F. Summary of Assumptions for 2018 Reference Projects .......................................... 51

\section{List of Figures}

Figure ES1. Component-level LCOE contribution for the 2018 land-based wind reference project. ix Figure ES2. Component-level LCOE contribution for the 2018 fixed-bottom offshore wind reference project.............................................................................................................. ix

Figure ES3. Component-level LCOE contribution for the 2018 floating offshore wind reference project.

Figure ES4. Land-based wind power plant assumptions and ranges for key LCOE input

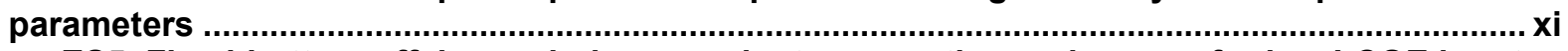

Figure ES5. Fixed-bottom offshore wind power plant assumption and ranges for key LCOE input parameters ...............................................................................................................................

Figure ES6. Floating offshore wind power plant assumptions and ranges for key LCOE input

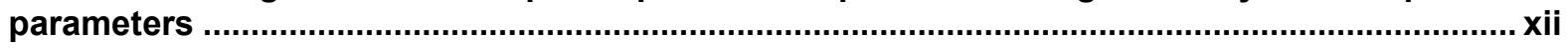

Figure 1. CapEx for the land-based reference wind power plant project........................................... 7 
Figure 2. Component-level LCOE contribution for the 2018 land-based-wind reference project .... 14 Figure 3. Component-level LCOE breakdown for the 2018 land-based-wind reference project ...... 15

Figure 4. Sensitivity of land-based-wind LCOE to key input parameters .......................................... 15

Figure 5. National land-based-wind resource supply curve with 2018 U.S. installed projects......... 17

Figure 6. Pathway to LCOE reduction in 2030 by LCOE parameter ................................................... 18

Figure 7. Land-based wind GPRA cost trajectories for LCOE (in 2015 USD) ................................... 19

Figure 8. Capital expenditures for the fixed-bottom offshore wind reference project ..................... 22

Figure 9. Capital expenditures for the floating offshore wind reference project ............................. 24

Figure 10. Component-level LCOE contribution for the 2018 fixed-bottom offshore wind reference project.

Figure 11. Component-level cost breakdown for the 2018 fixed-bottom offshore wind reference

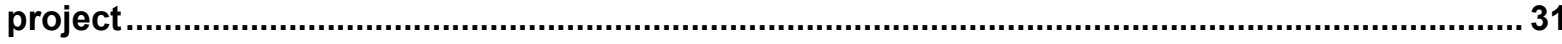

Figure 12. Component-level LCOE contribution for the 2018 floating offshore wind reference project

Figure 13. Component-level cost breakdown for the 2018 floating offshore wind reference project

32

Figure 14. Sensitivity of fixed-bottom offshore wind LCOE to key input parameters ...................... 33

Figure 15. Sensitivity of floating offshore wind LCOE to key input parameters ................................. 33

Figure 16. National fixed-bottom and floating offshore wind supply curve ....................................35

Figure 17. Fixed-bottom wind GPRA cost trajectories for LCOE....................................................... 36

Figure 18. Fixed-bottom cost reductions in GPRA cost trajectories for LCOE................................ 36

\section{List of Tables}

Table ES1. Summary of the Land-Based Reference Project using 2.4-megawatt (MW) Wind Turbines.

Table ES2. Summary of the Fixed-Bottom Reference Project using 5.5-MW Wind Turbines ........... vii

Table ES3. Summary of the Floating Offshore Reference Project using 5.5-MW Turbines .............. viii

Table 1. Land-Based Wind GPRA Baseline and Target LCOE ...................................................... 3

Table 2. Offshore Fixed-Bottom Wind GPRA Baseline and Target LCOE......................................... 3

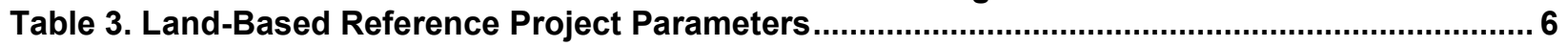

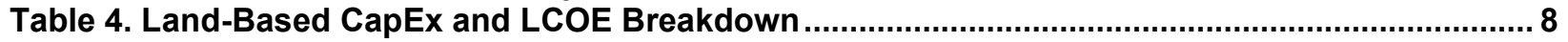

Table 5. Reference Land-Based Turbine Parameters ..................................................................... 9

Table 6. Reference Land-Based-Wind Resource Assumptions ........................................................ 10

Table 7. Reference Land-Based-Wind Losses and Availability Assumptions................................. 10

Table 8. Reference Land-Based-Wind Power Plant AEP and Capacity Factor Summary ................. 10

Table 9. Land-Based-Wind Reference Project OpEx ................................................................... 11

Table 10. Summary of Land-Based-Wind Reference Project Economic Evaluation Metrics ............. 13

Table 11. Summary of Inputs and Reference Project LCOE for 2018 Land-Based Installations ...... 14

Table 12. Offshore Reference Project Parameters (Fixed-Bottom and Floating Substructures) ..... 21

Table 13. Fixed-Bottom Offshore CapEx and LCOE Breakdown ..................................................... 23

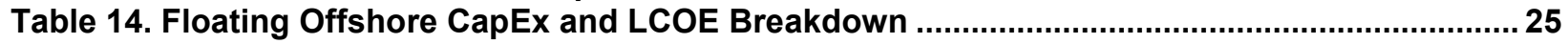

Table 15. Reference Offshore Turbine Parameter Input Assumptions ............................................ 26

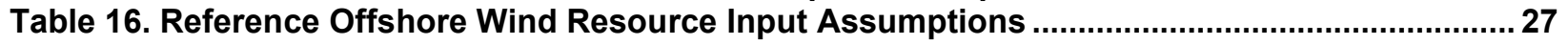

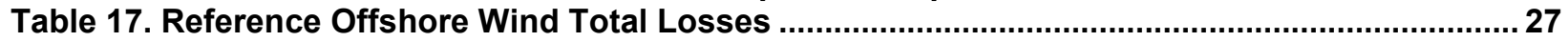

Table 18. Reference Offshore Wind Net Annual Energy Production .................................................. 27

Table 19. Offshore Wind Reference Project OpEx........................................................................... 28

Table 20. Summary of Offshore Reference Project Economic Evaluation Metrics..........................29

Table 21. Fixed-Bottom Offshore Wind LCOE and Reference Projects Cost Breakdown................. 29

Table 22. Floating Offshore Wind LCOE and Reference Projects Cost Breakdown .......................... 31

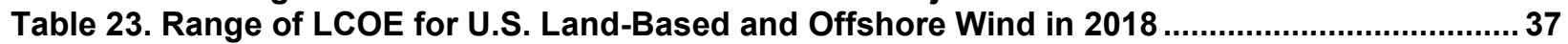

Table A1. Summary of Land-Based Capital Recovery Factor, Fixed Charge Rate, and Levelized Cost of Energy for a 30-Year Useful Life..................................................................................... 43

Table B1. Summary of Offshore Capital Recovery Factor, Fixed Charge Rate, and Levelized Cost

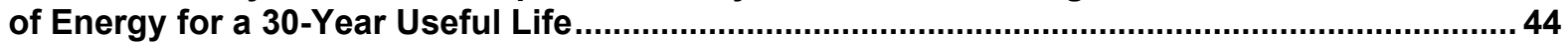

Table C1. Summary of Projected Technology Characteristics for the 2030 Representative Turbines 


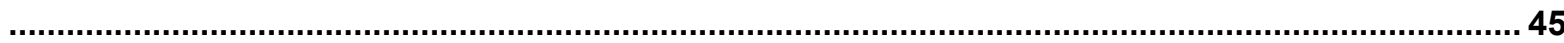

Table C2. Summary of Modeled Capital Costs for the 2030 Representative Wind Plants ............... 46

Table C3. Summary of Assumed Operation and Maintenance Costs for the 2030 Representative

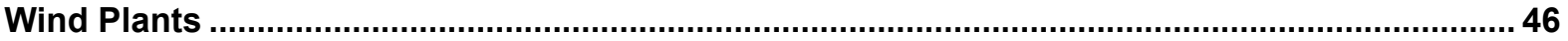

Table C4. Summary of Calculated Net Capacity Factors for the 2030 Representative Wind Plants 47 Table C5. Summary of Assumed Fixed Charge Rate and Calculated Levelized Cost of Energy for

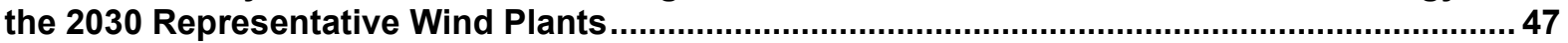

Table D1. Spatial Parameters for Regional Reference Sites ........................................................ 49

Table F1. Land-Based-Wind Reference Project Levelized Cost of Energy (LCOE) Assumptions.... 51

Table F2. Fixed-Bottom Offshore Wind Reference Project LCOE Assumptions................................ 53

Table F3. Floating Offshore Wind Reference Project LCOE Assumptions ...................................... 55 


\section{Background}

This report estimates the levelized cost of energy (LCOE) for land-based and offshore wind projects in the United States. LCOE is a metric used to assess the cost of electricity generation and the total power-plant-level impact from technology design changes and can be used to compare costs of all types of generation. The specific LCOE method applied in this analysis is described in "A Manual for the Economic Evaluation of Energy Efficiency and Renewable Energy Technologies" (Short et al. 1995).

This report provides an update to the "2017 Cost of Wind Energy Review" (Stehly et al. 2018) and a look at the 2018 wind industry LCOE, turbine costs, financing, and market conditions. More specifically, this 2018 report includes:

- Estimated LCOE for a representative, land-based wind project installed in a moderate wind resource (i.e., average wind power class 4) in the United States in 2018

- Estimated LCOE for representative offshore (fixed-bottom and floating) projects using National Renewable Energy Laboratory (NREL) models and databases of globally installed projects. Representative sites on the U.S. North Atlantic Coast (fixed-bottom) and Pacific Coast (floating) were assessed using lease and call for information and nominations data from the Bureau of Ocean Energy Management as well as various geospatial data sets

- Sensitivity analyses showing the range of effects that basic LCOE variables could have on the cost of wind energy for land-based and offshore wind power plants

- Updates to the national supply curves for land-based and offshore wind based on geographically specific wind resource conditions paired with approximate wind turbine size characteristics

- Projected land-based and offshore wind cost trajectories from 2018 through 2030 used for U.S. Department of Energy (DOE) annual wind power LCOE reporting as required by the Government Performance and Results Act (GPRA).

This report addresses a number of assumptions and cost variables but does not include the full spectrum of drivers that affect wind energy prices. For example, it does not consider policy incentives (such as the production tax credit [PTC]), factors from underlying economic conditions (such as an economic recession), the cost of building long-haul interstate transmission, or potential grid integration costs. These important variables can have an impact by increasing or decreasing project costs or delaying projects. Nevertheless, their exclusion is consistent with past economic analyses conducted by NREL (Stehly et al. 2018), as LCOE is not traditionally defined as a measure of all societal costs and benefits associated with power generation resources.

The standard Annual Technology Baseline (ATB) LCOE equation (NREL's Annual Technology Baseline and Standard Scenarios web page: atb.nrel.gov) can be simplified for each technology. 
For wind, the following equation is used to calculate LCOE:

$$
\mathrm{LCOE}=\frac{(\mathrm{CapEx} \times \mathrm{FCR})+\mathrm{OpEx}}{\left(\mathrm{AEP}_{\text {net }} / 1,000\right)}
$$

where

LCOE $=$ levelized cost of energy (\$/megawatt-hour $[\mathrm{MWh}])$

$\mathrm{FCR}=$ fixed charge rate $(\%)$

CapEx $=$ capital expenditures $(\$ /$ kilowatt $[\mathrm{kW}])$

$\mathrm{AEP}_{\text {net }}=$ net average annual energy production $(\mathrm{MWh} /$ megawatt $[\mathrm{MW}] /$ year $[\mathrm{yr}])$

OpEx $=$ operational expenditures $(\$ / \mathrm{kW} / \mathrm{yr})$.

The first three basic inputs into the LCOE equation - capital expenditures (CapEx), operational expenditures $(\mathrm{OpEx})$, and net average annual energy production $\left(\mathrm{AEP}_{\mathrm{net}}\right)$ - enable this equation to capture system-level impacts from design changes (e.g., larger rotors or taller wind turbine towers). The fourth basic input - a fixed charge rate (FCR) - represents the amount of revenue required to pay the annual carrying charges as applied to the CapEx on that investment during the expected project economic life. All analysis and LCOE results are in 2018 U.S. dollars (USD) throughout this report unless otherwise noted. The upcoming sections define the approach to calculating the LCOE following the respective NREL system cost breakdown structures to organize data. This report also describes each component of the LCOE equation (such as CapEx, OpEx, AEP, and FCR), the market context, and a range of data for typical U.S. wind projects in 2018. 


\section{U.S. Department of Energy Goals and Reporting Requirements}

Every year, the DOE Wind Energy Technologies Office (WETO) reports the LCOE for landbased and fixed-bottom offshore wind to satisfy GPRA reporting requirements. The annually reported LCOE values are measured against current year and future LCOE targets set by WETO. The official GPRA levelized cost of energy end-point targets presented in this report were set in 2015 for land-based wind and updated in 2019 for fixed-bottom offshore wind. Updates to the LCOE targets are periodically implemented to keep performance measures current with developments in the market and reduce the impact of inflation on LCOE for land-based and offshore wind projects. The GPRA targets are based on trajectories for land-based and fixedbottom offshore ${ }^{5}$ wind projects that span from the current year to 2030. A summary of the GPRA targets for land-based wind is shown in Table 1 and for offshore fixed-bottom wind in Table 2. It is required that each year the actual costs for land-based and fixed-bottom wind LCOE be reported against the GPRA targets. This report provides the cost data to DOE to meet the annual reporting requirement required by the GPRA. The assumptions and calculations for land-based wind and fixed-bottom offshore wind projects used in GPRA reporting are presented in more detail in Section 4.9 and Section 5.9, respectively.

Table 1. Land-Based Wind GPRA Baseline and Target LCOE

\begin{tabular}{|lc|c|}
\hline & 2016 (Baseline) & 2030 (Target) \\
\hline Land-based LCOE $(2015 \$ / \mathrm{MWh})$ & 56 & 23 \\
\hline
\end{tabular}

Note: The GPRA baseline and target levelized cost of energy in Table 1 are reported in 2015 USD for land-based wind because WETO will report land-based wind values in 2015 USD.

Table 2. Offshore Fixed-Bottom Wind GPRA Baseline and Target LCOE

\begin{tabular}{|l|c|c|}
\hline & 2019 (Baseline) & 2030 (Target) \\
\hline Offshore fixed-bottom LCOE $(2018 \$ / \mathrm{MWh})$ & 89 & 51 \\
\hline
\end{tabular}

Note: The GPRA baseline and target levelized cost of energy in Table 2 are reported in 2018 USD because WETO will report offshore fixed-bottom wind values in 2018 USD.

\footnotetext{
${ }^{5}$ WETO does not report GPRA costs or targets for floating offshore wind.
} 


\section{Approach}

This "2018 Cost of Wind Energy Review" applies a similar approach as the past cost of wind energy review reports (Tegen et al. 2012, 2013; Moné et al. 2015a, 2015b, 2017; Stehly et al. $2017,2018)$. The analysis uses a number of data sources and models to estimate the cost of wind energy. All models and data have, at some point, been tested, documented, and verified within NREL, other national laboratories, universities, and industry to ensure that the methodology and tools are as accurate as possible. The land-based wind data use the annually released "Wind Technologies Market Report" authored by Lawrence Berkeley National Laboratory. Specific to the "2018 Cost of Wind Energy Review," the data come from Wiser and Bolinger (2019). The market data supporting the offshore wind analysis are limited to international projects and proposed U.S. projects reported in the "2018 Offshore Wind Technologies Market Report" (Musial et al. 2019) and stored in NREL's offshore wind database ${ }^{6}$ of global offshore projects. Given the market and model data available, the general approach to estimating the levelized cost of wind energy includes:

- Evaluating market conditions and data for projects that have been installed in the United States in a given year to understand total land-based CapEx, AEP, annual OpEx for recently installed projects, and representative turbine technology. Representative turbine characteristics (i.e., rating, rotor diameter, and hub height) are taken as market averages. Accordingly, LCOE estimates reflect average empirical conditions to the extent possible.

- Evaluating market conditions and data for projects that have been installed in Europe and Asia when considering offshore wind technology in a given year to understand total CapEx, OpEx, and representative turbine technology. AEP and balance-of-system (BOS) costs are modeled using the specified U.S. North Atlantic site conditions. The primary sources for these data are NREL's offshore wind database and the "2018 Offshore Wind Technologies Market Report" (Musial et al. 2019).

- Supplementing available market data with modeled data based on a representative or reference project that reflects technology and project parameters for a given year. We used the following suite of NREL models to complete the LCOE analysis:

○ The 2015 Cost and Scaling Model $^{7}$ (CSM). We used the CSM to estimate landbased wind turbine component costs using scaling relationships at the component level (e.g., blade, hub, generator, and tower) that reflect the component-specific and often nonlinear relationships between size and cost.

○ The Land-Based-Wind BOS model. ${ }^{8}$ We used the BOS model to estimate all other components of the wind power plant other than the turbine's tower and rotor nacelle assembly using scaling relationships based on empirical data obtained from a landbased wind developer and wind industry stakeholders.

\footnotetext{
${ }^{6}$ NREL's offshore wind database is used as an internal reference and is not publicly available.

${ }^{7}$ NREL's 2015 Cost and Scaling Model is used as an internal reference and is not publicly available.

${ }^{8}$ NREL's Land-Based-Wind Balance of System model is used as an internal reference and is not publicly available.
} 
○ The NREL Offshore Wind Cost $\operatorname{Model}^{9}$ (Beiter et al. 2016), which is also referred to as the Offshore Wind Regional Cost Analyzer (ORCA). We used ORCA to estimate offshore turbine costs using scaling relationships from collected global offshore wind industry empirical data and to estimate offshore wind power plant losses and availability.

○ The System Advisor Model (SAM) (NREL's System Advisor Model web page: https://sam.nrel.gov/). We used SAM to estimate net energy production for landbased wind and ORCA to estimate net energy production for offshore wind power plants based on turbine rated capacity, rotor diameter, hub height, and a representative wind resource.

- Combining the market data and modeled data described earlier to estimate the primary elements necessary to calculate LCOE (i.e., CapEx, OpEx, AEP, and FCR) and provide details about wind technology costs and performance that are aligned with market data but reported at a more detailed resolution. Unless specifically stated, all data and analysis used in this report are in 2018 USD, taking into account changes resulting from inflation from previous reports.

\footnotetext{
${ }^{9}$ We implement continual updates to the NREL Offshore Wind Cost Model to best align with current offshore wind industry data. The NREL Offshore Wind Cost Model is also referred to as the Offshore Regional Cost Analyzer (ORCA) and is used in other forthcoming NREL publications. Details on the updates are presented in Appendix E.
} 


\section{Land-Based Wind}

The turbine characteristics used in the land-based wind reference project were derived from the "2018 Wind Technologies Market Report" (Wiser and Bolinger 2019). Reference project wind turbine and component costs are based on a hypothetical wind turbine that comprises the average parameters - nameplate capacity, rotor diameter, and hub height — of turbines that were installed in the United States in 2018. This type of turbine rests on a standard spread-foot foundation design and incorporates a three-stage planetary/helical gearbox feeding a high-speed asynchronous generator. The 2018 reference project wind regime is intended to reflect an average wind power class 4 (NREL's Renewable Resource Data Center web page: https://rredc.nrel.gov/wind/pubs/atlas/tables/1-1T.html) wind resource site that is consistent with prior versions of this report and a typical plant size of $200 \mathrm{MW}$. An additional analysis performing a bottom-up cost estimate on land-based wind technology in 2030 was used to inform the 2019 ATB (NREL's Annual Technology Baseline and Standard Scenarios web page: atb.nrel.gov). The details of the analysis are documented in Appendix C.

\subsection{Land-Based Reference Project}

The land-based reference project is intended to represent a wind site found in the interior region of the United States. The wind power plant specific to this analysis consists of 83 wind turbines that are each rated at $2.4 \mathrm{MW}$ (based on the average turbine size installed in the United States in 2018), equating to a 200-MW wind power plant capacity. These reference project parameters are summarized in Table 3. Further detail on the turbine parameters are summarized in Table 5. The wind power plant layout is roughly placed in a grid layout at an elevation around 450 meters (m) above sea level. The wind power plant is assumed to be operating for 25 years with no catastrophic operation and maintenance (O\&M) events.

Table 3. Land-Based Reference Project Parameters

\begin{tabular}{|lc|}
\hline \multicolumn{2}{|l|}{ Project Parameters } \\
\hline Turbine rated power (MW) & 2.4 \\
\hline Number of turbines & 83 \\
\hline Wind plant capacity (MW) & 200 \\
\hline Altitude above mean sea level (measured at turbine foundation [m]) & 450 \\
\hline Project design life (years) & 25 \\
\hline
\end{tabular}

Note: Project design life refers to the time in which the wind power plant is expected to operate (not referring to the turbine's design life for engineering or certification purposes).

\subsection{Land-Based Capital Expenditures}

The weighted-average CapEx data are published annually by DOE (Wiser and Bolinger 2019). We used the NREL 2015 CSM to determine the component cost breakdown given the total CapEx cost estimates reported by Wiser and Bolinger (2019). The NREL 2015 CSM uses curve fits from commercial turbine component design and cost data while providing the ability to adjust inputs, such as overhead, profit, and transportation. Figure 1 illustrates the breakdown of CapEx for the NREL land-based reference project. In the figure, the CapEx component percentages highlighted in shades of green capture the turbine capital cost, the percentages highlighted in blue capture the BOS share of capital costs, and the components highlighted in 
purple capture the financial CapEx. For information on the assumptions and inclusions of the individual components, see the "2013 Cost of Wind Energy Review" (Moné et al. 2015a). Some costs, such as transportation, are rolled up into higher categories (such as nacelle and blades), as the specific data are difficult to obtain based on a theoretical reference site and an unspecified turbine manufacturer.

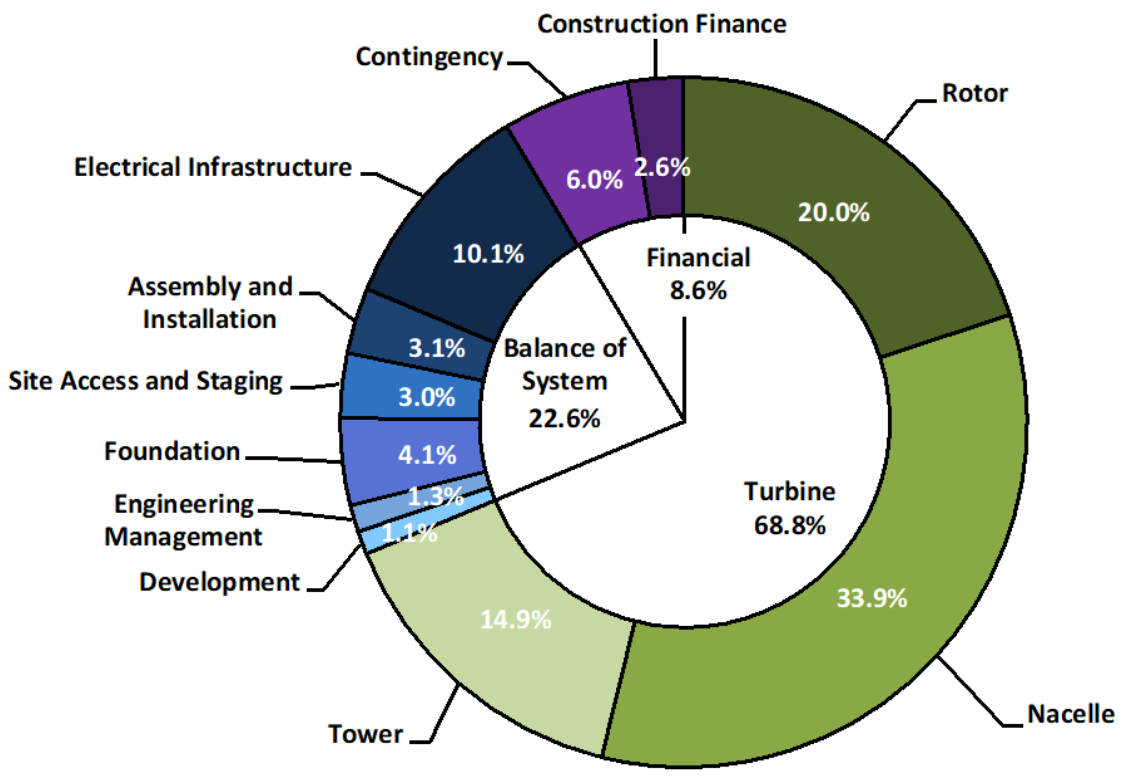

Figure 1. CapEx for the land-based reference wind power plant project

Table 4 summarizes the costs for the reference project's individual components (including their contribution to LCOE). More details on the representative wind power plant's energy production and financial assumptions used to calculate LCOE are provided in Section 4.3 and Section 4.5, respectively. 
Table 4. Land-Based CapEx and LCOE Breakdown

\begin{tabular}{|c|c|c|}
\hline & $\begin{array}{c}\text { 2.4-MW Land-Based } \\
\text { Turbine } \\
(\$ / k W)\end{array}$ & $\begin{array}{c}\text { 2.4-MW Land-Based } \\
\text { Turbine } \\
\text { (\$/MWh) }\end{array}$ \\
\hline Rotor module & 293 & 6.0 \\
\hline Blades & 188 & 3.9 \\
\hline Pitch assembly & 61 & 1.3 \\
\hline Hub assembly & 45 & 0.9 \\
\hline Nacelle module & 498 & 10.3 \\
\hline Nacelle structural assembly & 100 & 2.1 \\
\hline Drivetrain assembly & 195 & 4.0 \\
\hline Nacelle electrical assembly & 170 & 3.5 \\
\hline Yaw assembly & 33 & 0.7 \\
\hline \multirow[t]{2}{*}{ Tower module } & 219 & 4.5 \\
\hline & 1,011 & 20.8 \\
\hline Development cost & 16 & 0.3 \\
\hline Engineering and management & 19 & 0.4 \\
\hline Foundation & 60 & 1.2 \\
\hline Site access and staging & 45 & 0.9 \\
\hline Assembly and installation & 45 & 0.9 \\
\hline Electrical infrastructure & 148 & 3.0 \\
\hline Balance of system & 332 & 6.8 \\
\hline Construction financing cost & 39 & 0.8 \\
\hline \multirow[t]{2}{*}{ Contingency fund } & 88 & 1.8 \\
\hline & 127 & 2.6 \\
\hline Total capital expenditures & 1,470 & 30.3 \\
\hline
\end{tabular}

Because of CapEx variability among projects, we established estimates for the turbine component costs using the NREL 2015 CSM. We estimated BOS costs using NREL's LandBased-Wind BOS model, which relies on scaling relationships and costs derived from detailed data obtained through a major engineering, procurement, and construction firm active in the wind industry to characterize costs. Construction financing was estimated assuming a 3-year construction duration and distributing the capital and interest over the 3 years using the same methodology as NREL's 2019 ATB for land-based wind. We estimated the project contingency at $6 \%$ of CapEx, which is consistent with industry reporting. Total installed project CapEx for U.S. projects in 2018 came in at $\$ 1,470 / \mathrm{kW}$ (Wiser and Bolinger 2019), which is a decrease from 
last year's cost report of $\$ 1,649 / \mathrm{kW}^{10}$ primarily from lower turbine prices in reported installed project costs in 2018 .

\subsection{Land-Based Technology Characteristics and Annual Energy Production}

\subsubsection{Turbine Parameters}

For the purpose of this report, the turbine parameters are specific to the turbine and independent of the wind resource characteristics. These parameters consist not only of turbine size (such as rated power, rotor diameter, and hub height), but also of turbine operating characteristics (such as coefficient of power, maximum tip speed, maximum tip-speed ratio, and drivetrain design). Because the three-stage planetary/helical gearbox with a high-speed asynchronous generatorstyle drivetrain topology dominates the U.S. market, this type of drivetrain was selected for the baseline turbines used in this analysis. The power curve for the 2.4-MW land-based turbine is derived from NREL's SAM (NREL's System Advisor Model web page: https://sam.nrel.gov/). A summary of the turbine parameters is shown in Table 5. For specific approaches regarding additional turbine parameters (e.g., power curves), see the "2010 Cost of Wind Energy Review" (Tegen et al. 2012).

Table 5. Reference Land-Based Turbine Parameters

\begin{tabular}{|lc|}
\hline & Turbine Parameters \\
\hline Turbine rated power $(\mathrm{MW})$ & 2.4 \\
\hline Turbine rotor diameter $(\mathrm{m})$ & 115.6 \\
\hline Turbine hub height $(\mathrm{m})$ & 88.1 \\
\hline Maximum rotor tip speed (meters per second $[\mathrm{m} / \mathrm{s}])$ & 80 \\
\hline Tip-speed ratio at maximum coefficient of power $\left(\mathrm{C}_{\mathrm{p}}\right)$ & 8 \\
\hline Drivetrain design & Geared \\
\hline Cut-in wind speed $(\mathrm{m} / \mathrm{s})$ & 3 \\
\hline Cut-out wind speed $(\mathrm{m} / \mathrm{s})$ & 25 \\
\hline Maximum coefficient of power & 0.47 \\
\hline
\end{tabular}

\subsubsection{Wind Resource}

The average wind speed can vary from project to project across the United States. The annual average wind speed chosen for the reference project analysis, consistent with prior reports, is 7.25 meters per second $(\mathrm{m} / \mathrm{s})$ at $50 \mathrm{~m}$ above ground level $(7.86 \mathrm{~m} / \mathrm{s}$ at a hub height of $88.1 \mathrm{~m})$. This wind speed is intended to be generally indicative of the wind regime for projects installed in moderate-quality sites (i.e., average wind power class 4). We applied an elevation of $450 \mathrm{~m}$ above sea level based on this concept of using a representative site that would have a similar altitude to a project located within the interior of the country. A summary of the wind resource assumptions for the 2018 representative site is included in Table 6.

\footnotetext{
${ }^{10}$ For comparison purposes, last year's CapEx was inflated from 2017 USD to 2018 USD assuming a $2.4 \%$ cumulative rate of inflation from the Bureau of Labor and Statistics (undated).
} 
Table 6. Reference Land-Based-Wind Resource Assumptions

\begin{tabular}{|lc|}
\hline \multicolumn{2}{|c|}{ Wind Resource Characteristics } \\
\hline Annual average wind speed at a 50-m height $(\mathrm{m} / \mathrm{s})$ & 7.25 \\
\hline Annual average wind speed at an 88.1-m hub height $(\mathrm{m} / \mathrm{s})$ & 7.86 \\
\hline Weibull k & 2.0 \\
\hline Shear exponent & 0.143 \\
\hline Turbine elevation (meters above sea level) & 450 \\
\hline
\end{tabular}

\subsubsection{Losses and Availability}

Although some losses can be affected by turbine design or wind resource characteristics, they are treated as independent of any other input in this simplified analysis. Types of losses accounted for here include array wake losses, electric collection and transmission losses (from the substation to the point of interconnection), and blade soiling losses, totaling $15 \%$. A wind power plant availability of $98 \%$ is assumed, indicating that the wind project is ready to produce power between wind turbine cut-in and cut-out wind speeds $98 \%$ of the time. Net average AEP is calculated by applying all losses and availability to the gross AEP. Table 7 shows the estimated losses and availability for the land-based reference wind power plant.

Table 7. Reference Land-Based-Wind Losses and Availability Assumptions

\begin{tabular}{|ll|}
\hline \multicolumn{2}{|c|}{ Losses } \\
\hline Losses (i.e., array, energy conversion, and line) & $15 \%$ \\
\hline Availability & $98 \%$ \\
\hline
\end{tabular}

\subsubsection{Annual Energy Production}

The AEP for this analysis was computed using SAM. The model uses an idealized power curve based on the turbine configuration and computes annual energy capture for a wind project that is specified by the wind resource and the wind power plant's assumed losses and availability. The result of these calculations yields a net energy capture of 3,648 MWh/MW/year, which corresponds to a $41.6 \%$ net capacity factor assuming 8,760 hours in a year. For reference, the generation-weighted average capacity factor for the interior region reported by Wiser and Bolinger (2019) in calendar year 2018 is $43.1 \%$ for projects built from 2014 to 2017 . The net energy capture and net capacity factor for the reference wind plant are shown in Table 8.

Table 8. Reference Land-Based-Wind Power Plant AEP and Capacity Factor Summary

\begin{tabular}{|lc|}
\hline \multicolumn{2}{|c|}{ AEP and Capacity Factors } \\
\hline Net energy capture (MWh/MW/year) & $7.25 \mathrm{~m} / \mathrm{s}$ at $50 \mathrm{~m}$ \\
\hline Net capacity factor $(\%)$ & 3,648 \\
\hline
\end{tabular}

\subsection{Land-Based Operation and Maintenance Expenditures}

OpEx costs are generally expressed in two categories: 1) fixed O\&M costs (e.g., scheduled plant maintenance or land lease costs) and 2) variable O\&M costs (e.g., unscheduled plant maintenance). For simplicity, annual OpEx can be converted to a single term and expressed as 
either dollars per kilowatt per year $(\$ / \mathrm{kW} / \mathrm{yr})$ or dollars per megawatt-hour $(\$ / \mathrm{MWh})$. This analysis uses the dollars-per-kilowatt-per-year convention. Unfortunately, O\&M market data are not widely available; therefore, the recent U.S. wind industry survey, "Assessing wind power operating costs in the United States: Results from a survey of wind industry experts" (Wiser et al. 2019) is used to inform the O\&M cost estimates for the representative wind plant. For recently installed projects, entering commercial operations from 2015 through 2018, the survey results anticipate an average range of O\&M costs between $\$ 33$ and $\$ 59 / \mathrm{kW} / \mathrm{yr}$. The average across respondents was $\sim \$ 44 / \mathrm{kW} / \mathrm{yr}$ and is assumed to be the all-in levelized OpEx for the representative project. ${ }^{11}$ The annual O\&M cost from the expert survey and the calculated O\&M cost on an energy basis for the representative wind plant is shown in Table 9.

Table 9. Land-Based-Wind Reference Project OpEx

\begin{tabular}{|ccc|}
\hline 2.4-MW Land-Based & $\begin{array}{c}\text { Turbine } \\
(\$ / k W / y r)\end{array}$ & $\begin{array}{c}\text { 2.4-MW Land-Based } \\
\text { Turbine }\end{array}$ \\
OpEx & 44 & $1 / M W h$
\end{tabular}

\subsection{Land-Based-Wind Finance}

This section describes the financing assumptions for the report's representative land-based-wind reference project in the United States in 2018. It is important to distinguish between financing assumptions and financial costs. Financial costs, which are part of CapEx according to the system cost breakdown structure, include items such as insurance, contingency, and reserve accounts. Financing assumptions, on the other hand, refer to the cost of interest and other carrying charges, corporate taxes, and depreciation (represented by the FCR in this report), applied to the total CapEx. To capture the financing structure and costs, a fixed charge rate, detailed in Section 4.5.2, is used for the LCOE equation.

\subsubsection{Discount Rate}

Typically, various financial terms, such as the cost of debt or equity, are captured in the discount rate, which is in turn used to estimate the cost of energy. For this analysis, we calculate the discount rate as the after-tax weighted-average cost of capital (WACC) and we presume that the reported yields for equity are after-tax yields and can be used directly in the WACC calculation. The cost of debt (as a value) is also reported, but because interest on debt is tax deductible, we use an effective corporate marginal tax rate to determine an after-tax cost of debt for the discount rate calculation. The cost of capital data collected by Lawrence Berkeley National Laboratory (Wiser and Bolinger 2019) gives a basis for WACC assumptions for the representative wind project in 2018 and results in a nominal WACC of 7.59\%. This WACC was derived assuming a debt fraction of $51 \%$, nominal debt interest rate of $4.5 \%$, nominal return on equity of $12 \%$, and a $26 \%$ tax rate. ${ }^{12}$ Each actual project, however, has a unique risk profile, financing terms, and ownership structure. For this reason, a single WACC representing the entire fleet of 2018 wind

\footnotetext{
${ }^{11}$ Given the scarcity and varying quality of the data, OpEx may vary substantially among projects, and the data included here may not fully represent the challenges that OpEx present to the wind power industry.

${ }^{12}$ Because these data are derived from installed projects in 2018, they include the impact of the PTC on the debt ratio even though the LCOE estimates do not include the PTC.
} 
installations should be viewed cautiously and used to illustrate general market trends and conditions only.

In financial modeling, corporate tax rates are often presented as a composite, or effective, tax rate. This rate is calculated from a blend of the highest marginal corporate tax rate of $21 \%{ }^{13}$ and an approximate typical state corporate tax rate. Because state taxes are typically deductible expenses on federal tax returns, the blended rate is represented as $26 \%$ reported in NREL's ATB. Wind projects are often organized as disregarded entities for tax purposes (i.e., no taxes are paid by the project entity) and taxes are paid further up the organizational structure at some corporate level.

The inflation rate has been set to $2.5 \%$. This rate aligns with the inflation rate provided in NREL's ATB. Discount rates are initially calculated in nominal after-tax USD, and an estimate of inflation is used to calculate a discount rate in real after-tax USD.

Although the PTC is a critical component for wind projects installed in 2018, it is expected to phase out in future years. ${ }^{14}$ Research has shown that one likely outcome of the termination of the PTC is increased project leverage, which will reduce the higher-cost tax-equity portion of project finance. This shift of capital structure is expected to partially offset the impact of the lack of PTC (Bolinger 2014). For example, assuming that project leverage increases from $40 \%$ to $60 \%$ results in a reduction in nominal after-tax WACC of over 1 percentage point (Mai et al. 2015).

\subsubsection{Economic Evaluation Metrics}

In the economic evaluation of wind energy investments there are two important metrics: the capital recovery factor (CRF) and FCR. The FCR represents the amount of annual revenue required to pay the carrying charge ${ }^{15}$ as applied to the CapEx on that investment during the expected project economic life. ${ }^{16}$ The FCR is based on the CRF but also reflects corporate income taxes and depreciation. The ATB methodology is used to calculate the FCR.

The CRF is defined as "the uniform periodic payment, as a fraction of the original investment cost that will fully repay a loan including all interest, over the term of the loan" (Short et al. 1995). The CRF can be thought of as the recurring fixed payment over the life of a loan common to most types of mortgages. For example, a $\$ 100$ loan at $8 \%$ interest amortized over 20 years

\footnotetext{
13 The U.S. tax reform bill passed and signed into law in December 2017 (Tax Cuts and Jobs Act, H.R. 1) lowers the corporate tax rate from $35 \%$ to $21 \%$; hence, the $21 \%$ corporate tax rate is used in this year's report assuming the final investment decisions for projects commissioned in 2018 would have been made under the reformed corporate tax rate.

14 "In December 2015, Congress passed a 5-year phased-down extension of the PTC. To qualify, projects must begin construction before January 1, 2020. In May 2016, the IRS issued guidance allowing four years for project completion after the start of construction, without the burden of having to prove continuous construction. In extending the PTC, Congress also included a periodic reduction in the value of the credit for projects starting construction after 2016. Specifically, the PTC will phase down in increments of 20 percentage points per year for projects starting construction in 2017 (80\% PTC), 2018 (60\%), and 2019 (40\%)" (Wiser and Bolinger 2016). Although the PTC was scheduled to phase out completely by the end of 2019, a change to the year-end tax package in 2019 has extended the PTC through the end of 2020 (40\%) (Amendment to Rules Committee Print 116-44. Sec. 127 [2019]).

${ }^{15}$ Carrying charges include the return on debt, return on equity, taxes, and depreciation.

16 The FCR does not allow for detailed analysis of specific financing structures; however, these structures can be represented through the use of a WACC as the discount rate input.
} 
requires a constant annual payment of $\$ 10.18$ (equivalent to the CRF). Notably, the CRF ignores the impact of corporate income taxes, thus is applicable to a no-tax investment scenario, such as from a government investment.

A reasonable assumption for land-based wind projects is that $95 \%$ of the project capital cost is eligible for 5-year (Modified Accelerated Cost Recovery System [MACRS]) depreciation, and the balance of the project capital cost is eligible for 15-year MACRS. In this work, the MACRS assumption is further simplified by assuming that $100 \%$ of the wind project cost basis is eligible for 5-year MACRS.

Table 10 presents the estimated WACC, CRF, and FCR in nominal and real terms using the after-tax WACC discount rate of $7.59 \%$ and $4.96 \%$, respectively, a project design lifetime of 25 years, and a net present value depreciation factor of $82 \%$ (assuming a 5-year MACRS depreciation schedule). The nominal and real CRF are estimated at 9.04\% and $7.07 \%$, respectively. The nominal FCR is estimated at $9.6 \%$ and the real FCR is estimated at $7.51 \%$. As noted in Short et al. (1995), comparisons of two or more capital investments should be on a consistent tax treatment basis (i.e., both investments using a before-tax method or an after-tax method).

Table 10. Summary of Land-Based-Wind Reference Project Economic Evaluation Metrics

\begin{tabular}{|lcc|}
\hline Weighted-average cost of capital (\%) & Nominal & Real \\
\hline Capital recovery factor (\%) & $9.0 \%$ & $5.0 \%$ \\
\hline Fixed charge rate (\%) & $9.6 \%$ & $7.1 \%$ \\
\hline
\end{tabular}

\subsection{Land-Based-Wind Levelized Cost of Energy}

The levelized cost of energy for the 2018 representative land-based wind power plant is calculated using the formulation presented in NREL's ATB and the representative turbine technology parameters, site conditions, wind resource, and cost estimates (i.e., CapEx, FCR, OpEx, and AEP). The LCOE value for the 2018 representative plant is estimated at \$42/MWh. Table 11 summarizes the costs for the primary components on a per-kilowatt and per-megawatthour basis. The graphic in Figure 2 illustrates the LCOE breakdown for the primary components of the representative wind plant, whereas Figure 3 depicts the absolute LCOE values for each of the components. 
Table 11. Summary of Inputs and Reference Project LCOE for 2018 Land-Based Installations

\begin{tabular}{|c|c|c|}
\hline & $\begin{array}{c}\text { 2.4-MW Land-Based } \\
\text { Turbine } \\
(\$ / k W)\end{array}$ & $\begin{array}{l}\text { 2.4-MW Land-Based } \\
\text { Turbine } \\
\text { (\$/MWh) }\end{array}$ \\
\hline Turbine capital cost & 1,011 & 20.8 \\
\hline Balance of system & 332 & 6.8 \\
\hline Financial costs & 127 & 2.6 \\
\hline CapEx & 1,470 & 30.3 \\
\hline OpEx (\$/kW/yr) & 44 & 12.1 \\
\hline Fixed charge rate (real) [\%] & \multicolumn{2}{|c|}{$7.5 \%$} \\
\hline Net annual energy production (MWh/MW/yr) & \multicolumn{2}{|c|}{3,648} \\
\hline Net capacity factor $(\%)$ & \multicolumn{2}{|c|}{$41.5 \%$} \\
\hline TOTAL LCOE (\$/MWh) & \multicolumn{2}{|c|}{42} \\
\hline
\end{tabular}

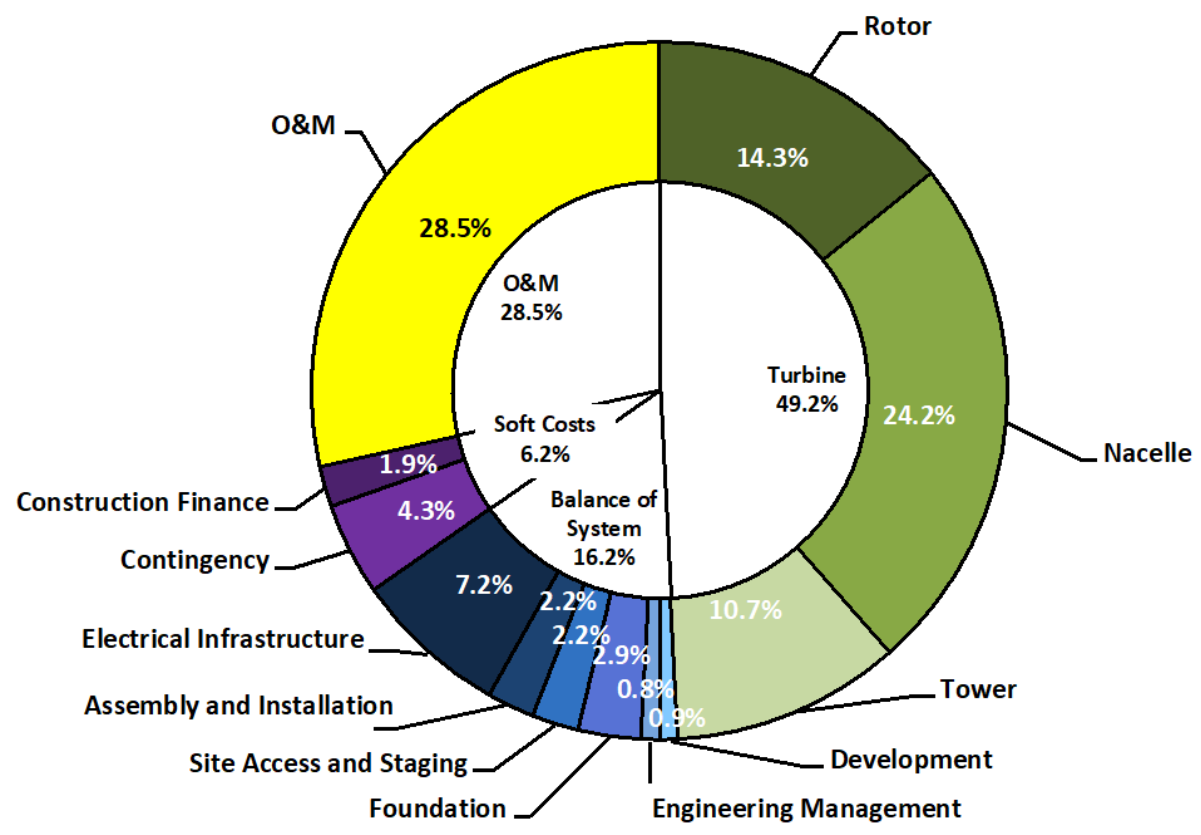

Figure 2. Component-level LCOE contribution for the 2018 land-based-wind reference project 


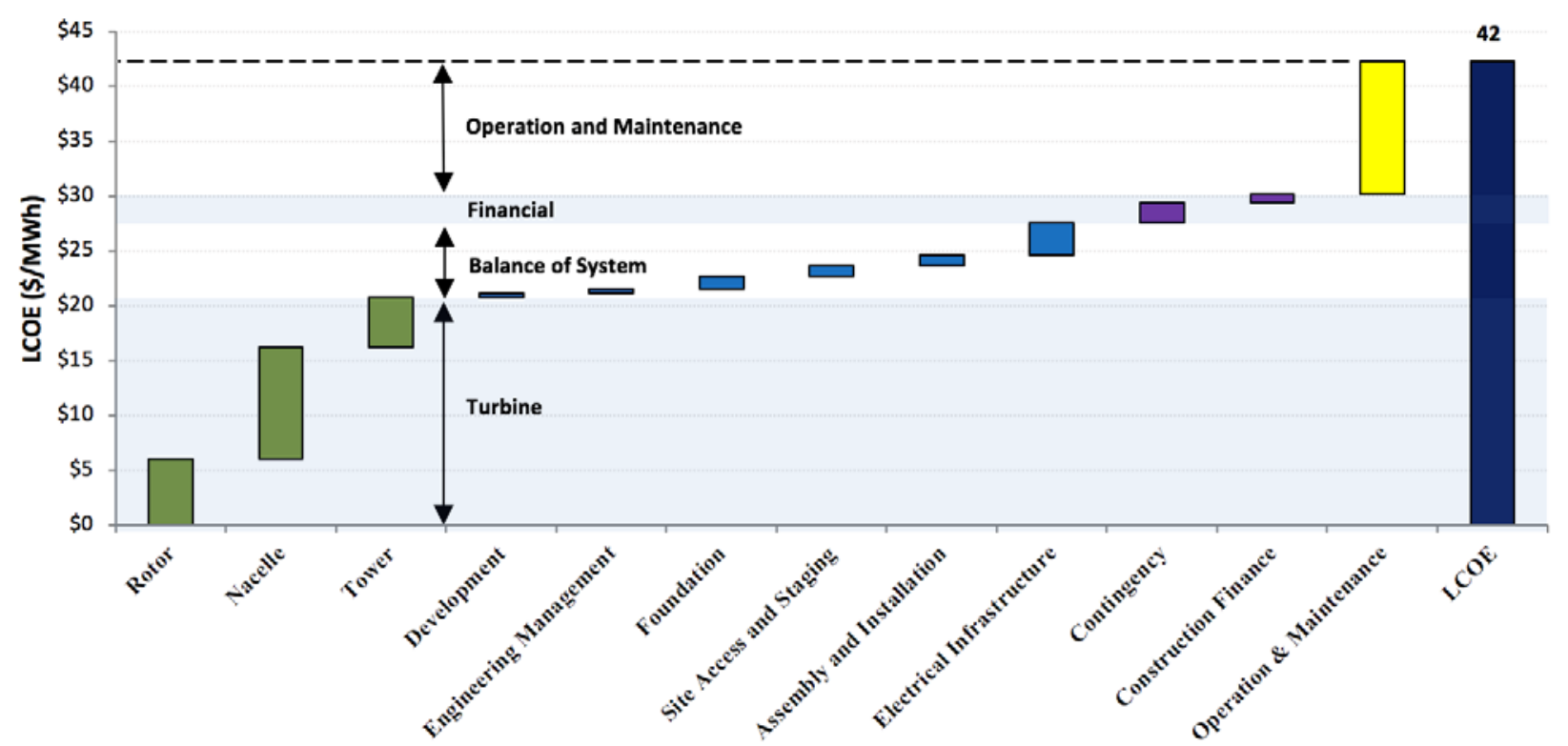

Figure 3. Component-level LCOE breakdown for the 2018 land-based-wind reference project

\subsection{Land-Based-Wind Levelized Cost of Energy Sensitivities}

The input parameters described earlier reflect the land-based reference wind project; however, input parameters for a near-term wind project are subject to considerable uncertainty. As a result, it is beneficial to investigate how this variability may impact the LCOE. The sensitivity analysis shown in Figure 4 focuses on the basic LCOE inputs: CapEx, OpEx, capacity factor (a surrogate for AEP), and FCR, which is broken into its principal elements: discount rate and economic operational lifetime.

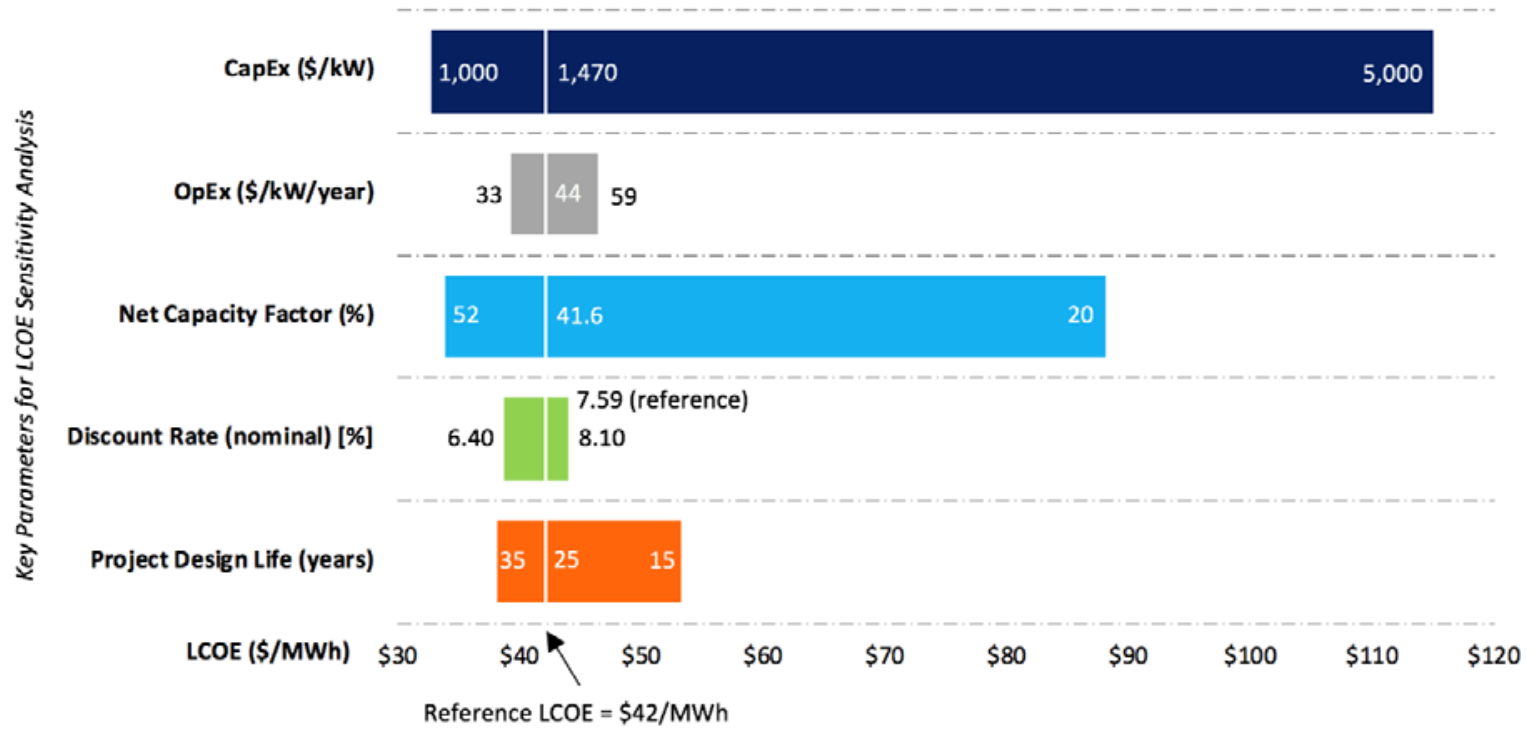

Figure 4. Sensitivity of land-based-wind LCOE to key input parameters

Note: The reference LCOE reflects a representative industry LCOE. Changes in LCOE for a single variable can be understood by moving to the left or right along a specific variable. Values on the $\mathrm{x}$-axis indicate how the LCOE will change as a given variable is altered and all others are assumed constant (i.e., remain reflective of the reference project). 
Sensitivity analyses are conducted by holding all reference project assumptions constant and altering only the variable in question. Sensitivity ranges for all parameters except for project design life are pulled from representative industry data or analysis contained in the "2018 Wind Technologies Market Report” (Wiser and Bolinger 2019). This selection of ranges provides insight into how real-world ranges influence LCOE. Keeping the same 200-MW project size, the sensitivity analysis yields ranges in LCOE from a low of $\$ 33 / \mathrm{MWh}$ to a high of $\$ 115 / \mathrm{MWh}-\mathrm{a}$ low-to-high delta of $\$ 82 / \mathrm{MWh}$. Within the ranges shown, CapEx has the greatest impact on landbased-wind LCOE followed by impacts from net capacity factor and then project design life. Project CapEx appears to have the greatest influence with respect to decreasing the LCOE relative to the reference project driven by reductions in reported installed project costs from lower turbine prices.

\subsection{Land-Based Supply Curve}

The land-based supply curve illustrates LCOE across the contiguous United States using the 2018 market data from Wiser and Bolinger (2019) and the Wind Integration National Dataset Toolkit (Wind Integration National Dataset Toolkit web page: https://www.nrel.gov/grid/windtoolkit.html). The toolkit provides meteorological conditions for more than 126,000 sites in the continental United States for the years 2007 to 2013. The LCOE for each of the potential wind power plant locations is computed using a site-specific CapEx and net AEP using a geographicinformation-system-based algorithm. The estimated theoretical capacity for the United States is calculated to be just under 10,000 gigawatts (GW), assuming a wind power plant density of 3 $\mathrm{MW} / \mathrm{kilometer}^{2}$. The LCOE calculated for this theoretical capacity ranges from $\$ 31 / \mathrm{MWh}$ for the best sites in the United States and extends beyond \$200/MWh for nonideal sites. Figure 5 shows this supply curve. For illustrative purposes, the LCOE is calculated for the land-based wind projects installed in 2018 using the same site-specific methodology for the 126,000 theoretical locations, which are shown on the supply curve (marked by green circles). In the figure, most of the installed projects in 2018 are grouped near the left side of the supply curve, where LCOE values are lowest, with fewer scattered when moving toward the right of the supply curve with higher LCOE values. Also shown is the calculated LCOE for the reference land-based wind project (indicated by the orange diamond), which is based on the 2018 market data from Wiser and Bolinger (2019) and the representative wind site characteristics.

It is important to note that the potential wind power plant capacity available over a range of LCOE varies by geographic region primarily because of the available wind resource characteristics. Incremental costs associated with labor rates, material costs, logistical or siting challenges, and distance to existing transmission infrastructure also contribute to regional differences. This range of costs is illustrated in the supply curve (Figure 5), wherein the cluster of installed wind projects in 2018 is toward the lower LCOE end of the supply curve and reflects projects built in the interior region of the United States where the wind resource is favorable. On the other side of the spectrum, the higher LCOE values on the supply curve reflect sites with a relatively lower-quality wind resource and may occur in many regions of the country depending on local meteorological and terrain features. 


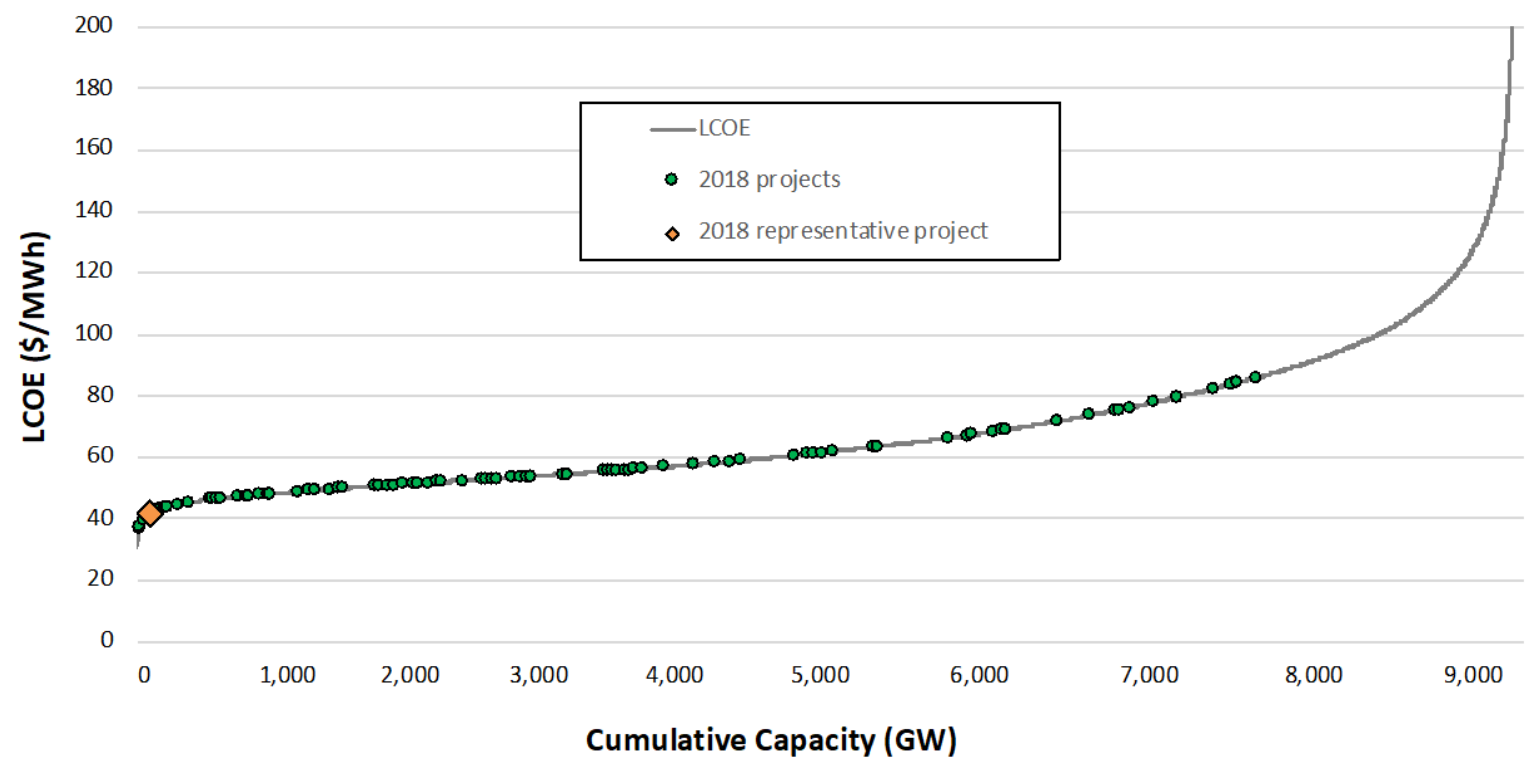

Figure 5. National land-based-wind resource supply curve with 2018 U.S. installed projects

\subsection{Land-Based-Wind Discussion of Results in Context of DOE Goals}

In this section, we present the official land-based-wind GPRA levelized cost of energy end-point target in 2030. The GPRA trajectory starts at \$56/MWh (in 2015 USD) in 2016, which was baselined in 2015, and is projected to the \$23/MWh (in 2015 USD) target in 2030. The 2030 target is derived from the analysis conducted in "Enabling the SMART Wind Power Plant of the Future Through Science-Based Innovation" (Dykes et al. 2017) study. The pathway for LCOE reduction from the 2015 baseline to the 2030 target is primarily driven by the increase in AEP through turbine scaling, enhanced control strategies, and reducing wind plant losses $(\$ 20 / \mathrm{MWh}$ [in 2015 USD]). The secondary driver in decreasing LCOE is through reductions in CapEx from wind power plant economies of scale, turbine scaling, and efficient manufacturing capabilities (\$8/MWh [in 2015 USD]). The remaining LCOE reductions are derived from decreasing OpEx through advanced O\&M strategies (\$4/MWh [in 2015 USD]) and lowering the cost of capital from increased certainty of future plant performance and reduced risk (\$1/MWh [in 2015 USD]). This LCOE reduction pathway is illustrated in Figure 6. 


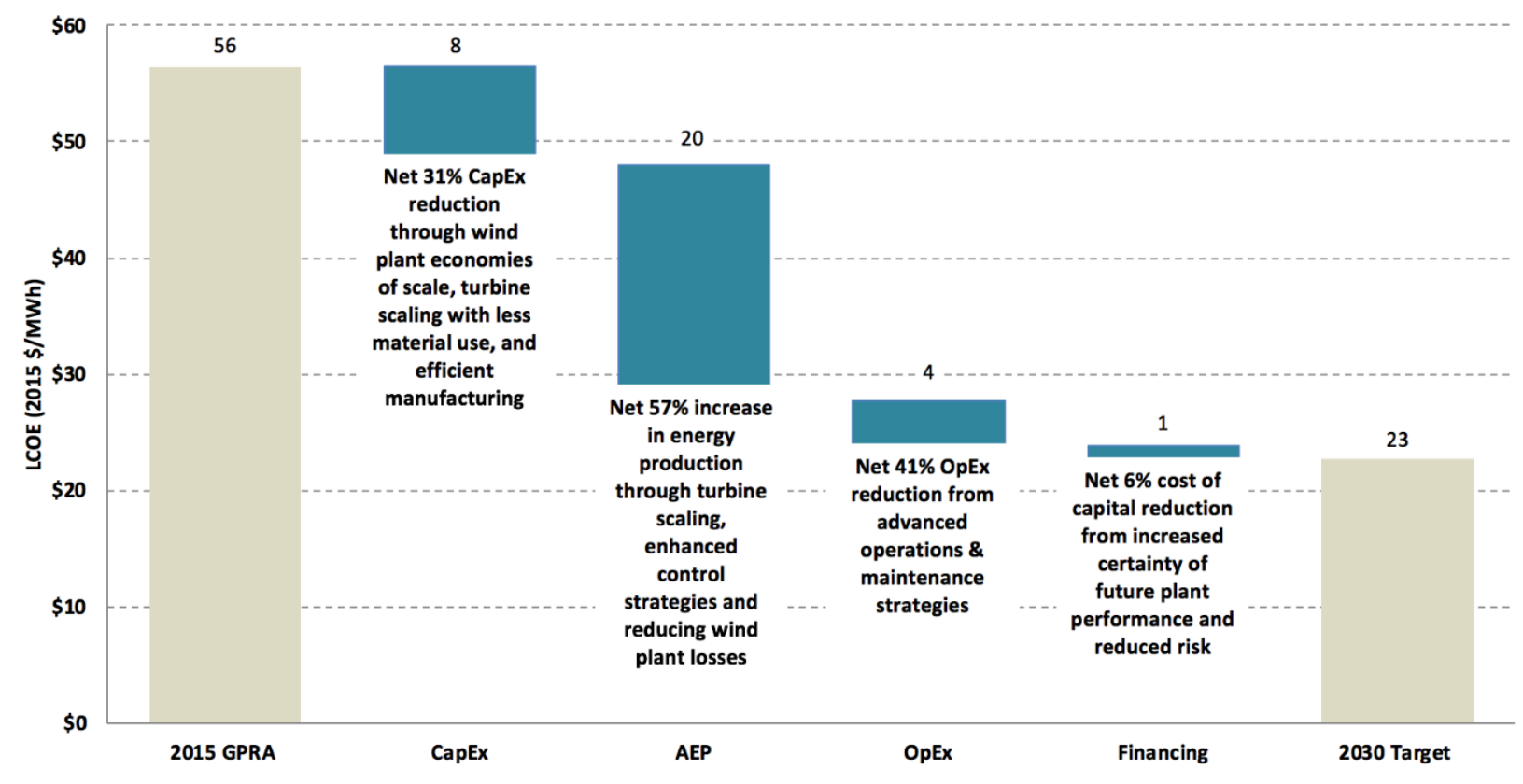

Figure 6. Pathway to LCOE reduction in 2030 by LCOE parameter

The GPRA trajectory and 2030 target are shown in Figure 7. To track LCOE progress against the GPRA trajectory, the historical LCOE (starting from the baseline year) and the current LCOE value assessed in this year's report are plotted. The GPRA baseline and target levelized cost of energy are reported in 2015 USD for land-based wind because WETO will report land-based wind values in 2015 USD. The current and historical LCOE values are labeled as "Actuals" in Figure 7. 


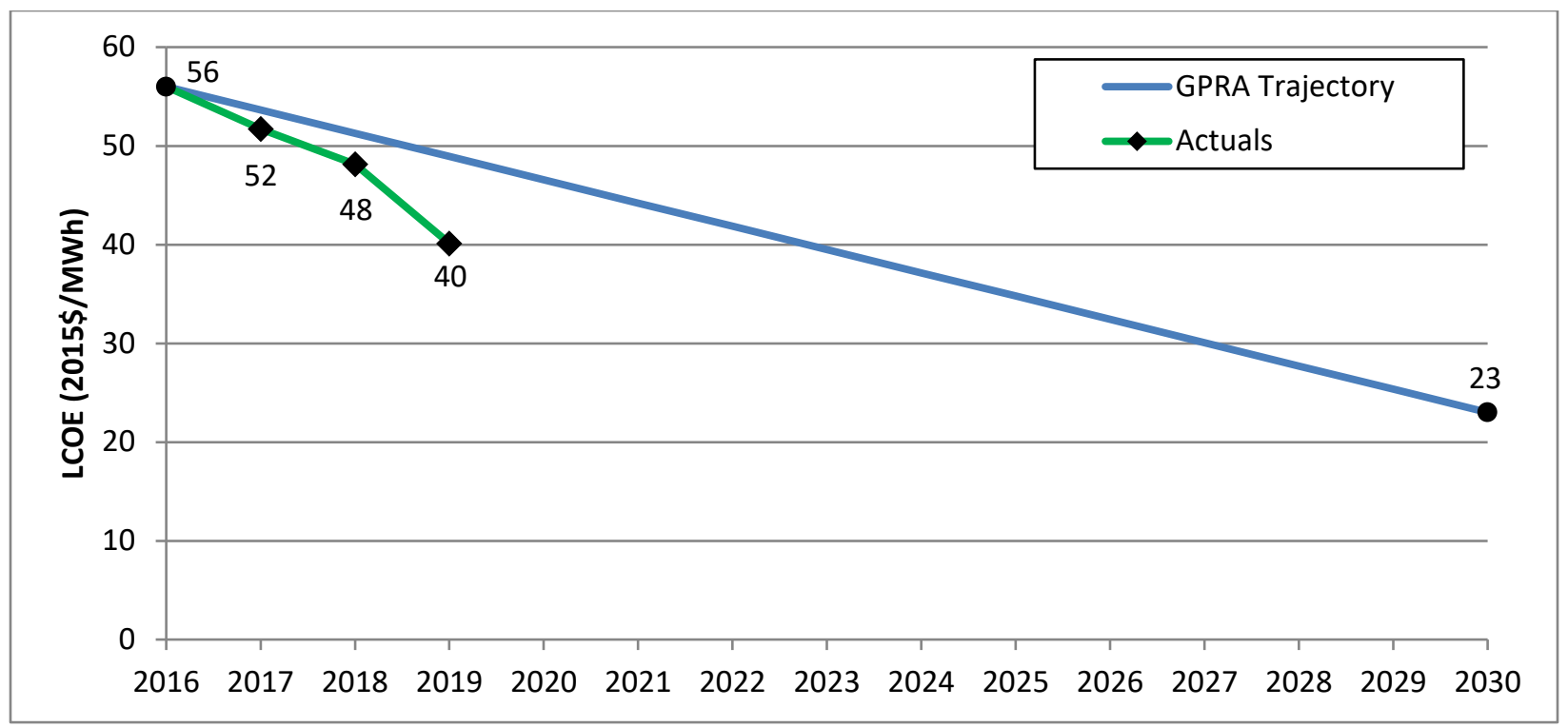

Figure 7. Land-based wind GPRA cost trajectories for LCOE (in 2015 USD)

Note: The dramatic drop in LCOE between 2018 and 2019 is due largely in part to updates made to the financing assumptions. In previous years, WETO reported land-based financing using a constant and conservative FCR. The land-based FCR was updated in 2019 reporting to maintain reporting consistency between land-based wind and offshore wind. Land-based-wind cost of capital data collected by Lawrence Berkeley National Laboratory (Wiser and Bolinger 2019) gives a basis for WACC assumptions for the representative wind project in 2018 and results in a nominal WACC of $7.59 \%$. 


\section{Offshore Wind}

This section explains the methodology and assumptions of calculating LCOE for U.S. offshore wind with each subsection detailing the data and assumptions used. The data from this analysis are derived from NREL's internal offshore wind database, which is populated by global market data and used to analyze market trends for offshore wind costs in Europe to determine cost projections for the United States and inform internal NREL modeling. The analysis uses data and information from the "2018 Offshore Wind Technologies Market Report" (Musial et al. 2019) and NREL's 2019 ATB (NREL's Annual Technology Baseline and Standard Scenarios web page: atb.nrel.gov) for offshore wind. In this report, we update costs and financial parameters to conform with the most recent industry and market developments. Additionally, we introduce new reference sites to reflect site conditions that are representative of near- to medium-term U.S. project development. Additional details are provided in Section 5.1 and Appendix D.

\subsection{Offshore Reference Project}

For the purposes of this study, offshore wind is broken into two technology categories: fixedbottom wind, and floating wind. The two substructure technologies are used in different site conditions; hence, this analysis considers two separate offshore reference sites (one for fixed bottom and one for floating). The two refence sites are used to calculate LCOE for each of the technologies; however, the fixed-bottom site is used for GPRA reporting.

We assessed a reference project at the fixed-bottom and floating sites, which each comprise 109 wind turbines rated at 5.5 MW- the turbine capacity reported in Musial et al. (2019) in 2018 (a total wind power plant capacity of $600 \mathrm{MW})$. The turbines are oriented in a grid layout and are expected to operate for 25 years without any catastrophic O\&M events. Turbines at the fixedbottom reference site are assumed to be supported by a monopile substructure $50 \mathrm{~km}$ from cable landfall at a water depth of $34 \mathrm{~m}$, which is similar to the characteristics of the wind energy areas located in the North Atlantic region. At the floating reference site, the turbines are assumed to be held by a semisubmersible substructure $36 \mathrm{~km}$ from cable landfall at a water depth of $739 \mathrm{~m}$, which is analogous to features of the Pacific Coast. Additional information on the types of fixedbottom and floating wind substructures can be found in Musial et al. (2017).

The array cable system and electrical line that connects to the offshore substation is a 33-kilovolt collection system design. The export cable from the offshore substation that is used to transfer the power to landfall assumes a 220-kilovolt export system. Specific to the floating reference site, cost premiums are applied to the array and export cable systems to account for the use of dynamic cables. A summary of the two offshore reference site characteristics is provided in Table 12. Further details on the development of the fixed-bottom and floating reference sites are presented in Appendix D. 
Table 12. Offshore Reference Project Parameters (Fixed-Bottom and Floating Substructures)

\begin{tabular}{|c|c|c|}
\hline \multicolumn{3}{|c|}{ Project Parameters } \\
\hline & Fixed Bottom & Floating \\
\hline Region & North Atlantic & Pacific Coast \\
\hline Turbine rated power (MW) & 5.5 & 5.5 \\
\hline Number of turbines & 109 & 109 \\
\hline Wind plant capacity (MW) & 600 & 600 \\
\hline Water depth (m) & 34 & 739 \\
\hline Substructure type & Monopile & Semisubmersible \\
\hline Distance from shore $(\mathrm{km})$ & 50 & 36 \\
\hline Project design life (yr) & 25 & 25 \\
\hline
\end{tabular}

\subsection{Offshore Capital Expenditures}

Given the relatively limited number of offshore wind projects in the United States and the lack of publicly available data, we obtained the CapEx estimates using ORCA (Beiter et al. 2016). The representative turbine characteristics (i.e., turbine capacity, rotor diameter, and hub height) used as inputs to the model were obtained from the "2018 Offshore Wind Technologies Market Report" (Musial et al. 2019). The capacity-weighted average turbine installed globally in 2018 was 5.5 MW with a 140-m rotor diameter at a 94-m hub height. We used these turbine parameters in combination with the spatial parameters presented in Table 12 for the fixed-bottom and floating reference sites to calculate CapEx.

The ORCA model yields a total installed CapEx value of $\$ 4,444 / \mathrm{kW}$ for the fixed-bottom reference site and $\$ 5,355 / \mathrm{kW}$ for the floating reference site. It should be noted that the CapEx estimates for floating offshore wind in this analysis assume a 5.5-MW turbine and are not necessarily optimized for floating offshore wind applications, therefore, they may negatively impact CapEx estimates. Progression to larger turbines is likely to coincide with deployment of commercial-scale floating wind technologies (Spyroudi 2016).

A breakdown of the CapEx for the fixed-bottom offshore reference project is shown in Figure 8. The shades of green represent the turbine cost, shades of blue represent BOS costs, and shades of purple represent financial costs. Further details on the BOS cost breakdown are provided in Maness et al. (2016). The dollar-value component cost breakdown is shown in Table 13. Figure 9 and Table 14 describe the same breakdown for the floating offshore reference project. 


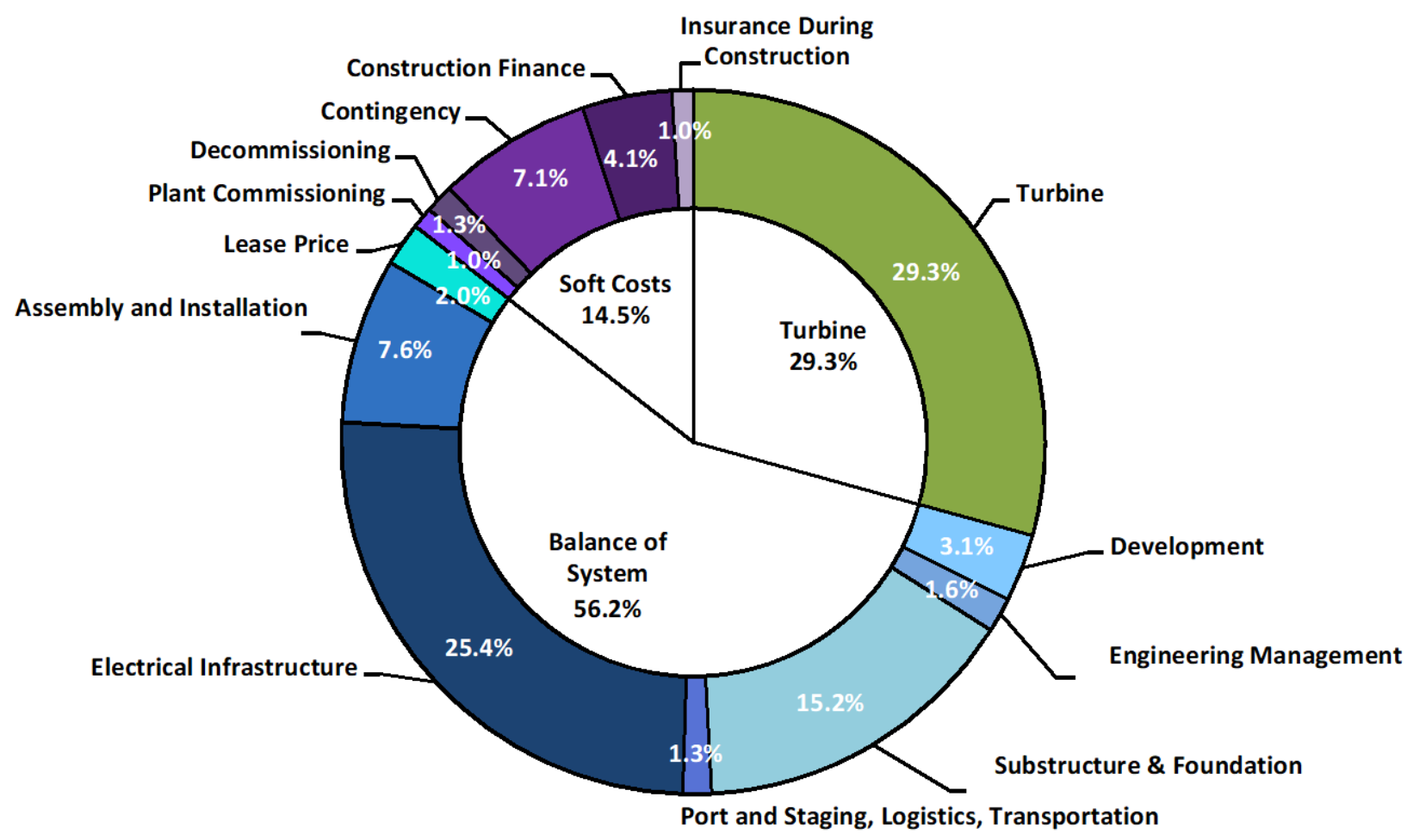

Figure 8. Capital expenditures for the fixed-bottom offshore wind reference project 
Table 13. Fixed-Bottom Offshore CapEx and LCOE Breakdown

\begin{tabular}{|c|c|c|}
\hline & $\begin{array}{c}\text { 5.5-MW Fixed-Bottom } \\
\text { Offshore Turbine } \\
(\$ / \mathrm{kW})\end{array}$ & $\begin{array}{c}\text { 5.5-MW Fixed-Bottom } \\
\text { Offshore Turbine } \\
\text { (\$/MWh) }\end{array}$ \\
\hline TURBINE CAPITAL COST & 1,301 & 17.2 \\
\hline Development cost & 138 & 1.8 \\
\hline Engineering and management & 70 & 0.9 \\
\hline Substructure and foundation & 676 & 8.9 \\
\hline Port and staging, logistics, transportation & 58 & 0.8 \\
\hline Electrical infrastructure & 1,130 & 14.9 \\
\hline Assembly and installation & 338 & 4.5 \\
\hline Lease price & 88 & 1.2 \\
\hline BALANCE OF SYSTEM & 2,498 & 33.0 \\
\hline Insurance during construction & 44 & 0.6 \\
\hline Decommissioning bond & 58 & 0.8 \\
\hline Construction financing & 183 & 2.4 \\
\hline Contingency & 316 & 4.2 \\
\hline Plant commissioning & 44 & 0.6 \\
\hline SOFT COSTS & 645 & 8.5 \\
\hline TOTAL CAPITAL EXPENDITURES & 4,444 & 58.8 \\
\hline
\end{tabular}

Note: The electrical infrastructure cost category includes construction and fabrication costs of both the land-based and offshore substations, and does not include installation costs for the electrical system, as they are included in the assembly and installation costs. 


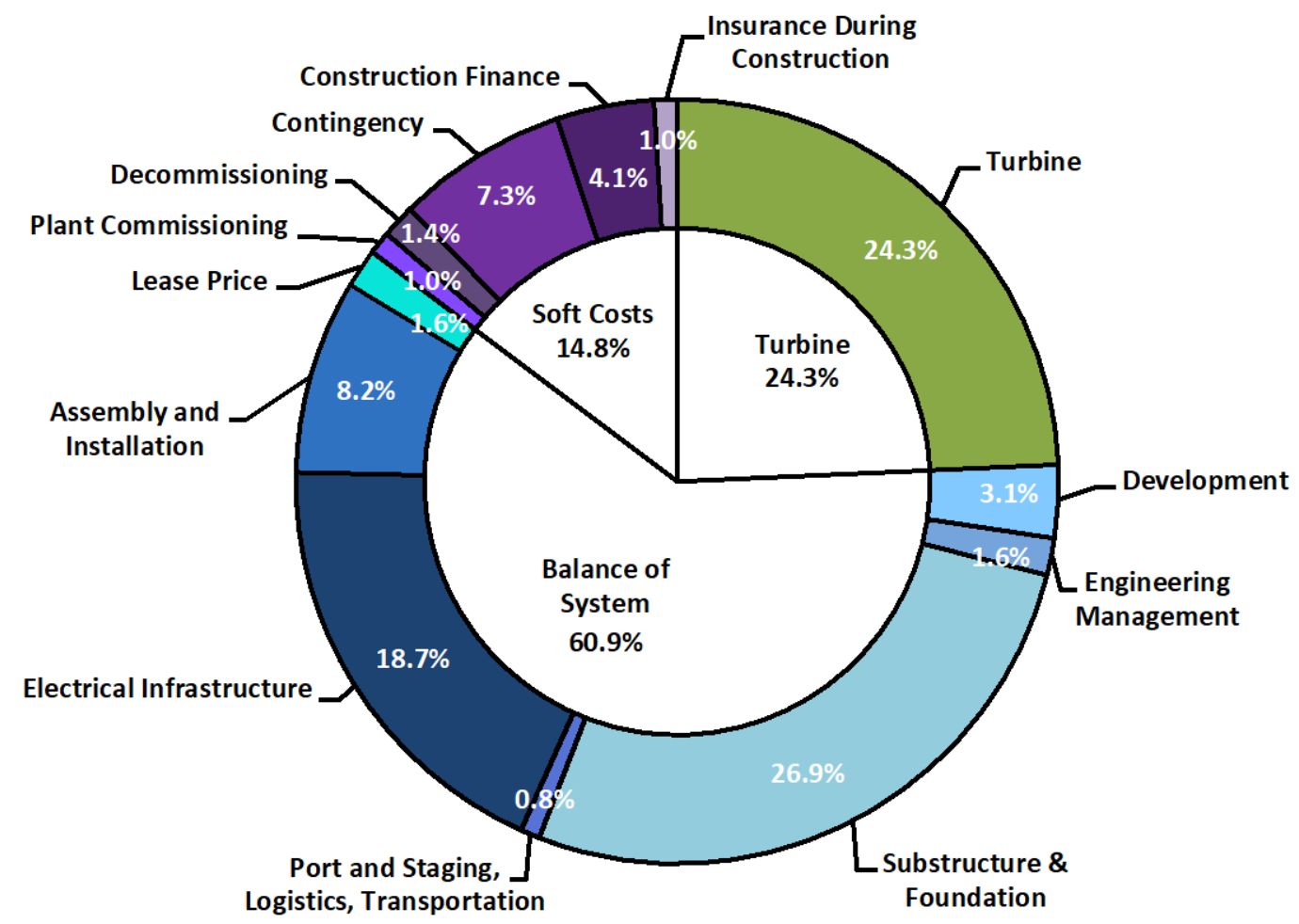

Figure 9. Capital expenditures for the floating offshore wind reference project 
Table 14. Floating Offshore CapEx and LCOE Breakdown

\begin{tabular}{|c|c|c|}
\hline & $\begin{array}{c}\text { 5.5-MW Floating } \\
\text { Offshore Turbine } \\
\qquad(\$ / k W)\end{array}$ & $\begin{array}{c}\text { 5.5-MW Floating } \\
\text { Offshore Turbine } \\
\text { (\$/MWh) }\end{array}$ \\
\hline TURBINE CAPITAL COST & 1,301 & 22.0 \\
\hline Development cost & 165 & 2.8 \\
\hline Engineering and management & 85 & 1.4 \\
\hline Substructure and foundation & 1,443 & 24.4 \\
\hline Port and staging, logistics, transportation & 44 & 0.7 \\
\hline Electrical infrastructure & 999 & 16.9 \\
\hline Assembly and installation & 440 & 7.4 \\
\hline Lease price & 88 & 1.5 \\
\hline BALANCE OF SYSTEM & 3,263 & 55.3 \\
\hline Insurance during construction & 52 & 0.9 \\
\hline Decommissioning bond & 76 & 1.3 \\
\hline Construction financing & 221 & 3.7 \\
\hline Contingency & 389 & 6.6 \\
\hline Plant commissioning & 52 & 0.9 \\
\hline SOFT COSTS & 790 & 13.4 \\
\hline TOTAL CAPITAL EXPENDITURES & 5,355 & 90.7 \\
\hline
\end{tabular}

Notes:

- The electrical infrastructure cost category includes construction and fabrication costs of both the land-based and offshore substations; this category does not include installation costs for the electrical system, as they are included in the assembly and installation costs.

- Take caution should if comparing fixed-bottom and floating offshore wind project costs because there are significant differences in spatial parameters between the representative sites selected for each technology.

There is a notable difference between the cost components that make up the land-based and offshore projects. In the land-based project, $69 \%$ of the cost is related to the wind turbine. For the offshore project, the turbine makes up $29 \%$ of the fixed-bottom offshore and $24 \%$ of the floating offshore reference project costs. The substructure and foundation portion of the BOS costs is the primary cause for the cost differences between the fixed-bottom and floating offshore projects. The analysis indicates that the fixed-bottom substructure is about $47 \%$ of the cost of the floating substructure (assuming a monopile for fixed bottom and a semisubmersible for floating). The other differences in the BOS and financial costs are related to the empirically-based cost and scaling relationships - some of which are a calculated as a percentage of total costs. 


\subsection{Offshore Technology Characteristics and Annual Energy Production}

Offshore wind turbines are continuing their upscaling trend. Looking ahead, turbines installed are expected to exceed $10 \mathrm{MW}$, as turbine manufacturers are announcing 12-MW turbines ready to be shipped in 2021 (GE Renewable Energy 2018). Some offshore wind developers are anticipating 13- to 15-MW turbines to be on the market by 2024 (DONG Energy 2017). Larger turbine sizes are enabled in offshore applications, in part, because there are fewer transportation and installation limits than for land-based projects. Furthermore, incorporating larger turbines in a project's design may also reduce the balance-of-plant costs and result in fewer turbines to service (Musial et al. 2017).

\subsubsection{Turbine Parameters}

The offshore wind turbine technology characteristics for this analysis are calculated using a capacity-weighted average of the global offshore wind projects installed in 2018. The results of this calculation yield a turbine rating of $5.5 \mathrm{MW}$, rotor diameter of $140.4 \mathrm{~m}$, and a hub height of $93.8 \mathrm{~m}$, as reported in Musial et al. (2019). These values and additional assumptions for the offshore turbine characteristics are summarized in Table 15.

Table 15. Reference Offshore Turbine Parameter Input Assumptions

\begin{tabular}{|l|c|}
\hline \multicolumn{2}{|c|}{ Turbine Parameters } \\
\hline Turbine rated power $(\mathrm{MW})$ & 5.5 \\
\hline Turbine rotor diameter $(\mathrm{m})$ & 140.4 \\
\hline Turbine hub height $(\mathrm{m})$ & 93.8 \\
\hline Drivetrain design & Geared \\
\hline Cut-in wind speed $(\mathrm{m} / \mathrm{s})$ & 3 \\
\hline Cut-out wind speed $(\mathrm{m} / \mathrm{s})$ & 25 \\
\hline
\end{tabular}

\subsubsection{Wind Resource}

In this report, we conducted an analysis assessing the wind resource for the fixed-bottom and floating reference sites in the North Atlantic and Pacific Coast, respectively. The details of this analysis and its results are presented in Appendix D. We calculated the annual average wind speed in the North Atlantic to be $8.43 \mathrm{~m} / \mathrm{s}$ at $50 \mathrm{~m}(8.97 \mathrm{~m} / \mathrm{s}$ at $93.8 \mathrm{~m})$, and $7.67 \mathrm{~m} / \mathrm{s}$ at $50 \mathrm{~m}$ $(8.17 \mathrm{~m} / \mathrm{s}$ at $93.8 \mathrm{~m})$ for the Pacific Coast. The wind resource parameters are summarized in Table 16. 
Table 16. Reference Offshore Wind Resource Input Assumptions

\begin{tabular}{|l|c|c|}
\hline \multicolumn{3}{|c|}{ Wind Resource Characteristics } \\
\hline Annual average wind speed at a 50-m height $(\mathrm{m} / \mathrm{s})$ & 8.43 & 7.67 \\
\hline Annual average wind speed at a 93.8-m hub height $(\mathrm{m} / \mathrm{s})$ & 8.97 & 8.17 \\
\hline Weibull k & 2.1 & 2.1 \\
\hline Shear exponent & 0.1 & 0.1 \\
\hline
\end{tabular}

\subsubsection{Losses and Availability}

The U.S. offshore reference project considers losses from wind power plant array wake impacts, inefficiencies in power collection and transmission, and losses from wind power plant availability. These losses and availability estimates are determined using ORCA (Beiter et al. 2016), which performs calculations based on a specific wind power plant layout and site-specific meteorological ocean conditions. The total system losses for the fixed-bottom technology in the North Atlantic are 16.2\%, whereas the system losses for the floating offshore technology in the Pacific Coast region are $21.0 \%$. The primary differences in loss between these offshore technologies are the additional electrical losses for floating wind in deeper waters (i.e., $34 \mathrm{~m}$ versus $739 \mathrm{~m}$ ), and wake losses from the different reference sites. Table 17 summarizes the losses and availability estimates for the fixed-bottom and floating offshore wind technologies.

Table 17. Reference Offshore Wind Total Losses

\begin{tabular}{|l|c|c|}
\hline & $\begin{array}{c}\text { Lorth Atlantic } \\
\text { (Fixed Bottom) }\end{array}$ & $\begin{array}{c}\text { Pacific Coast } \\
\text { (Floating) }\end{array}$ \\
\hline Total system losses (\%) & $16.2 \%$ & $21.0 \%$ \\
\hline
\end{tabular}

\subsubsection{Annual Energy Production}

The net AEP is calculated using the turbine technology parameters and wind resource inputs, and by applying the appropriate losses and availability estimates. The net AEP is calculated for the offshore reference project for both fixed-bottom and floating offshore applications using ORCA. The resulting net AEP for the fixed-bottom configuration in the North Atlantic is 4,257 $\mathrm{MWh} / \mathrm{MW} /$ year, with a $48.6 \%$ net capacity factor, and 3,324 MWh/MW/year for the floating configuration in the Pacific Coast region, with a 37.9\% net capacity factor. These values are summarized in Table 18.

Table 18. Reference Offshore Wind Net Annual Energy Production

\begin{tabular}{|l|c|c|}
\hline \multicolumn{2}{|c|}{ Net Annual Energy Production } \\
\hline Net energy capture (MWh/MW/year) & $\begin{array}{c}\text { North Atlantic } \\
\text { (Fixed Bottom) }\end{array}$ & $\begin{array}{c}\text { Pacific Coast } \\
\text { (Floating) }\end{array}$ \\
\hline Net capacity factor (\%) & 4,257 & 3,324 \\
\hline
\end{tabular}

Capacity factors in the United States are expected to vary widely depending on the project location and turbine technology. Improving the performance of offshore wind turbines and arrays 
has been a continued focus of industry and research activities. More information on the global trends for offshore wind power plant performance can be found in Musial et al. (2017).

\subsection{Offshore Operation and Maintenance Expenditures}

OpEx can vary greatly between projects for a number of reasons; however, the two largest cost drivers are the distance from the project to the maintenance facilities and the meteorological ocean climate at the site (Maples et al. 2013; Pietermen et al. 2011). Beiter et al. (2016) evaluated the O\&M for fixed-bottom and floating substructures located at sites with various wave heights, water depths, and distances from ports informed by parametric studies using the Energy Research Centre of the Netherlands O\&M Tool. ${ }^{17}$ The North Atlantic fixed-bottom and Pacific Coast floating offshore reference projects assume the same operational costs (e.g., annual leases and fees) of $\$ 30 / \mathrm{kW} / \mathrm{yr}$, whereas the maintenance expenditures differ between the two because they each use a different maintenance strategy (i.e., in situ versus tow to shore) and have distinctive site characteristics (i.e., distance from operations port, meteorological ocean conditions, and water depth), resulting in $\$ 129 / \mathrm{kW} / \mathrm{yr}$ for the fixed-bottom project and $\$ 137 / \mathrm{kW} / \mathrm{yr}$ for the floating project. These O\&M costs and the LCOE component breakdown are shown in Table 19.

Table 19. Offshore Wind Reference Project OpEx

\begin{tabular}{|c|c|c|c|c|}
\hline & \multicolumn{2}{|c|}{$\begin{array}{l}\text { North Atlantic } \\
\text { (Fixed Bottom) }\end{array}$} & \multicolumn{2}{|c|}{$\begin{array}{l}\text { Pacific Coast } \\
\text { (Floating) }\end{array}$} \\
\hline & (\$/kW/yr) & $\begin{array}{l}\text { (\$/kilowatt- } \\
\text { hour [kWh]) }\end{array}$ & (\$/kW/yr) & (\$/kWh) \\
\hline Operation & 30 & 7.1 & 30 & 9.1 \\
\hline Maintenance & 99 & 23.2 & 107 & 32.1 \\
\hline OpEx & 129 & 30.3 & 137 & 41.2 \\
\hline
\end{tabular}

\subsection{Offshore Finance}

This section describes the financing assumptions for the report's representative offshore wind (both fixed bottom and floating) reference projects in the United States in 2018. The offshore financing assumptions are primarily informed by the work done in NREL's 2019 ATB.

\subsubsection{Discount Rate}

Although it is evident that an individual project's financing terms will reflect its specific risk profile, new assumptions and ranges of nominal discount rates for offshore wind have been developed that are based largely on observations from the recent European market, assessing theoretical commercial wind projects in the United States, and NREL's 2019 ATB. For this analysis, we assume the discount rate and other economic evaluation metrics to be similar for the North Atlantic and Pacific Coast representative projects. The updated nominal WACC for 2018 is $5 \%$, which corresponds to a real WACC of $2.4 \%$, assuming a $2.5 \%$ inflation rate. Underlying assumptions for marginal tax rate and inflation are consistent with those presented in Section 4.5.1.

\footnotetext{
${ }^{17}$ Operation and maintenance costs for offshore wind projects are assumed to include labor, vessels, equipment, scheduled maintenance, unscheduled maintenance, land-based support, and administration.
} 


\subsubsection{Economic Evaluation Metrics}

To determine the LCOE for the 2018 representative offshore wind projects, a similar FCR methodology that was used for the land-based representative wind project is applied (see Section 4.5) and informed by the 2019 ATB. The FCR includes the present value of the accumulated depreciation benefit and ignores bonus depreciation. Assuming a project life of 25 years and discount rates and depreciation benefits as calculated, the offshore reference project nominal and real FCR for fixed-bottom and floating technologies is $7.4 \%$ and $5.6 \%$, respectively. Table 20 presents a summary of nominal and real WACC, CRF, and FCR that is used throughout the offshore analysis.

Table 20. Summary of Offshore Reference Project Economic Evaluation Metrics

\begin{tabular}{|lcc|} 
& $\begin{array}{c}\text { North Atlantic and Pacific Coast } \\
\text { (Fixed Bottom and Floating) } \\
\text { Nominal }\end{array}$ & $\begin{array}{c}\text { Real } \\
\text { WACC (\%) }\end{array}$ \\
\hline CRF (\%) & $7.0 \%$ & $2.4 \%$ \\
\hline FCR (\%) & $7.1 \%$ & $5.4 \%$ \\
\hline
\end{tabular}

\subsection{Offshore Reference Project Levelized Cost of Energy}

Based on the offshore turbine technology parameters, site conditions, wind resource, and cost estimates, the CapEx, FCR, OpEx, and AEP are plugged into the LCOE equation and the LCOE is computed to estimate a 2018 offshore reference wind power plant for fixed-bottom and floating technologies. LCOE for the North Atlantic representative project is calculated at $\$ 89 / \mathrm{MWh}$ and $\$ 132 / \mathrm{MWh}$ for the representative project on the Pacific Coast. Table 21 summarizes the fixed-bottom costs for the primary components (including their contribution to LCOE) in the North Atlantic. The graphic in Figure 10 illustrates the LCOE breakdown for the primary components of the North Atlantic wind plant, whereas Figure 11 provides a graphical representation of LCOE by line item. Table 22, Figure 12, and Figure 13 show the cost values, LCOE breakdown, and the LCOE values for the floating project in the Pacific Coast region.

Table 21. Fixed-Bottom Offshore Wind LCOE and Reference Projects Cost Breakdown

\begin{tabular}{|c|c|c|}
\hline & $\begin{array}{c}\text { 5.5-MW Fixed-Bottom } \\
\text { Offshore Turbine } \\
(\$ / \mathrm{kW})\end{array}$ & $\begin{array}{c}\text { 5.5-MW Fixed-Bottom } \\
\text { Offshore Turbine } \\
\text { (\$/MWh) }\end{array}$ \\
\hline Turbine capital cost & 1,301 & 17.2 \\
\hline Balance of system & 2,498 & 33.0 \\
\hline Financial costs & 645 & 8.5 \\
\hline CapEx & 4,444 & 58.8 \\
\hline OpEx (\$/kW/yr) & 129 & 30.3 \\
\hline Fixed charge rate (real) [\%] & \multicolumn{2}{|c|}{$5.6 \%$} \\
\hline Net annual energy production (MWh/MW/yr) & \multicolumn{2}{|c|}{4,257} \\
\hline Net capacity factor $(\%)$ & \multicolumn{2}{|c|}{$48.6 \%$} \\
\hline Total LCOE (\$/MWh) & \multicolumn{2}{|c|}{89} \\
\hline
\end{tabular}




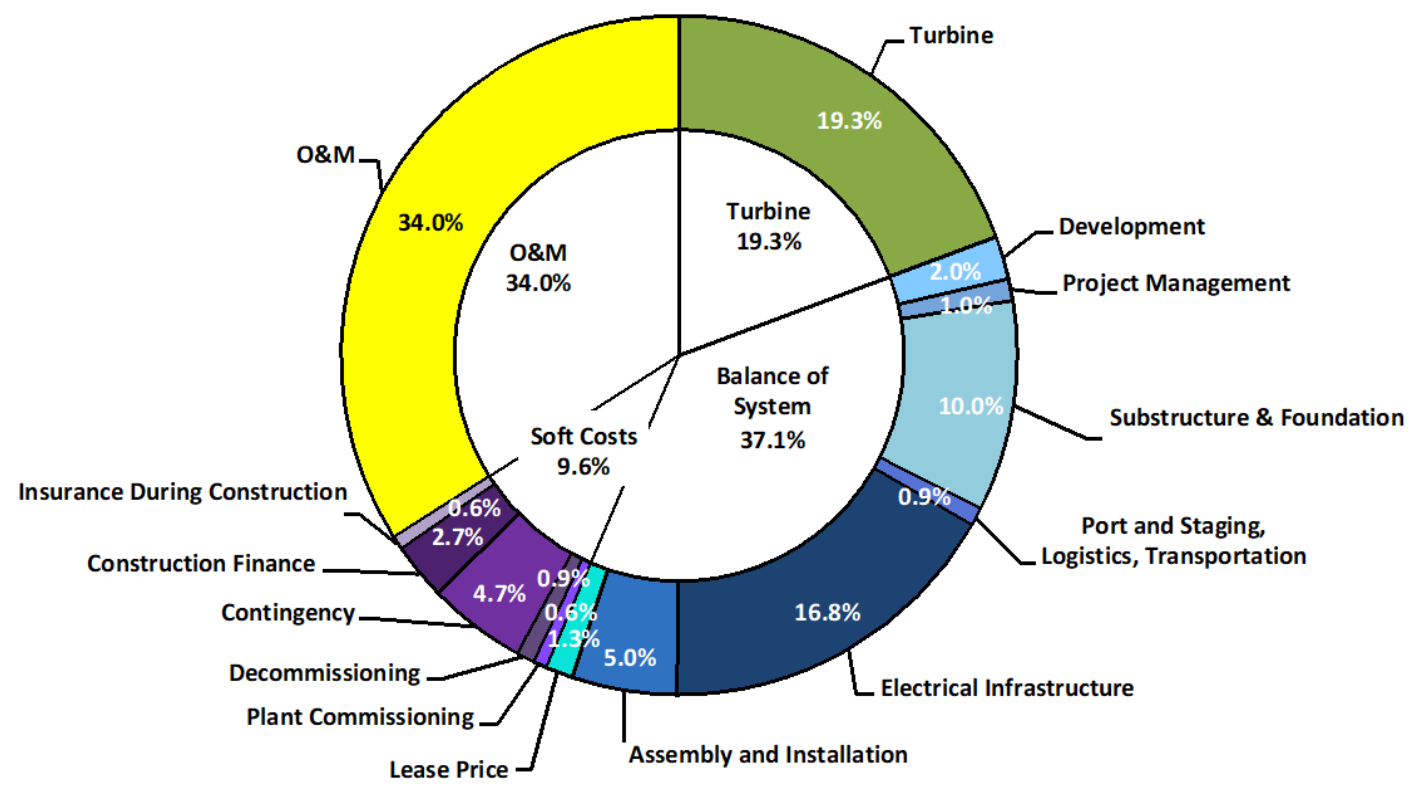

Figure 10. Component-level LCOE contribution for the 2018 fixed-bottom offshore wind reference project 


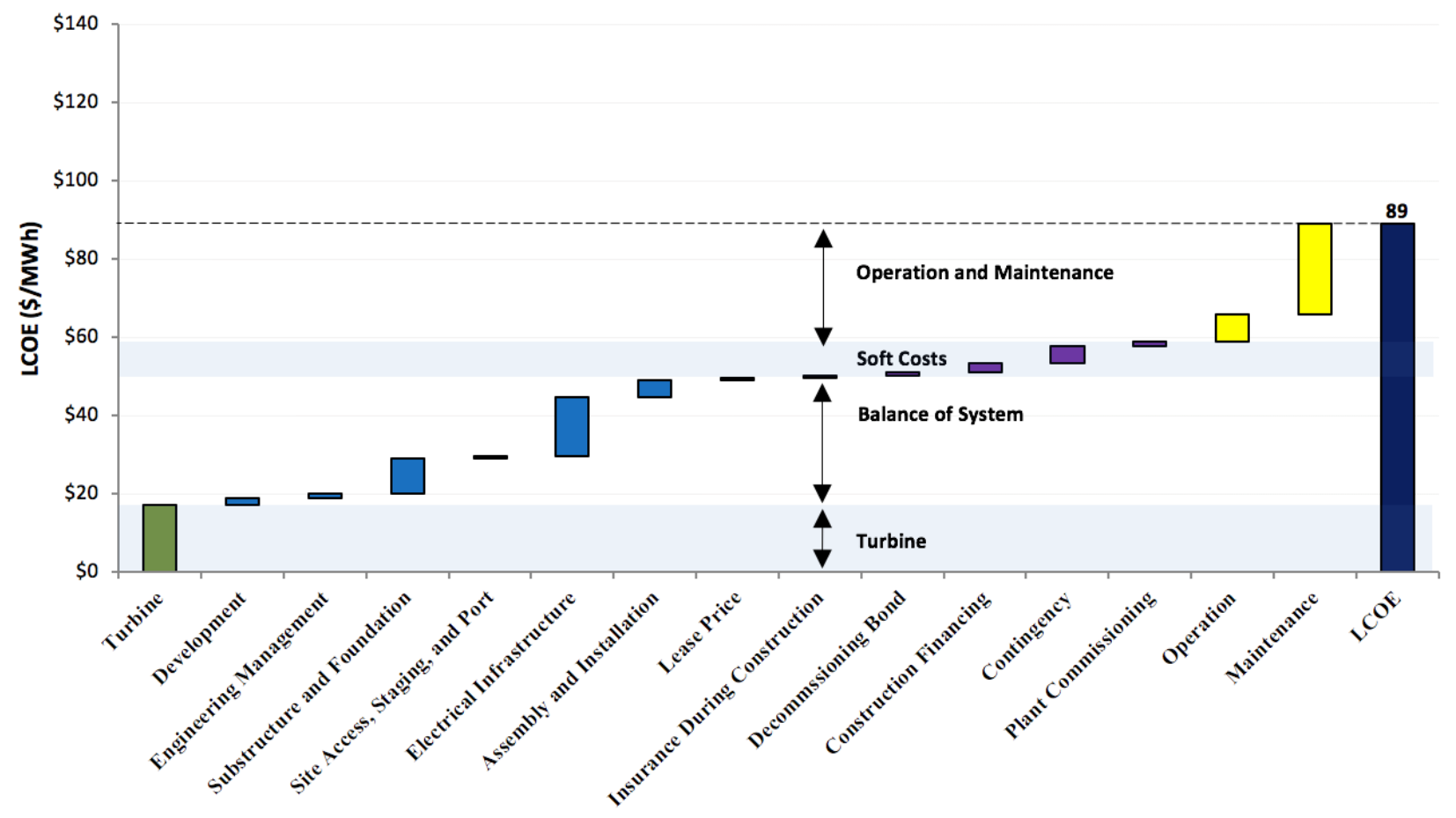

Figure 11. Component-level cost breakdown for the 2018 fixed-bottom offshore wind reference project

Table 22. Floating Offshore Wind LCOE and Reference Projects Cost Breakdown

\begin{tabular}{|c|c|c|}
\hline & $\begin{array}{l}\text { 5.5-MW Floating } \\
\text { Offshore Turbine }\end{array}$ & $\begin{array}{l}\text { 5.5-MW Floating } \\
\text { Offshore Turbine }\end{array}$ \\
\hline & $(\$ / k W)$ & (\$/MWh) \\
\hline Turbine capital cost & 1,301 & 22.0 \\
\hline Balance of system & 3,263 & 55.3 \\
\hline Financial costs & 790 & 13.4 \\
\hline CapEx & 5,355 & 90.7 \\
\hline OpEx (\$/kW/yr) & 137 & 41.2 \\
\hline Fixed charge rate (real) [\%] & \multicolumn{2}{|c|}{$5.6 \%$} \\
\hline Net annual energy production (MWh/MW/yr) & \multicolumn{2}{|c|}{3,324} \\
\hline Net capacity factor (\%) & \multicolumn{2}{|c|}{$37.9 \%$} \\
\hline Total LCOE (\$/MWh) & \multicolumn{2}{|c|}{132} \\
\hline
\end{tabular}




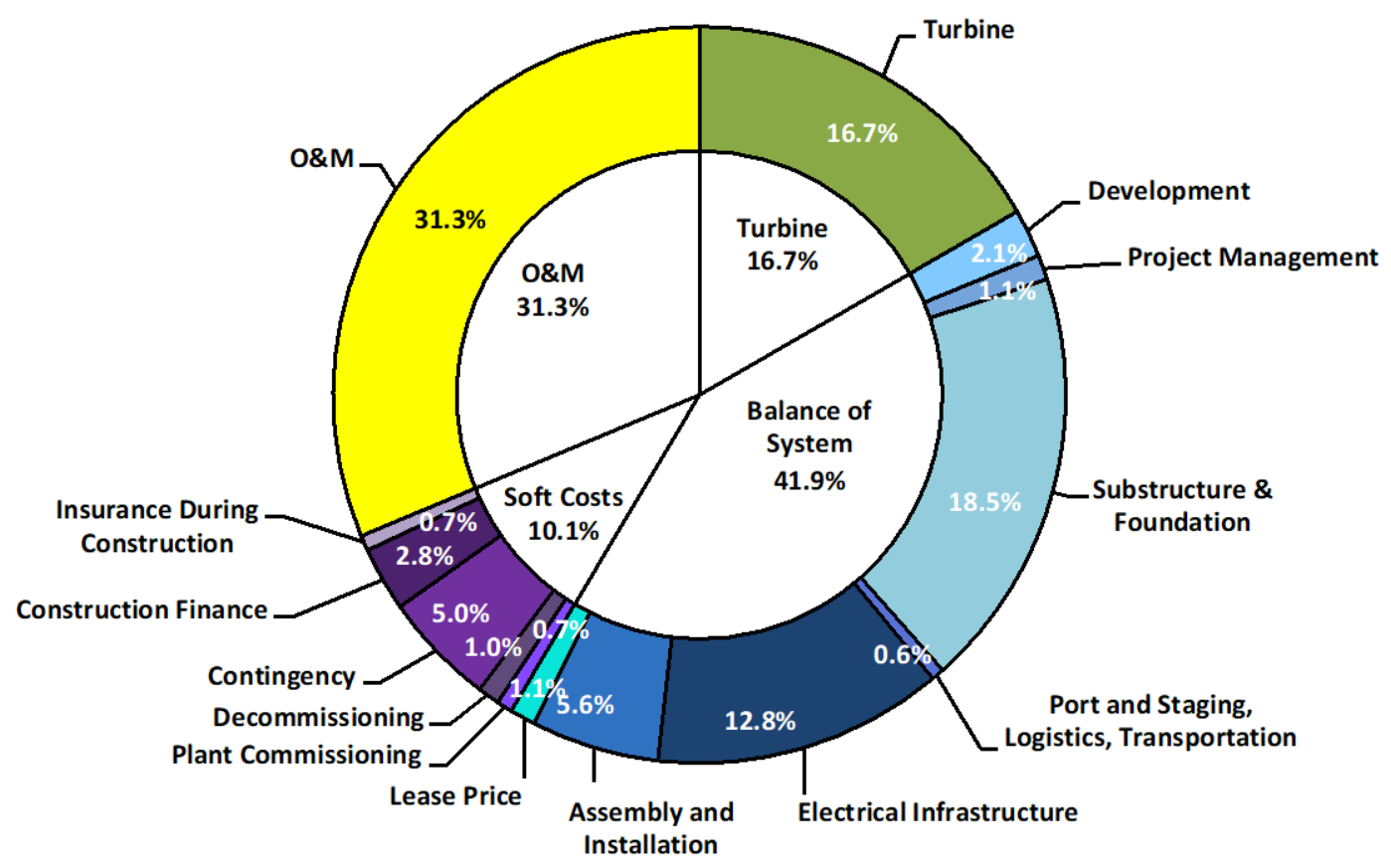

Figure 12. Component-level LCOE contribution for the 2018 floating offshore wind reference project

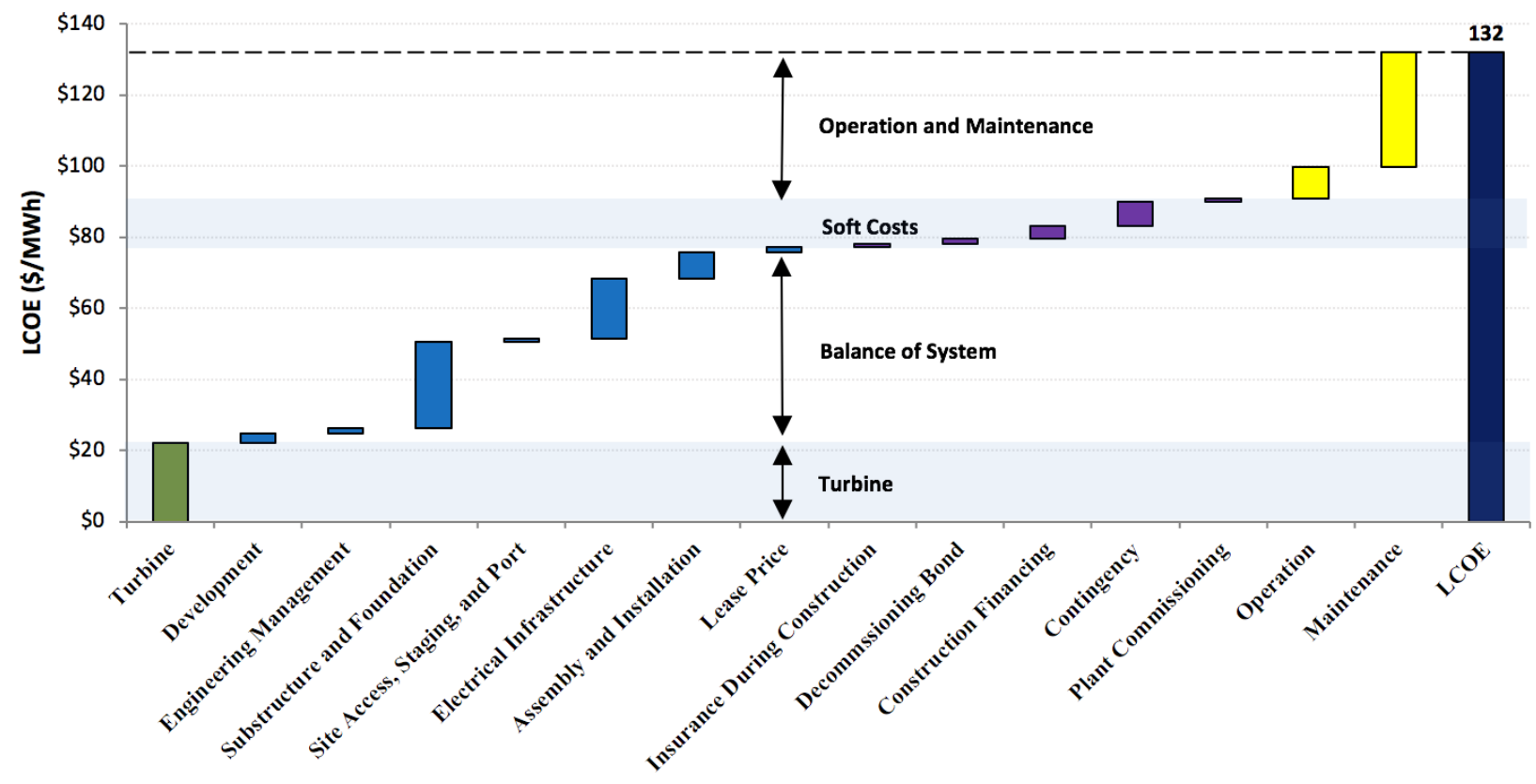

Figure 13. Component-level cost breakdown for the 2018 floating offshore wind reference project 5.7 Offshore Levelized Cost of Energy Sensitivities

The LCOE parameters described earlier in this report represent the fixed-bottom and floating offshore reference wind projects; however, input parameters for a near-term wind project are subject to considerable uncertainty. Hence, it is beneficial to investigate how this variability may 
impact the LCOE. The sensitivity analysis shown in Figure 14 (for the North Atlantic fixedbottom site) and Figure 15 (for the Pacific Coast floating site) focuses on the basic LCOE inputs: CapEx, OpEx, net capacity factor, and FCR, which are broken into two principal elements - discount rate and economic operational lifetime. We determined the sensitivity ranges for the LCOE inputs by examining the globally installed offshore projects in 2018 reported in Musial et al. (2019) and NREL's offshore wind database.

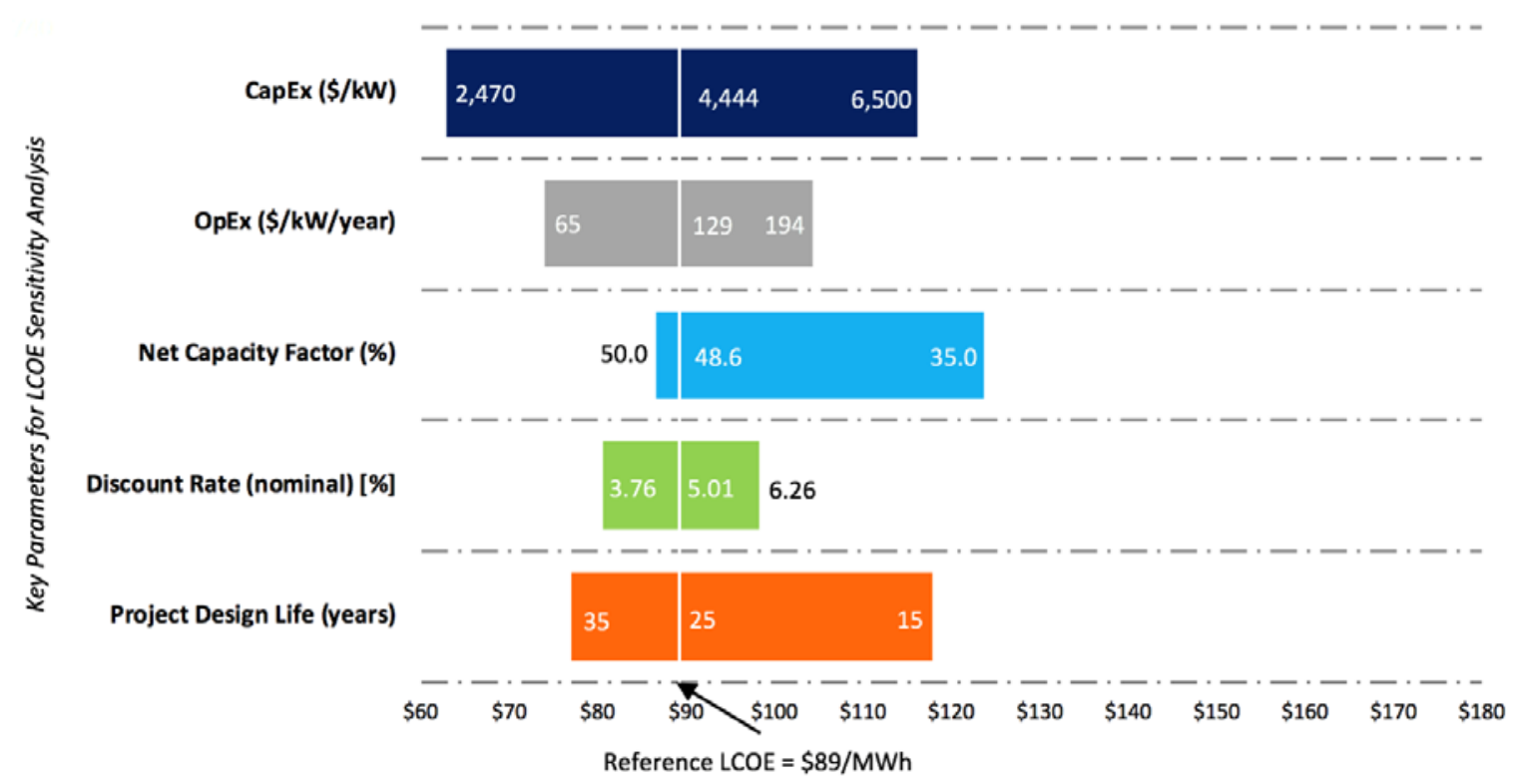

Figure 14. Sensitivity of fixed-bottom offshore wind LCOE to key input parameters

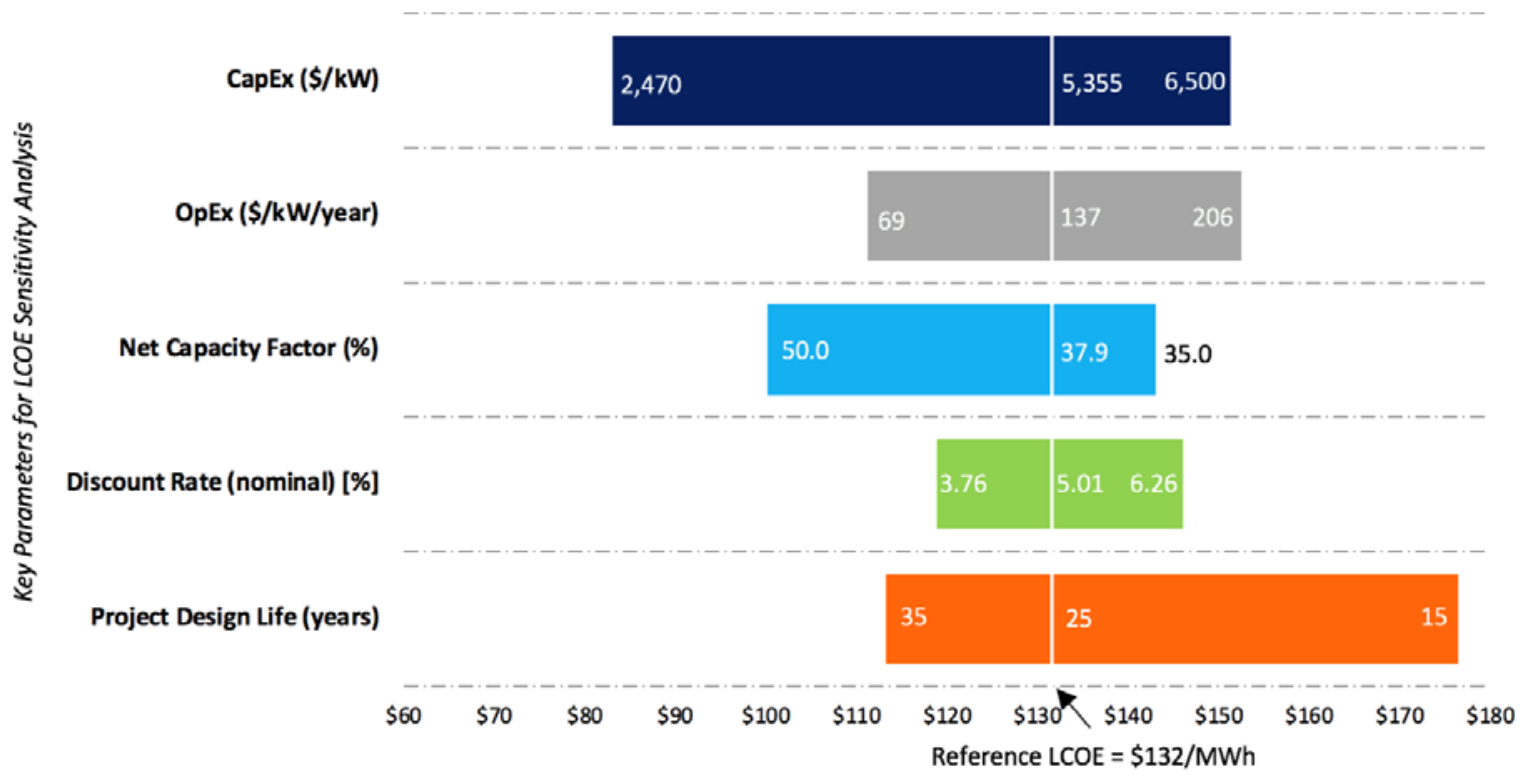

Figure 15. Sensitivity of floating offshore wind LCOE to key input parameters

Note: The reference LCOE reflects a representative industry LCOE. Changes in LCOE for a single variable can be understood by moving to the left or right along a specific variable. Values on the x-axis indicate how the LCOE will change as a given variable is altered and all others are assumed constant (i.e., remain reflective of the reference project). 
Sensitivity analyses are conducted by holding all reference project assumptions constant and altering only the variable in question. Sensitivity ranges are selected to represent the highs and lows observed in the industry and from the data in Musial et al. (2019). This selection of ranges provides insight into how real-world ranges influence LCOE. Keeping the same 600-MW project size, the sensitivity analysis yields ranges in LCOE from a low of $\$ 63 / \mathrm{MWh}$ to a high of $\$ 124 / \mathrm{MWh}$ for fixed-bottom configurations (Figure 14), and a low of $\$ 83 / \mathrm{MWh}$ to a high of $\$ 176 /$ MWh for floating configurations (Figure 15). Within the ranges shown, CapEx and project design life are the two factors that are shown to have the greatest impact on offshore wind LCOE, with CapEx having the greatest influence on decreasing LCOE relative to the reference projects.

\subsection{Offshore Supply Curve}

Nearly 2,060 GW of offshore wind technical resource potential is estimated by Musial et al. (2016) for all major U.S. coastal regions (excluding Alaska and Hawaii). ${ }^{18}$ The LCOE for each of the potential wind power plant locations is computed using a site-specific CapEx and net AEP using a geographic-information-system-based algorithm that is used in Beiter et al. (2017). LCOE, which includes the cost of transmission and was calculated for this theoretical capacity, ranged from just below $\$ 70 / \mathrm{MWh}$ to $\$ 235 / \mathrm{MWh}$. Figure 16 illustrates the supply curve of the gross offshore wind resource potential and highlights the 2018 fixed-bottom (marked with a blue marker) and floating (marked with an orange marker) offshore reference sites, using an updated version of ORCA (Beiter et al. 2016) and the representative offshore sites and wind characteristics presented in Section 5.3.

Note that the potential wind power plant capacity available over a range of LCOE varies by offshore geographic region primarily because of the available wind resource, distance from port, and water depth. Incremental costs associated with labor rates, material costs, logistical or siting challenges, and distance to existing transmission infrastructure also contribute to regional differences.

\footnotetext{
${ }^{18}$ The offshore wind technical resource potential does not consider exclusion areas (e.g., conflicting use areas).
} 


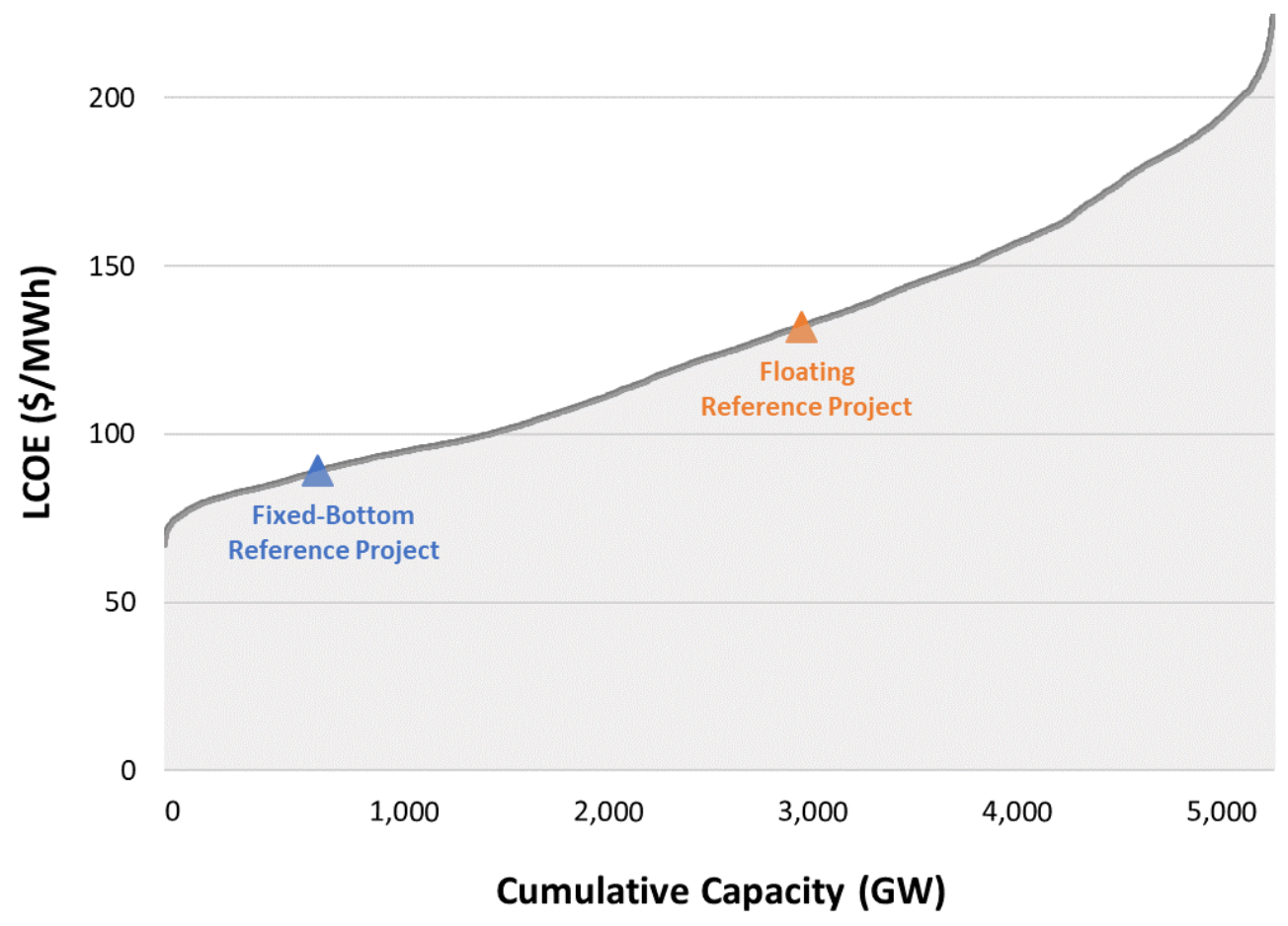

Figure 16. National fixed-bottom and floating offshore wind supply curve

\subsection{Offshore Discussion of Results in Context of DOE Goals}

In this section, we present the official fixed-bottom offshore wind GPRA levelized cost of energy 2030 target, which has been rebaselined in this report. The 2030 target analysis estimates the future CapEx and O\&M costs using ORCA (Beiter et al. 2016) and assuming a wind power plant comprising 15-MW turbines placed in the North Atlantic reference site. The cost reduction trajectory is also informed by technology innovations considered in the spatial economic analysis by Beiter et al. (2016). This assessment estimates the wind plant's CapEx to be $\$ 3,476 / \mathrm{kW}$, with an O\&M cost of $\$ 60 / \mathrm{kW} / \mathrm{yr}$ operating at a $58 \%$ net capacity factor. The future financial assumptions are informed by NREL's 2019 ATB, with an operation life of 25 years for a 5.7\% real FCR. The $2030 \mathrm{LCOE}$ calculated from this analysis is $\$ 51 / \mathrm{MWh}$ and is designated as the 2030 GPRA target. The GRPA targets for 2019 through 2030 are shown in Figure 17. The reported LCOE value for 2019 is calculated in this report (Section 5.6) and labeled as "Historically Reported Data" in Figure 17. 


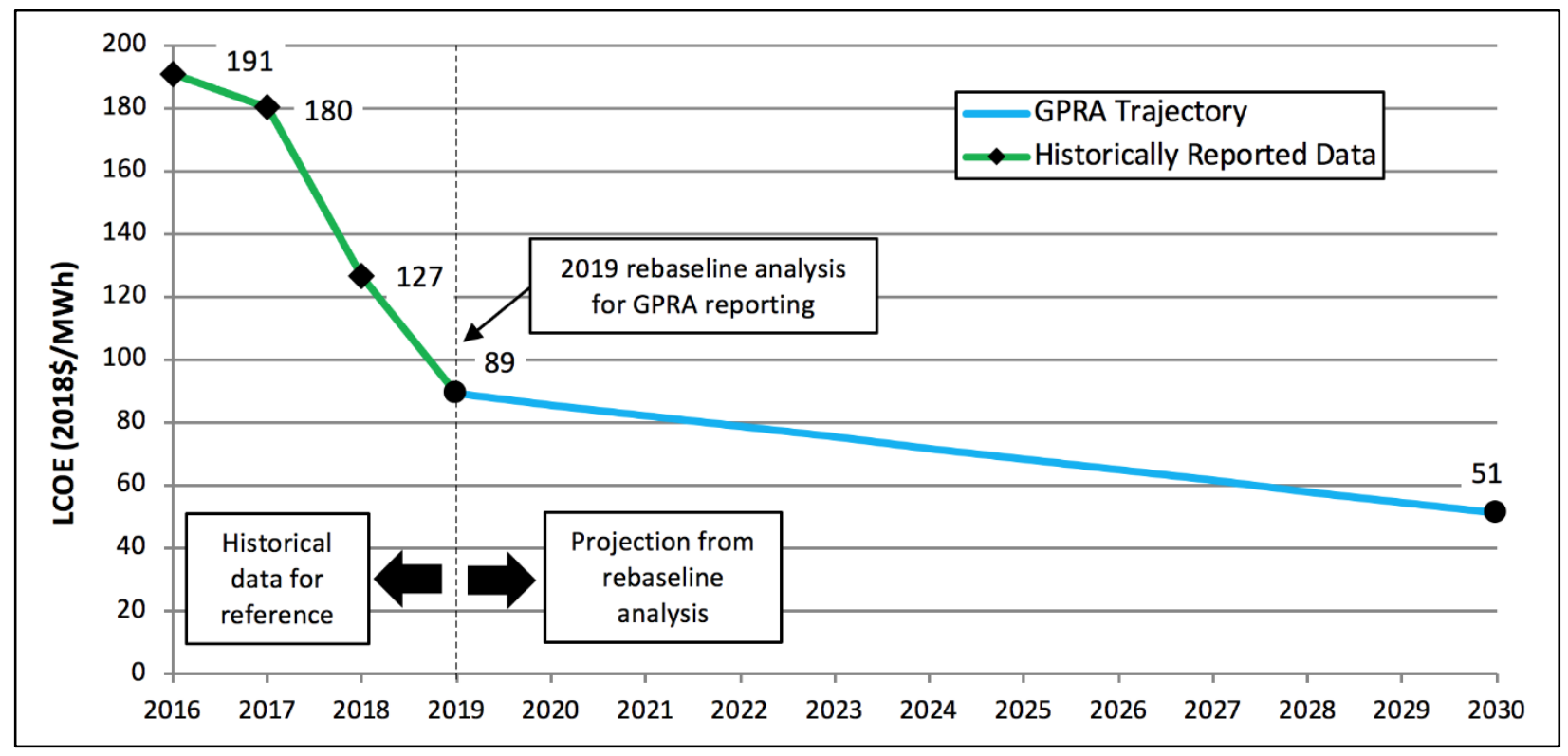

Figure 17. Fixed-bottom wind GPRA cost trajectories for LCOE

The reduction in the estimated LCOE ("GPRA goal") between 2019 and 2030 is categorized into various cost components: O\&M expenditures $(\$ 17 / \mathrm{MWh})$, CapEx components (i.e., turbine, electric system, and support structure; $\$ 12 / \mathrm{MWh})$, and improvements in AEP (\$9/MWh). These categories and their respective cost reductions are shown in Figure 18.

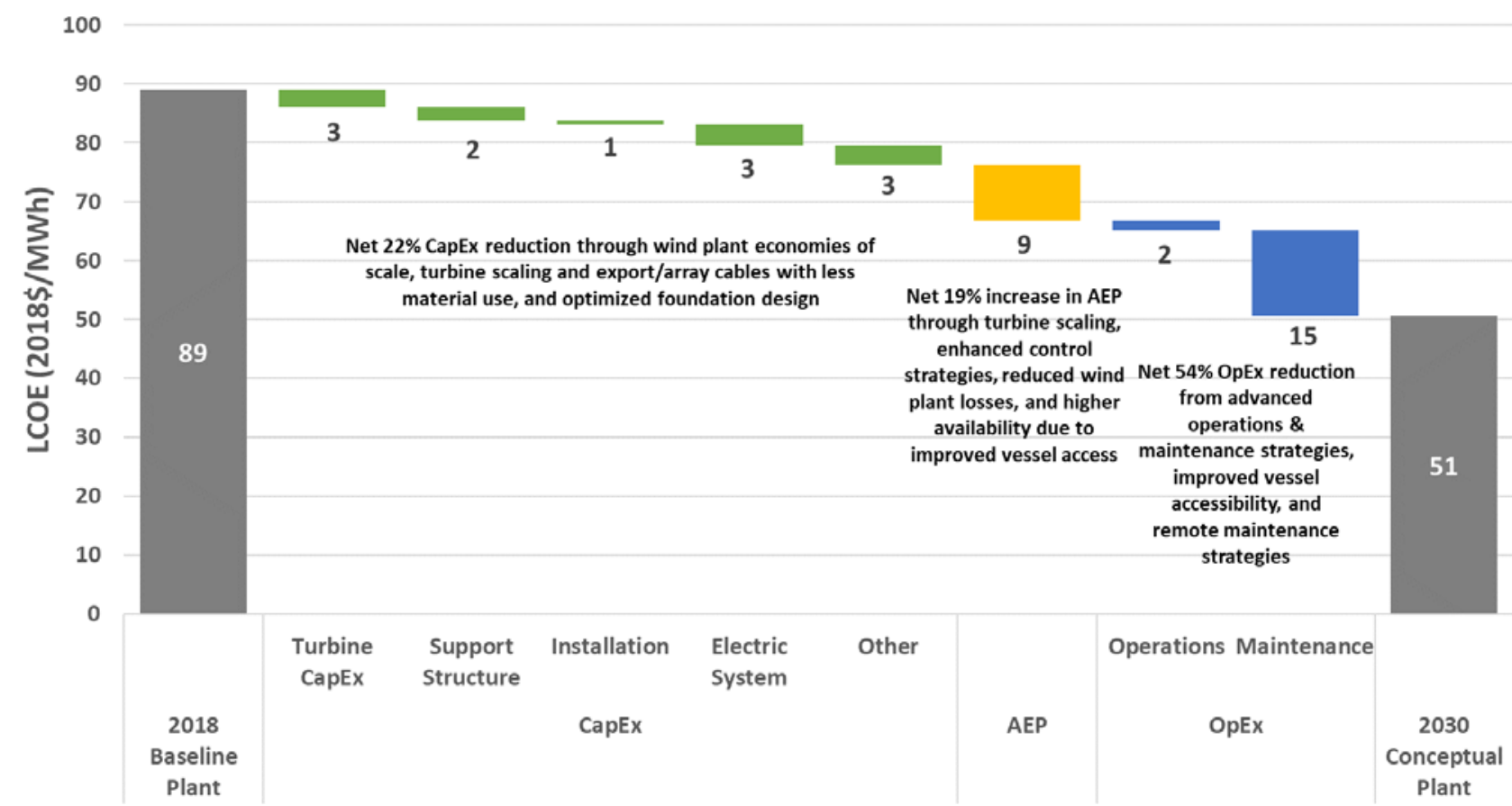

Figure 18. Fixed-bottom cost reductions in GPRA cost trajectories for LCOE 


\section{Conclusions and Future Work}

This analysis presents a picture of the levelized cost of land-based and offshore wind energy using empirically-derived and modeled data representative of 2018 market conditions. Scenario planning and modeling activities often focus on one number (or cost) for land-based LCOE and one for offshore LCOE. In reality, the cost of land-based wind energy varies greatly across the United States and offshore wind LCOE varies significantly across Europe and Asia (Table 23).

Notably, the LCOE analysis presented in this report is only one way to measure the cost of wind energy. It does not include other costs and price issues that influence a given wind project's viability, such as transmission, environmental impacts, military constraints, or other areas of consideration (e.g., public policy, consumer costs, energy prices, or public acceptance). In addition, these LCOE estimates do not reflect the value of electricity, incentives, or other policy mechanisms (such as production tax credits or investment tax credits) that affect the sales price of electricity produced from wind projects.

Table 23. Range of LCOE for U.S. Land-Based and Offshore Wind in 2018

\begin{tabular}{|c|c|c|c|c|}
\hline & \multicolumn{2}{|c|}{ Land-Based Wind Projects } & \multicolumn{2}{|c|}{ Offshore Wind Projects } \\
\hline & Low & High & Low & High \\
\hline CapEx (\$/kW) & 1,000 & 5,000 & 2,470 & 6,500 \\
\hline OpEx (\$/kW/yr) & 33 & 59 & 65 & 194 \\
\hline Net capacity factor (\%) & $20 \%$ & $52 \%$ & $35 \%$ & $50 \%$ \\
\hline Discount rate (nominal) [\%] & $6.4 \%$ & $8.1 \%$ & $3.8 \%$ & $6.3 \%$ \\
\hline Operational life (years) & 15 & 35 & 15 & 35 \\
\hline LCOE (\$/MWh) & 33 & 115 & 83 & 176 \\
\hline
\end{tabular}

The analysis and findings in this report helped generate the following conclusions:

- LCOE estimates continue to show a downward trend from the 2010 Cost of Wind Energy Review (Tegen et al. 2012) to 2017. Land-based and offshore technologies have shown similar cost reduction trends.

- The reference project LCOE for land-based installations are observed to be $\$ 42 / \mathrm{MWh}$; the full range of single-variable, land-based sensitivity estimates covers $\$ 33-\$ 115 / \mathrm{MWh}$.

- The reference offshore LCOE project estimates are \$89/MWh for fixed-bottom substructures and \$132/MWh for floating substructures, with a single-variable sensitivity range of $\$ 83-\$ 176 / \mathrm{MWh}$. This range is mostly influenced by the large variation in CapEx $(\$ 2,470-\$ 6,500 / \mathrm{kW})$ reported by project developers and is in part a function of differences in water depth and distance to shore. Offshore wind cost reductions show a steep reduction through 2018 and are showing alignment more with recent European project bids or "strike prices" and might suggest continued significant reductions in the coming years.

- The sensitivity analysis shows that LCOE can vary widely based on changes in any one of several key factors. The largest effect on LCOE for land-based wind is CapEx 
followed by net capacity factor, then project design life. The largest effect on LCOE for fixed-bottom and floating offshore wind is CapEx followed by project design life, then net capacity factor.

- The range of LCOE calculated for the more than 10,000 GW of theoretical land-based wind capacity ranges from $\$ 31 / \mathrm{MWh}$ to beyond $\$ 200 / \mathrm{MWh}$, with an estimated LCOE range of $\$ 37-\$ 86 / \mathrm{MWh}$ for the projects installed in 2018. For fixed-bottom and floating offshore wind technology, an LCOE range between $\$ 67 / \mathrm{MWh}$ and $\$ 233 / \mathrm{MWh}$ is estimated for approximately $5,430 \mathrm{GW}$ of theoretical capacity for all major U.S. coastal regions (excluding Alaska and Hawaii). The fixed-bottom representative offshore site is on the lower end of this range at $\$ 89 / \mathrm{MWh}$, whereas the floating representative site is near the middle of the range at $\$ 132 / \mathrm{MWh}$.

- The 2019 GPRA target for land-based wind is $\$ 49 / \mathrm{MWh}$ compared to the actual LCOE estimate of \$40/MWh in 2015 USD. ${ }^{19}$ For fixed-bottom offshore wind, the GPRA target for 2019 is $\$ 161 /$ MWh compared to the actual LCOE estimate of $\$ 89 / \mathrm{MWh}$ in 2018 USD.

NREL continues to work to gain a better understanding of costs associated with many components of wind turbines and their related systems. Ongoing collaboration with industry, growing data sets, and enhanced modeling capabilities are expected to continue to lead to better insights and increased awareness of current and future wind power system and component costs.

Future updates to this report are anticipated to help maintain a perspective on costs that is grounded in real-time market changes and to offer greater insight into the costs and performance of individual components related to the wind electric generation system. In addition, these reports are intended to provide greater clarity regarding wind energy costs and the effects of changes in specific variables on LCOE. The data and tools developed from this work will be used to help inform projections, goals, and improvement opportunities. As the industry evolves and matures, these data provide current representative project costs and LCOE estimates for scenario planning, modeling, and goal setting.

Future work entails three primary objectives: (1) continuing to enhance data representing marketbased costs, performance, and technology trends to reflect actual wind industry experience, (2) enhancing the fidelity of bottom-up cost and performance estimation for individual wind plant components, and (3) understanding sensitivities to factors, such as regional differences, site characteristics, and technology choices. In 2020 and beyond, NREL will continue to work with industry and national laboratory partners to obtain project-specific data to validate and improve models.

\footnotetext{
${ }^{19}$ The 2019 GPRA target and actual levelized cost of energy values for land-based wind are reported in 2015 USD because WETO will report land-based wind values in 2015 USD.
} 


\section{References}

Amendment to Rules Committee Print 116-44. Sec. 127. Credit for Electricity Produced from Certain Renewable Resources. December 2019. https://amendmentsrules.house.gov/amendments/HWC 103 xml1217190022572257.pdf.

Beiter, P., W. Musial, A. Smith, L. Kilcher, R. Damiani, M. Maness, S. Sirnivas, T. Stehly, V. Gevorgian, M. Mooney, G. Scott. 2016. A Spatial-Economic Cost Reduction Pathway Analysis for U.S. Offshore Wind Energy Development from 2015-2030 (Technical Report), NREL/TP6A20-66579. National Renewable Energy Laboratory (NREL), Golden, CO (US). https://www.nrel.gov/docs/fy16osti/66579.pdf.

Beiter, P., W. Musial, L. Kilcher, M. Maness, A. Smith. 2017. An Assessment of the Economic Potential of Offshore Wind in the United States from 2015 to 2030 (Technical Report), NREL/TP-6A20-67675. National Renewable Energy Laboratory (NREL), Golden, CO (US). https://www.nrel.gov/docs/fy17osti/67675.pdf.

Beiter, P., P. Spitsen, W. Musial, E. Lantz. 2019. The Vineyard Wind Power Purchase Agreement: Insights for Estimating Costs of U.S. Offshore Wind Projects (Technical Report), NREL/TP-5000-72981. National Renewable Energy Laboratory (NREL), Golden, CO (US). https://www.nrel.gov/docs/fy19osti/72981.pdf.

Bolinger, M. 2014. An Analysis of the Costs, Benefits, and Implications of Different Approaches to Capturing the Value of Renewable Energy Tax Incentives. Lawrence Berkeley National Laboratory. https://emp.lbl.gov/sites/default/files/lbnl-6610e.pdf.

Bureau of Labor and Statistics. Undated. “CPI Inflation Calculator.” Accessed September 2017. https://www.bls.gov/data/\#calculators.

Bureau of Ocean Energy Management. 2019. "Lease and Grant Information." https://www.boem.gov/Lease-and-Grant-Information/.

DONG Energy (Orsted). 2017. "DONG Energy awarded three German offshore wind projects." Accessed December 2017. http://www.dongenergy.com/en/media/newsroom/companyannouncements-details?omxid=1557851.

Dykes, K., M. Hand, T. Stehly, P. Veers, M. Robinson, E. Lantz. 2017. Enabling the SMART Wind Power Plant of the Future Through Science-Based Innovation (Technical Report). NREL/TP-5000-68123. National Renewable Energy Laboratory (NREL). Golden, CO (US). https://www.nrel.gov/docs/fy17osti/68123.pdf.

GE Renewable Energy. 2018. "GE announces Haliade-X, the world's most powerful offshore wind turbine.” Accessed June 2018. https://www.genewsroom.com/press-releases/ge-announceshaliade-X-worlds-most-powerful-offshore-wind-turbine-284260. 
Gilman, P., B. Maurer, L. Feinberg, A. Duerr, L. Peterson, W. Musial, P. Beiter, J. Golladay, J. Stromberg, I. Johnson, D. Boren, A. Moore. 2016. National Offshore Wind Strategy: Facilitating the Development of the Offshore Wind Industry in the United States. DOE/GO-102016-4866. U.S. Department of Energy, Washington, D.C. (US).

http://energy.gov/sites/prod/files/2016/09/f33/National-Offshore-Wind-Strategy-report09082016.pdf.

Hundleby, G., K. Freeman, A. Logan, and C. Frost. 2017. Floating Offshore: 55 Technology Innovations That Will Have Greater Impact on Reducing the Cost of Electricity from European Floating Offshore Wind Farms. KiC InnoEnergy and BVG Associates.

http://www.innoenergy.com/new-floating-offshore-wind-report-55-technology-innovations-thatwill-impact-the-lcoe-in-floating-offshore-wind-farms/.

Johnson, Nick, Pietro Bortolotti, Katherine Dykes, Garrett Barter, Patrick Moriarty, Scott Carron, Fabian Wendt, Paul Veers, Josh Paquette, Chris Kelly, and Brandon Ennis. 2019. Investigation of Innovative Rotor Concepts for the Big Adaptive Rotor Project. Golden, CO: National Renewable Energy Laboratory. NREL/TP-5000-73605. https://www.nrel.gov/docs/fy19osti/73605.pdf.

Lantz, E., R. Roberts, J. Nunemaker, E. DeMeo, K. Dykes, and G. Scott. 2019. Increasing Wind Turbine Tower Heights: Opportunities and Challenges (Technical Report). NREL/TP-500073629. National Renewable Energy Laboratory (NREL), Golden, CO (US). https://www.nrel.gov/docs/fy19osti/73629.pdf.

Mai, T., W. Cole, V. Krishnan, M. Bolinger. 2015. "Impact of Federal Tax Policy on UtilityScale Solar Deployment Given Financing Interactions.” NREL/PR-6A20-65014. National Renewable Energy Laboratory (NREL), Golden, CO (US). http://www.nrel.gov/docs/fy16osti/65014.pdf.

Maness, M., B. Maples, and A. Smith. 2016. NREL Offshore Balance-of-System Model (Technical Report). TP-6A20-66874. National Renewable Energy Laboratory (NREL), Golden, CO (US). http://www.nrel.gov/docs/fy17osti/66874.pdf.

Maples, B., G. Saur, M. Hand, R. van de Pietermen, T. Obdam. 2013. Installation, Operation, and Maintenance Strategies to Reduce the Cost of Offshore Wind Energy (Technical Report). NREL/TP-5000-57403. National Renewable Energy Laboratory (NREL), Golden, CO (US). http://www.nrel.gov/docs/fy13osti/57403.pdf.

Moné, C., A. Smith, B. Maples, and M. Hand. 2015a. 2013 Cost of Wind Energy Review (Technical Report). NREL/TP-5000-63267. National Renewable Energy Laboratory (NREL), Golden, CO (US). http://www.nrel.gov/docs/fy15osti/63267.pdf.

Moné, C., T. Stehly, B. Maples, and E. Settle. 2015b. 2014 Cost of Wind Energy Review (Technical Report). NREL/TP-6A20-64281. National Renewable Energy Laboratory (NREL), Golden, CO (US). http://www.nrel.gov/docs/fy16osti/64281.pdf. 
Moné, C., M. Hand, M. Bolinger, J. Rand, D. Heimiller, J. Ho. 2017. 2015 Cost of Wind Energy Review (Technical Report). NREL/TP-6A20-66861. National Renewable Energy Laboratory (NREL), Golden, CO (US). https://www.nrel.gov/docs/fy17osti/66861.pdf.

Musial, W., P. Beiter, D. Heimiller, and G. Scott. 2016. 2016 Offshore Wind Energy Resource Assessment for the United States (Technical Report). NREL/TP-5000-66599. National Renewable Energy Laboratory (NREL), Golden, CO (US). http://www.nrel.gov/docs/fy16osti/66599.pdf.

Musial, W., P. Beiter, P. Schwabe, T. Tian, T. Stehly, P. Spitsen. 2017. 2016 Offshore Wind Technologies Market Report. DOE/GO-102017-5031. U.S. Department of Energy, Washington, D.C. (US).

https://energy.gov/sites/prod/files/2017/08/f35/2016\%20Offshore $\% 20$ Wind $\% 20$ Technologies $\% 2$ 0Market $\% 20$ Report.pdf.

Musial, W., P. Beiter, P. Spitsen, J. Nunemaker, V. Gevorgian. 2019. 2018 Offshore Wind Technologies Market Report. DOE/GO-102019-5192. U.S. Department of Energy, Washington, D.C. (US). https://www.energy.gov/eere/wind/downloads/2018-offshore-wind-market-report

National Renewable Energy Laboratory (NREL). (Internal, n.d.). Offshore Wind Database.

NREL. (Internal, n.d.). Land-Based-Wind Balance of System Model.

NREL. (n.d.). “Annual Technology Baseline and Standard Scenarios.”. Accessed August 2019. https://atb.nrel.gov/.

NREL. (n.d.) "Renewable Resource Data Center.”. Accessed August 2017. http://rredc.nrel.gov/wind/pubs/atlas/tables/1-1T.html.

NREL. (n.d.). “System Advisor Model (SAM).” Accessed June 2019. https://sam.nrel.gov/.

NREL. (n.d.). "Wind Integration National Dataset Toolkit.”. Accessed December 2019. https://www.nrel.gov/grid/wind-toolkit.html.

Pietermen, R., H. Braam, T. Obdam, L. Rademakers, T. van der Zee. 2011. Optimisation of maintenance strategies for offshore wind farms. Energy research Centre of the Netherlands. https://publicaties.ecn.nl/PdfFetch.aspx?nr=ECN-M--11-103.

Short, W., D. J. Packey, and T. Holt. 1995. A Manual for the Economic Evaluation of Energy Efficiency and Renewable Energy Technologies (Technical Report). NREL/TP-462-5176.

National Renewable Energy Laboratory (NREL), Golden, CO (US).

http://www.nrel.gov/docs/legosti/old/5173.pdf.

Shreve, D. (2018). United States Wind Energy Market Outlook. Wood Mackenzie.

Spyroudi, A. 2016. Cost Modelling Analysis of Floating Wind Technologies: Assessing the Potential of TLPWIND. Offshore Renewable Energy Catapult.

https://ore.catapult.org.uk/app/uploads/2017/12/SP00006-Cost-Modelling-Analysis-of-FloatingWind-Technologies.pdf. 
Stehly, T., D. Heimiller, G. Scott. 2017. 2016 Cost of Wind Energy Review (Technical Report). NREL/TP-6A20-70363. National Renewable Energy Laboratory (NREL), Golden, CO (US). https://www.nrel.gov/docs/fy18osti/70363.pdf.

Stehly, T., P. Beiter, D. Heimiller, G. Scott. 2018. 2017 Cost of Wind Energy Review (Technical Report). NREL/TP-6A20-72167. National Renewable Energy Laboratory (NREL), Golden, CO (US). https://www.nrel.gov/docs/fy18osti/72167.pdf.

Tax Cuts and Jobs Act, H.R. 1., $115^{\text {th }}$ Cong. (December 22, 2017), H.R. 1 - An Act to provide for reconciliation pursuant to titles II and $V$ of the concurrent resolution on the budget for fiscal year 2018. https://www.congress.gov/bill/115th-congress/house-bill/1.

Tegen, S., M. Hand, B. Maples, E. Lantz, S. Schwabe, A. Smith. 2012. 2010 Cost of Wind Energy Review (Technical Report). NREL/TP-5000-52920. National Renewable Energy Laboratory (NREL), Golden, CO (US). http://www.nrel.gov/docs/fy12osti/52920.pdf.

Tegen, S, E. Lantz, M. Hand, B. Maples, A. Smith, P. Schwabe. 2013. 2011 Cost of Wind Energy Review (Technical Report). NREL/TP-5000-56266. National Renewable Energy Laboratory (NREL), Golden, CO (US). http://www.nrel.gov/docs/fy13osti/56266.pdf.

U.S. Department of Energy (DOE). 2015. Wind Vision: A New Era for Wind Power in the United States. DOE/GO-102015-4557. DOE Office of Energy Efficiency and Renewable Energy. Washington, D.C. (US). http://www.energy.gov/sites/prod/files/WindVision_Report final.pdf.

Valpy, B. G. Hundleby, K. Freeman, A. Roberts, A. Logan. 2017. Future renewable energy costs: Offshore wind; 57 technology innovations that will have greater impact on reducing the cost of electricity from European offshore wind farms. InnoEnergy and BVG Associates. https://bvgassociates.com/wp-content/uploads/2017/11/InnoEnergy-Offshore-Wind-anticipatedinnovations-impact-2017 A4.pdf.

Wiser, R. and M. Bolinger. 2016. 2015 Wind Technologies Market Report. U.S. Department of Energy, Office of Energy Efficiency and Renewable Energy. Washington, D.C. (US). http://energy.gov/sites/prod/files/2016/08/f33/2015-Wind-Technologies-Market-Report08162016.pdf.

Wiser, R. and M. Bolinger. 2019. 2018 Wind Technologies Market Report. U.S. Department of Energy, Office of Energy Efficiency and Renewable Energy. Washington, D.C. (US). https://www.energy.gov/eere/wind/downloads/2018-wind-technologies-market-report.

Wiser, R., M. Bolinger, and E. Lantz. 2019. "Assessing wind power operating costs in the United States: Results from a survey of wind industry experts.” Renewable Energy Focus 30: 46-57. https://www.sciencedirect.com/science/article/pii/S1755008419300092. 


\section{Appendix A. Land-Based Wind 30-Year Financial Life Sensitivity}

The financial life is the period in which a project achieves the requisite cash flow it needs to recover its initial capital expenditures (CapEx) and meet investors' internal rate of return threshold. In basic levelized cost of energy (LCOE) analysis, this is the period in which capital is recovered at a specified rate of return, with a composite implied internal rate of return threshold based on the project's weighted-average cost of capital. In this report, the 25-year financial life assumption for the LCOE calculation was derived from the period associated with engineering certification processes and procedures. This appendix includes a calculation of the sensitivity of a longer land-based wind power plant financial life of 30 years and reports its impact on the cost of energy. We consider this extended financial life based on data from direct engagements with wind power plant owners. For this sensitivity analysis, we change the plant's financial life from 25 to 30 years. All other wind power plant assumptions (i.e., CapEx, operational expenditures, and net annual energy production remain the same as the analysis provided in the main body of this report. ${ }^{20} \mathrm{~A}$ summary of the financial parameters impacted by increasing the plant life to 30 years (i.e., capital recovery factor, fixed charge rate, and LCOE) are shown in Table A1.

Table A1. Summary of Land-Based Capital Recovery Factor, Fixed Charge Rate, and Levelized Cost of Energy for a 30-Year Useful Life

\begin{tabular}{|lcc|}
\hline & Nominal & Real \\
\hline Capital recovery factor (\%) & $8.5 \%$ & $6.5 \%$ \\
\hline Fixed charge rate (\%) & $9.1 \%$ & $6.9 \%$ \\
\hline $\begin{array}{l}\text { TOTAL LCOE (\$/megawatt- } \\
\text { hour [MWh]) }\end{array}$ & $\mathbf{4 0}$ \\
\hline
\end{tabular}

Based on this sensitivity analysis, extending the plant's financial life and assumed period in which the threshold internal rate of return is achieved from 25 to 30 years results in a reduction of LCOE of approximately $4.8 \%$ - a decrease from $\$ 42 / \mathrm{MWh}$ to $\$ 40 / \mathrm{MWh}$.

\footnotetext{
20 This sensitivity analysis only considers the extension of the financial life of the wind plant from 25 to 30 years, whereas extension of plant life will have impacts on a project's CapEx and OpEx.
} 


\section{Appendix B. Offshore Wind 30-Year Financial Life Sensitivity}

The authors performed the same financial life sensitivity analysis conducted for land-based wind in Appendix A for fixed-bottom and floating offshore wind. The analysis in this report considers a 25-year financial life derived from the period associated with engineering certification processes and procedures. This appendix includes a calculation of the sensitivity of a longer offshore wind power plant financial life of 30 years for fixed-bottom and floating wind facilities and reports its impact on the cost of energy. We consider this extended financial life based on data from direct engagements with wind power plant owners and analysis of the European offshore wind power plant lifetime. For this sensitivity analysis, we change the plant's financial life from 25 to 30 years. All other wind power plant assumptions (i.e., capital expenditures, operational expenditures, and net annual energy production) remain the same as the analysis provided in the main body of this report. ${ }^{21}$ A summary of the financial parameters impacted by increasing the plant life to 30 years (i.e., capital recovery factor, fixed charge rate, and levelized cost of energy [LCOE]) are shown in Table B1.

Table B1. Summary of Offshore Capital Recovery Factor, Fixed Charge Rate, and Levelized Cost of Energy for a 30-Year Useful Life

\begin{tabular}{|lcc|cc|} 
& \multicolumn{2}{c}{$\begin{array}{c}\text { North Atlantic } \\
\text { (Fixed Bottom) }\end{array}$} & \multicolumn{2}{c|}{$\begin{array}{c}\text { Pacific Coast } \\
\text { (Floating) }\end{array}$} \\
& Nominal & Real & Nominal & Real \\
\hline Capital recovery factor (\%) & $6.5 \%$ & $4.7 \%$ & $6.5 \%$ & $4.7 \%$ \\
\hline Fixed charge rate (\%) & $6.8 \%$ & $4.9 \%$ & $6.8 \%$ & $4.9 \%$ \\
\hline $\begin{array}{l}\text { TOTAL LCOE } \\
\text { (\$/megawatt-hour [MWh]) }\end{array}$ & \multicolumn{2}{|c|}{$\mathbf{8 2}$} & \multicolumn{2}{|c|}{$\mathbf{1 2 1}$} \\
\hline
\end{tabular}

Based on this sensitivity analysis, extending the plant's financial life and assumed period in which the threshold internal rate of return is achieved from 25 to 30 years results in reduced LCOE for the North Atlantic and Pacific Coast reference projects. Fixed-bottom projects may experience about an $8 \%$ reduction in LCOE from $\$ 89 / \mathrm{MWh}$ to $\$ 82 / \mathrm{MWh}$. Floating offshore projects may experience about a $8.3 \%$ reduction in LCOE, or a decrease from $\$ 132 / \mathrm{MWh}$ to \$121/MWh assuming a 30-year life.

\footnotetext{
${ }^{21}$ This sensitivity analysis only considers the extension of the financial life of the wind plant from 25 to 30 years, whereas extension of plant life will have impacts on a project's capital and operational expenditures.
} 


\section{Appendix C. Land-Based Wind 2030 Turbine Technology Assessment}

Since the release of the "Wind Vision" report (U.S. Department of Energy 2015) and "Enabling the SMART Wind Power Plant of the Future Through Science-Based Innovation" (Dykes et al. 2017), the wind industry's original equipment manufacturer and stakeholder community have frequently commented on the cost reductions presented in past releases of National Renewable Energy Laboratory's (NREL's) ATB (Annual Technology Baseline and Standard Scenarios web page: atb.nrel.gov) as being too conservative. Industry experts now anticipate wind energy LCOE of 2-2.5 cent/kilowatt-hour by the mid-2020s. Given this expert input, NREL has executed a bottom-up engineering analysis to estimate the future cost of wind energy.

The first step to the bottom-up analysis was to define a representative future turbine technology in 2030. The primary turbine technology characteristics considered include the turbine's nameplate rating, rotor diameter, and hub height. To define these 2030 characteristics, analysts used a combination of projected historical data (Wiser and Bolinger 2019) and future technology predictions from published literature (Shreve 2018). The outcome of this exercise projected the future turbine's rated power to be 4.5 megawatts (MW), with a rotor diameter of 167 meters (m) and a hub height of $110 \mathrm{~m}$. These characteristics are considered to be the median-innovation scenario and are summarized in Table $\mathrm{C} 1$.

As part of the analysis, a range of future turbine technology was considered and used to inform the 2019 ATB (Annual Technology Baseline and Standard Scenarios web page: atb.nrel.gov). Analysts determined a range of future wind turbine technologies for two additional turbine technology pathways in 2030: a high-innovation scenario, in which breakthrough science-based innovations increase net energy production and turbine scaling enable system cost reductions, and a low-innovation scenario, which included little change from the turbine technology of today. The high-innovation scenario introduces a higher-capacity 6-MW turbine with a 234-m rotor diameter on a $160-\mathrm{m}$ tower. The low-innovation scenario relies on a turbine that is commercially available today (i.e., a 4-MW rating with a 156-m rotor diameter on a $110-\mathrm{m}$ tower. The high- and low-innovation turbine characteristics are also presented in Table $\mathrm{C} 1$.

Table C1. Summary of Projected Technology Characteristics for the 2030 Representative Turbines

\begin{tabular}{|r|c|c|c|}
\hline \multirow{2}{*}{ Parameter } & $\begin{array}{c}\text { High Innovation } \\
\text { 10\%-35\% Probability }\end{array}$ & $\begin{array}{c}\text { Median Innovation } \\
\text { 35\%-65\% Probability }\end{array}$ & $\begin{array}{c}\text { Low Innovation } \\
\mathbf{6 5} \text {-90 Probability }\end{array}$ \\
\hline Turbine rating (MW) & 6 & 4.5 & 4 \\
\hline Hub height $(\mathrm{m})$ & 160 & 110 & 110 \\
\hline Rotor diameter $(\mathrm{m})$ & 234 & 167 & 156 \\
\hline Specific power (watts $\left./ \mathrm{m}^{2}\right)$ & 140 & 205 & 209 \\
\hline
\end{tabular}

Now with the 2030 technologies defined, analysts are able to perform the bottom-up cost modeling and wind plant performance analysis to estimate LCOE. The capital expenditure (CapEx) cost estimates were performed using NREL's 2015 Cost and Scaling Model and LandBased-Wind Balance of System (BOS) model. Where applicable, analysts applied cost adjustments to the modeled cost results to account for factors such as additional transportation 
costs for longer blades or additional tower material. This cost adjustment technique was applied to the three scenarios (i.e., low, median, and high innovation) based on the turbine-specific characteristics for each scenario. The cost adjustments were informed by current work on the Big Adaptive Rotors project (Johnson et al. 2019) and taller towers analysis (Lantz et al. 2019).

In all cases, the turbine's CapEx contributes the most to the total CapEx. The roughly 34\% difference in CapEx between the high- and low-innovation scenarios is an artifact of assuming innovations that enable the manufacturing, transportation, and installation of larger turbines (i.e., $6 \mathrm{MW}$ in the high-innovation scenario and $4 \mathrm{MW}$ in the low-innovation scenario). The cost estimates for BOS assumes a fixed wind power plant size of $200 \mathrm{MW}$ for all scenarios. A reduced number of turbines in the wind plant for the larger turbine ratings brings down the BOS costs; however, this is partially offset by the additional transportation and installation cost of the larger turbines. This is apparent in the high- and median-innovation scenarios, wherein the BOS costs for the median scenario is about $4.4 \%$ lower than the high-scenario case. The soft costs in the analysis were assumed to be $3 \%$ of the total turbine and BOS costs for all cases to account for construction finance and contingency. The summary of modeled CapEx estimates for the 2030 representative wind plants are shown in Table C2 and are used to inform the scenarios in the 2019 ATB (Annual Technology Baseline and Standard Scenarios web page: atb.nrel.gov).

Table C2. Summary of Modeled Capital Costs for the 2030 Representative Wind Plants

\begin{tabular}{|c|c|c|c|}
\hline Cost Category & $\begin{array}{c}\text { High Innovation } \\
\text { 10\%-35\% Probability }\end{array}$ & $\begin{array}{l}\text { Median Innovation } \\
35 \%-65 \% \text { Probability }\end{array}$ & $\begin{array}{c}\text { Low Innovation } \\
65 \%-90 \% \text { Probability }\end{array}$ \\
\hline Turbine $(\$ / \mathrm{kW})$ & 795 & 929 & 1,065 \\
\hline BOS $(\$ / k W)$ & 272 & 260 & 289 \\
\hline Soft Cost $(\$ / k W)$ & 33 & 36 & 40 \\
\hline Total $(\$ / \mathrm{kW})$ & 1,100 & 1,225 & 1,394 \\
\hline
\end{tabular}

Historical cost data are sometimes used to estimate learning rates, which trace the relationship between the cost of wind, for example, and cumulative installed wind capacity. These historical learning rates are then commonly extrapolated to forecast possible future costs. Since operation and maintenance (O\&M) market data are not widely available this methodology, which is presented in Wiser et al. (2019), was used to inform the O\&M estimates in 2030. The future average OpEx for the median-innovation scenario is estimated to be $\$ 39.0 / \mathrm{kW} / \mathrm{yr}$ with a range of $\$ 43.6 / \mathrm{kW} / \mathrm{yr}$ for the low-innovation scenario and $\$ 34.3 / \mathrm{kW} / \mathrm{yr}$ for the high-innovations scenario. A summary of the 2030 land-based wind OpEx estimates for each of the scenarios is presented in Table C3.

Table C3. Summary of Assumed Operation and Maintenance Costs for the 2030 Representative Wind Plants

\begin{tabular}{|c|c|c|c|}
\hline Cost Category & $\begin{array}{l}\text { High Innovation } \\
\text { 10\%-35\% Probability }\end{array}$ & $\begin{array}{l}\text { Median Innovation } \\
35 \%-65 \% \text { Probability }\end{array}$ & $\begin{array}{l}\text { Low Innovation } \\
65 \%-90 \% \text { Probability }\end{array}$ \\
\hline OpEx (\$/kW/year) & 34.3 & 39.0 & 43.6 \\
\hline
\end{tabular}


The 2030 wind plant performance values were calculated using NREL's SAM (NREL's System Advisor Model web page: https://sam.nrel.gov/). The model estimated the representative wind plant's capacity factors assuming an idealized power curve generated from the turbine characteristics (i.e., turbine rating and rotor diameter) defined for the low, median, and high scenarios. Additional reductions in wind plant losses (e.g., reduced wake losses) from Dykes et al. (2017) were also applied. The resulting net capacity factors, presented in Table C4, are calculated using the representative site details shown in Table 6 in Section 4.3.2. The values presented in Table $\mathrm{C} 4$ are selected from a large sample of calculated net capacity factor scenarios. The full analysis for the 2030 representative plants includes many variations of wind plant losses that were applied to inform the net capacity factors and used in the 2019 ATB (Annual Technology Baseline and Standard Scenarios web page: atb.nrel.gov).

Table C4. Summary of Calculated Net Capacity Factors for the 2030 Representative Wind Plants

\begin{tabular}{|c|c|c|c|}
\hline Parameter & $\begin{array}{c}\text { High Innovation } \\
10 \%-35 \% \text { Probability }\end{array}$ & $\begin{array}{c}\text { Median Innovation } \\
35 \%-65 \% \text { Probability }\end{array}$ & $\begin{array}{c}\text { Low Innovation } \\
65 \%-90 \% \text { Probability }\end{array}$ \\
\hline Net capacity factor (\%) & 58.8 (assuming $7.5 \%$ losses) & 48 (assuming $10 \%$ losses) & 45 (assuming $15 \%$ losses) \\
\hline
\end{tabular}

Finally, the LCOE calculation requires financial assumptions for the low-, median-, and highinnovation scenarios. These assumptions include financing the projects over 30 years, with a debt share of $70 \%$ and a debt rate of $3.7 \%$. The assumed equity return was $9 \%$. It should be noted that these financial assumptions are used for comparison purposes only and may not align with the more detailed financial analysis conducted in the 2019 ATB (Annual Technology Baseline and Standard Scenarios web page: atb.nrel.gov). Under these generic financial assumptions, the resulting fixed charge rate and calculated LCOE for the low-, median-, and high-innovation scenarios are summarized in Table $\mathrm{C} 5$.

Table C5. Summary of Assumed Fixed Charge Rate and Calculated Levelized Cost of Energy for the 2030 Representative Wind Plants

\begin{tabular}{|r|r|c|c|c|}
\hline Category & Parameter & $\begin{array}{c}\text { High Innovation } \\
10 \%-35 \% \\
\text { Probability }\end{array}$ & $\begin{array}{c}\text { Median Innovation } \\
\text { 35\%-65\% } \\
\text { Probability }\end{array}$ & $\begin{array}{c}\text { Low Innovation } \\
65 \%-90 \% \\
\text { Probability }\end{array}$ \\
\hline Useful life & Capital recovery period (years) & 30 & 30 & 30 \\
\hline Financing & Fixed charge rate (real; after tax) [\%] & 4.69 & 4.69 & 4.69 \\
\hline LCOE & LCOE (real) $[\$ / M W h]$ & 16.7 & 22.7 & 27.6 \\
\hline
\end{tabular}

The land-based wind 2030 technology analysis presented in this appendix outlines one technology pathway to achieve future cost reduction over three innovation cases. Although this analysis presents a single technology pathway to achieve future cost reductions, there is an unlimited number of technology pathways to achieve future cost reductions. 


\section{Appendix D. Offshore Wind Reference Site Development}

In this report, we introduced a new set of reference sites for fixed-bottom and floating offshore wind technology. These reference sites are intended to reflect site conditions represent near- to medium-term U.S. project development and based on a replicable methodology.

We conducted the following steps to identify a reference site for fixed-bottom and floating offshore wind technology, respectively:

1. For each offshore wind region (as specified in Gilman et al. 2016), we identified a 600megawatt (MW) cohesive area within each Bureau of Ocean Energy Management lease and Call Area delineation (Bureau of Ocean Energy Management 2019) that is closest to shore (measured by direct distance), while:

- Only considering lease area(s) if at least one is available within an offshore wind region

- Consider Call Area(s) if there is no designated lease area

- Assuming a turbine spacing of $3 \mathrm{MW} /$ square kilometer (Musial et al. 2016).

2. Define "reference site" parameters by averaging key spatial parameters across the areas defined in step \#1 for each offshore wind region:

- Water depth

○ Wind speed

○ Gross and net capacity factor

- Array efficiency

- Distance from site to cable landfall

- Distance from cable landfall to onshore substation

- Distance from site to construction port

○ Distance from site to operation \& maintenance port

○ Wave height.

3. Designated the "North Atlantic" offshore wind region to be the reference site for fixedbottom and the "Pacific Coast" to be representative for floating offshore wind technology. This determination was made because these regions experience the highest commercial activity for these technology types (Musial et al. 2019).

4. Specify the spatial parameters from step \#2 in the Offshore Wind Cost Model to determine LCOE.

Results for the spatial parameters calculated for each regional reference sites are shown in Table D1. 
Table D1. Spatial Parameters for Regional Reference Sites

\begin{tabular}{|c|c|c|c|c|c|c|c|c|c|c|}
\hline & Depth & $\begin{array}{c}\text { Wind } \\
\text { Speed }\end{array}$ & $\begin{array}{c}\text { GCF (6 } \\
\text { MW) }\end{array}$ & NCF & $\begin{array}{c}\text { Array } \\
\text { Efficiency }\end{array}$ & $\begin{array}{c}\text { Site to } \\
\text { Cable } \\
\text { Landfall }\end{array}$ & $\begin{array}{c}\text { Distance Cable } \\
\text { Landfall to } \\
\text { Substation }\end{array}$ & Site to CP & Site to OP & $\begin{array}{c}\text { Average } \\
\text { HS }\end{array}$ \\
\hline Units & $m$ & $m / s$ & $\%$ & $\%$ & $\%$ & $k m$ & $k m$ & $k m$ & $k m$ & $m$ \\
\hline $\begin{array}{c}\text { North } \\
\text { Atlantic }\end{array}$ & 34 & 9.03 & $58 \%$ & $48 \%$ & $92 \%$ & 50 & 9 & 116 & 114 & 1.2 \\
\hline $\begin{array}{c}\text { South } \\
\text { Atlantic }\end{array}$ & 30 & 8.58 & $53 \%$ & $44 \%$ & $92 \%$ & 51 & 7 & 118 & 118 & 1.2 \\
\hline $\begin{array}{c}\text { Pacific } \\
\text { Coast }\end{array}$ & 739 & 8.22 & $48 \%$ & $38 \%$ & $93 \%$ & 36 & 8 & 189 & 189 & 2.4 \\
\hline Hawaii & 764 & 8.59 & $52 \%$ & $43 \%$ & $94 \%$ & 18 & 10 & 36 & 36 & 1.6 \\
\hline
\end{tabular}

Note: The "North Atlantic" serves as fixed bottom and the "Pacific Coast" serves as the floating offshore wind technology reference site. The "South Atlantic" and "Hawaii" are included for reference only.

\section{Acronyms in Table D1:}

GCF: gross capacity factor

NCF: net capacity factor

$\mathrm{CP}$ : construction port

OP: operations port

HS: significant annual average wave height 


\section{Appendix E. Offshore Wind Cost Model Updates}

The National Renewable Energy Laboratory's Offshore Wind Cost Model, also referred to as the Offshore Regional Cost Analyzer (ORCA), is subject to continuous data updates and validation, which help ensure the model reflects the latest industry and market developments. The following key revisions to the model were implemented since the release of last year's annual cost report:

- Several cost elements, including finance terms like total capital expenditures (CapEx) and operational expenditures, turbine CapEx, and lease area price were validated through a detailed analysis of the power purchase agreement between Vineyard Wind LLC and Massachusetts electric distribution companies (Beiter et al. 2019). The agreement price for the first commercial-scale U.S. offshore wind project suggests that the cost premium for the "new" U.S. market is less pronounced than anticipated by many analysts.

- Turbine CapEx was reduced from previous estimates of about $\$ 1,600 /$ kilowatt to \$1,300/kilowatt in 2018 (informed by Efstathiou [2018] and Hundleby et al. [2017])

- Export system cable costs in 2019 were reduced by $25 \%$ compared to Beiter et al. (2016) to account for recent cost reductions resulting from low-cost material use (i.e., higher aluminum content), lower commodity prices, and cost reductions resulting from an antitrust case against an international cable cartel (Chee 2018).

- A lease price of $\$ 50$ million, which roughly corresponds to the price paid by Equinor for its New York lease area in 2016 (Musial et al. 2019), was included in the Offshore Wind Cost Model. ${ }^{22}$

- A new cost reduction trajectory from 2018 through 2032 was derived from an expert elicitation conducted by Valpy et al. (2017) and Hundleby et al. (2017).

- Floating substructure and array cable costs were updated through industry consultation.

${ }^{22}$ Note that in its latest auction, the Bureau of Ocean Energy Management awarded three offshore wind lease areas off Massachusetts in December 2018 at a lease sale price record of \$135 million each; more than tripling the previous record of $\$ 42$ million paid for the New York lease area sale in 2016 (Musial et al. 2019). 


\section{Appendix F. Summary of Assumptions for 2018 Reference Projects}

Table F1. Land-Based-Wind Reference Project Levelized Cost of Energy (LCOE) Assumptions

\begin{tabular}{|c|c|c|c|}
\hline Assumption & Units & Value & Notes \\
\hline \multicolumn{4}{|c|}{ Wind Plant Characteristics } \\
\hline Wind plant capacity & megawatt (MW) & 200 & \multirow{2}{*}{ Representative of commercial-scale projects } \\
\hline Number of turbines & & 83 & \\
\hline Turbine rating & MW & 2.4 & \multirow{3}{*}{$\begin{array}{l}\text { "2018 Wind Technologies Market Report" (Wiser and } \\
\text { Bolinger 2019) }\end{array}$} \\
\hline Rotor diameter & meter $(\mathrm{m})$ & 115.6 & \\
\hline Hub height & $\mathrm{m}$ & 88.1 & \\
\hline Specific power & $\begin{array}{c}\text { watts per square } \\
\text { meter }\left(\mathrm{W} / \mathrm{m}^{2}\right)\end{array}$ & 232 & Calculation \\
\hline Cut-in wind speed & $\begin{array}{l}\text { meters per second } \\
(\mathrm{m} / \mathrm{s})\end{array}$ & 3 & \multirow[t]{2}{*}{ Typical turbine characteristics } \\
\hline Cut-out wind speed & $\mathrm{m} / \mathrm{s}$ & 25 & \\
\hline $\begin{array}{l}\text { Annual average wind speed at } \\
50 \mathrm{~m}\end{array}$ & $\mathrm{~m} / \mathrm{s}$ & 7.25 & Class 4 wind site \\
\hline $\begin{array}{l}\text { Annual average wind speed at } \\
\text { hub height }\end{array}$ & $\mathrm{m} / \mathrm{s}$ & 7.86 & Power law calculation \\
\hline Weibull k factor & & 2.0 & \\
\hline Shear exponent & & 0.143 & Shear for neutral stability conditions \\
\hline Altitude above mean sea level & $\mathrm{m}$ & 450 & Altitude at turbine foundation \\
\hline Losses & $\%$ & $15 \%$ & \multirow{2}{*}{ "Wind Vision" (U.S. Department of Energy 2015) } \\
\hline Availability & $\%$ & $98 \%$ & \\
\hline Net energy capture & $\begin{array}{c}\text { megawatt-hour } \\
(\mathrm{MWh}) / \mathrm{MW} / \text { year } \\
(\mathrm{yr})\end{array}$ & 3,648 & \multirow[t]{2}{*}{ System Advisor Model calculation } \\
\hline Net capacity factor & $\%$ & $41.6 \%$ & \\
\hline \multicolumn{4}{|c|}{ Capital Expenditures (CapEx) } \\
\hline Total CapEx & $\$ /$ kilowatt $(\mathrm{kW})$ & 1,470 & $\begin{array}{l}\text { "2018 Wind Technologies Market Report" (Wiser and } \\
\text { Bolinger 2019) }\end{array}$ \\
\hline Turbine & $\$ / \mathrm{kW}$ & 1,011 & \multirow{11}{*}{2015 Cost and Scaling Model } \\
\hline Rotor module & $\$ / \mathrm{kW}$ & 293 & \\
\hline Blades & $\$ / \mathrm{kW}$ & 188 & \\
\hline Pitch assembly & $\$ / \mathrm{kW}$ & 61 & \\
\hline Hub assembly & $\$ / \mathrm{kW}$ & 45 & \\
\hline Nacelle module & $\$ / \mathrm{kW}$ & 498 & \\
\hline $\begin{array}{l}\text { Nacelle structural } \\
\text { assembly }\end{array}$ & $\$ / \mathrm{kW}$ & 100 & \\
\hline Drivetrain assembly & $\$ / \mathrm{kW}$ & 195 & \\
\hline $\begin{array}{l}\text { Nacelle electrical } \\
\text { assembly }\end{array}$ & $\$ / \mathrm{kW}$ & 170 & \\
\hline Yaw assembly & $\$ / \mathrm{kW}$ & 33 & \\
\hline Tower module & $\$ / \mathrm{kW}$ & 219 & \\
\hline
\end{tabular}




\begin{tabular}{|c|c|c|c|}
\hline Assumption & Units & Value & Notes \\
\hline Balance of system & $\$ / \mathrm{kW}$ & 332 & \multirow{7}{*}{$\begin{array}{l}\text { Land-based Balance of System Model (National } \\
\text { Renewable Energy Laboratory [NREL] 2010) }\end{array}$} \\
\hline Development cost & $\$ / \mathrm{kW}$ & 16 & \\
\hline Engineering management & $\$ / \mathrm{kW}$ & 19 & \\
\hline Foundation & $\$ / \mathrm{kW}$ & 60 & \\
\hline Site access and staging & $\$ / \mathrm{kW}$ & 45 & \\
\hline Assembly and installation & $\$ / \mathrm{kW}$ & 45 & \\
\hline Electrical infrastructure & $\$ / \mathrm{kW}$ & 148 & \\
\hline Soft costs & $\$ / \mathrm{kW}$ & 127 & \\
\hline Construction finance & $\$ / \mathrm{kW}$ & 39 & $\begin{array}{l}2019 \text { Annual Technology Baseline (NREL's Annual } \\
\text { Technology Baseline and Standard Scenarios web page: } \\
\text { atb.nrel.gov) }\end{array}$ \\
\hline Contingency & $\$ / \mathrm{kW}$ & 88 & $6 \%$ of total CapEx \\
\hline \multicolumn{4}{|c|}{ Operational Expenditures (OpEx) } \\
\hline Total OpEx & $\$ / \mathrm{kW} / \mathrm{yr}$ & 44 & (Wiser et al. 2019) \\
\hline \multicolumn{4}{|c|}{ Financials } \\
\hline Project design life & years & 25 & $\begin{array}{l}\text { Project life for Government Performance and Reporting } \\
\text { Act (GPRA) reporting }\end{array}$ \\
\hline $\begin{array}{l}\text { Tax rate (combined state and } \\
\text { federal) }\end{array}$ & $\%$ & $26 \%$ & \multirow{4}{*}{$\begin{array}{l}2019 \text { Annual Technology Baseline (NREL's Annual } \\
\text { Technology Baseline and Standard Scenarios web page: } \\
\text { atb.nrel.gov) }\end{array}$} \\
\hline Inflation rate & $\%$ & $2.5 \%$ & \\
\hline $\begin{array}{l}\text { Interest during construction } \\
\text { (nominal) }\end{array}$ & $\%$ & $4.5 \%$ & \\
\hline Construction finance factor & $\%$ & $103 \%$ & \\
\hline Debt fraction & $\%$ & $51 \%$ & \multirow{3}{*}{$\begin{array}{l}\text { “2018 Wind Technologies Market Report" (Wiser and } \\
\text { Bolinger 2019) }\end{array}$} \\
\hline Debt interest rate (nominal) & $\%$ & $4.5 \%$ & \\
\hline Return on equity (nominal) & $\%$ & $12 \%$ & \\
\hline $\begin{array}{l}\text { Weighted-average cost of } \\
\text { capital (WACC) (nominal; } \\
\text { after-tax) }\end{array}$ & $\%$ & $7.6 \%$ & \multirow{4}{*}{ Calculation } \\
\hline WACC (real; after-tax) & $\%$ & $5.0 \%$ & \\
\hline $\begin{array}{l}\text { Capital recovery factor } \\
\text { (nominal; after-tax) }\end{array}$ & $\%$ & $9.0 \%$ & \\
\hline $\begin{array}{l}\text { Capital recovery factor (real; } \\
\text { after-tax) }\end{array}$ & $\%$ & $7.1 \%$ & \\
\hline Depreciable basis & $\%$ & $100 \%$ & Simplified depreciation schedule \\
\hline Depreciation schedule & 5-year MACRS & $\begin{array}{c}\text { 5-year } \\
\text { MACRS* }\end{array}$ & Standard for U.S. wind projects \\
\hline $\begin{array}{l}\text { Depreciation adjustment (net } \\
\text { present value [NPV]) }\end{array}$ & $\%$ & $82 \%$ & \multirow{4}{*}{ Calculation } \\
\hline Project finance factor & $\%$ & $106 \%$ & \\
\hline $\begin{array}{l}\text { Fixed charge rate (FCR) } \\
\text { (nominal) }\end{array}$ & $\%$ & $9.6 \%$ & \\
\hline FCR (real) & $\%$ & $7.5 \%$ & \\
\hline Levelized cost of energy & $\$ / M W h$ & 42 & Calculation \\
\hline
\end{tabular}

*Modified Accelerated Cost Recovery System (MACRS) 
Table F2. Fixed-Bottom Offshore Wind Reference Project LCOE Assumptions

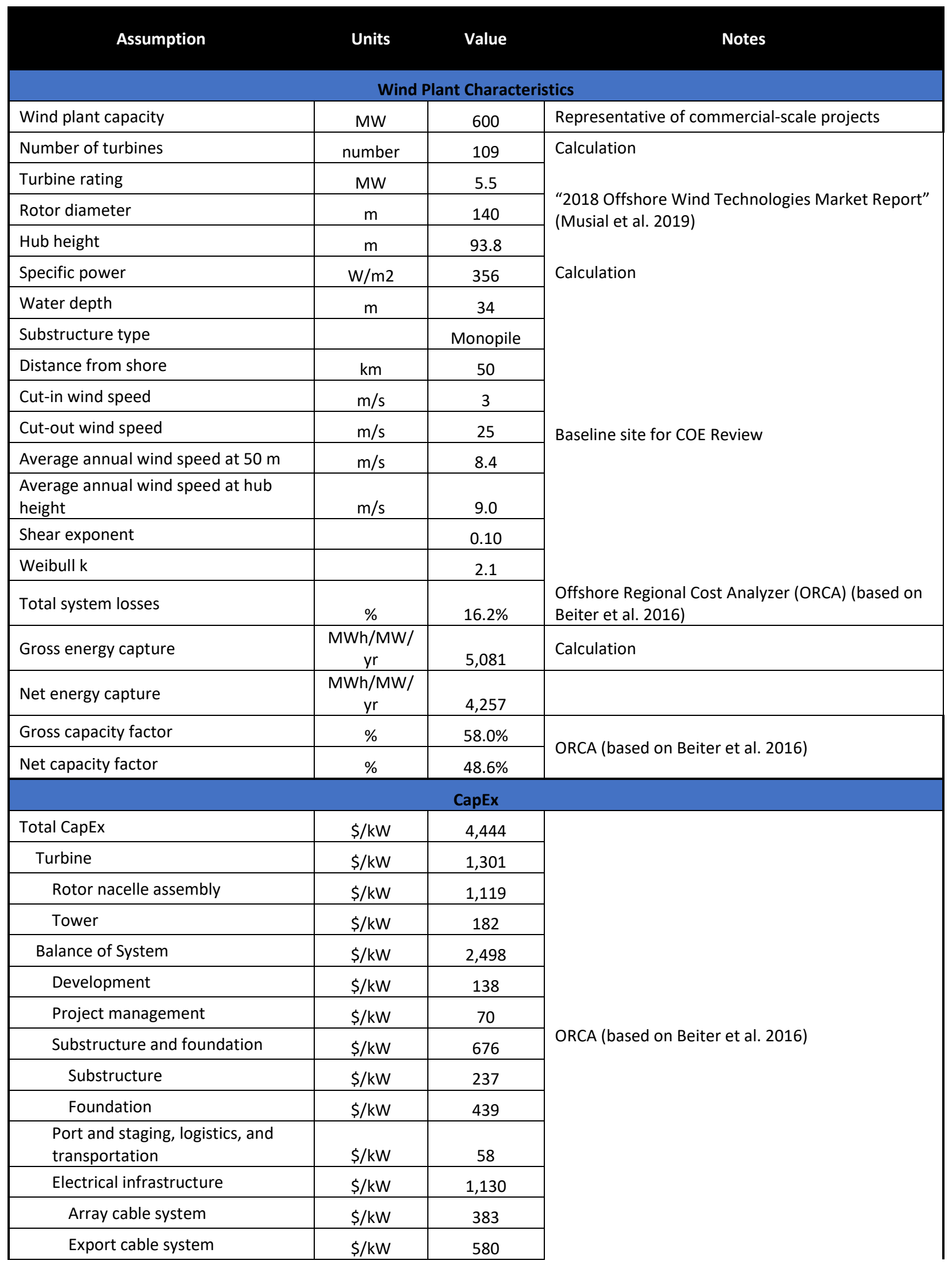




\begin{tabular}{|c|c|c|c|}
\hline Assumption & Units & Value & Notes \\
\hline Grid connection & $\$ / k W$ & 167 & \\
\hline Assembly and installation & $\$ / \mathrm{kW}$ & 338 & \\
\hline Turbine installation & $\$ / \mathrm{kW}$ & 122 & \\
\hline $\begin{array}{l}\text { Substructure and foundation } \\
\text { installation }\end{array}$ & $\$ / \mathrm{kW}$ & 217 & \\
\hline Soft Costs & $\$ / \mathrm{kW}$ & 645 & \\
\hline Insurance during construction & $\$ / \mathrm{kW}$ & 44 & \\
\hline Decommissioning bond & $\$ / \mathrm{kW}$ & 58 & \\
\hline Construction finance & $\$ / \mathrm{kW}$ & 183 & \\
\hline Sponsor contingency & $\$ / \mathrm{kW}$ & 316 & \\
\hline Procurement contingency & $\$ / \mathrm{kW}$ & 199 & \\
\hline Installation contingency & $\$ / \mathrm{kW}$ & 117 & \\
\hline Project completions/ commissioning & $\$ / \mathrm{kW}$ & 44 & \\
\hline \multicolumn{4}{|c|}{ OpEx } \\
\hline Total OpEx & $\$ / \mathrm{kW} / \mathrm{yr}$ & 129 & \multirow{3}{*}{ ORCA (based on Beiter et al. 2016) } \\
\hline Operations (pretax) & $\$ / \mathrm{kW} / \mathrm{yr}$ & 30 & \\
\hline Maintenance & $\$ / \mathrm{kW} / \mathrm{yr}$ & 99 & \\
\hline \multicolumn{4}{|c|}{ Financials } \\
\hline Project design life & years & 25 & Offshore wind project life for GPRA reporting \\
\hline Tax rate (combined state and federal) & $\%$ & $26 \%$ & \multirow{5}{*}{$\begin{array}{l}\text { Offshore wind financing assumptions for GPRA } \\
\text { reporting }\end{array}$} \\
\hline Inflation rate & $\%$ & $2.5 \%$ & \\
\hline Debt fraction & $\%$ & $75 \%$ & \\
\hline Debt interest rate (nominal) & $\%$ & $4.5 \%$ & \\
\hline Return on equity (nominal) & $\%$ & $10.0 \%$ & \\
\hline WACC (nominal; after tax) & $\%$ & $5.0 \%$ & \multirow{4}{*}{ Calculation } \\
\hline WACC (real; after tax) & $\%$ & $2.4 \%$ & \\
\hline $\begin{array}{l}\text { Capital recovery factor (nominal; after } \\
\text { tax) }\end{array}$ & $\%$ & $7.1 \%$ & \\
\hline Capital recovery factor (real; after tax) & $\%$ & $5.4 \%$ & \\
\hline Depreciable basis & $\%$ & $100 \%$ & Simplified depreciation schedule \\
\hline Depreciation schedule & & $\begin{array}{l}\text { 5-year } \\
\text { MACRS }\end{array}$ & Standard for U.S. wind projects \\
\hline Depreciation adjustment (NPV) & $\%$ & $87.4 \%$ & \multirow{4}{*}{ Calculation } \\
\hline Project finance factor & $\%$ & $104 \%$ & \\
\hline FCR (nominal) & $\%$ & $7.4 \%$ & \\
\hline FCR (real) & $\%$ & $5.6 \%$ & \\
\hline Levelized cost of energy & $\$ / \mathrm{MWh}$ & 89 & Calculation \\
\hline
\end{tabular}


Table F3. Floating Offshore Wind Reference Project LCOE Assumptions

\begin{tabular}{|c|c|c|c|}
\hline Assumption & Units & Value & Notes \\
\hline \multicolumn{4}{|c|}{ Wind Plant Characteristics } \\
\hline Wind plant capacity & MW & 600 & Representative of commercial-scale projects \\
\hline Number of turbines & number & 109 & Calculation \\
\hline Turbine rating & MW & 5.5 & \multirow{3}{*}{$\begin{array}{l}\text { "2018 Offshore Wind Technologies Market } \\
\text { Report" (Musial et al. 2019) }\end{array}$} \\
\hline Rotor diameter & $\mathrm{m}$ & 140 & \\
\hline Hub height & $\mathrm{m}$ & 93.8 & \\
\hline Specific power & $\mathrm{W} / \mathrm{m} 2$ & 356 & Calculation \\
\hline Water depth & $\mathrm{m}$ & 739 & \multirow{9}{*}{ Baseline site for COE Review } \\
\hline Substructure type & & $\begin{array}{l}\text { Semisubmersi } \\
\text { ble }\end{array}$ & \\
\hline Distance from shore & $\mathrm{km}$ & 36 & \\
\hline Cut-in wind speed & $\mathrm{m} / \mathrm{s}$ & 3 & \\
\hline Cut-out wind speed & $\mathrm{m} / \mathrm{s}$ & 25 & \\
\hline Average annual wind speed at $50 \mathrm{~m}$ & $\mathrm{~m} / \mathrm{s}$ & 7.7 & \\
\hline $\begin{array}{l}\text { Average annual wind speed at hub } \\
\text { height }\end{array}$ & $\mathrm{m} / \mathrm{s}$ & 8.2 & \\
\hline Shear exponent & & 0.10 & \\
\hline Weibull k & & 2.1 & \\
\hline Total system losses & $\%$ & $21.0 \%$ & ORCA (based on Beiter et al. 2016) \\
\hline Gross energy capture & $\begin{array}{c}\text { MWh/MW/ } \\
y r\end{array}$ & 4,205 & Calculation \\
\hline Net energy capture & $\begin{array}{l}\text { MWh/MW/ } \\
\mathrm{yr}\end{array}$ & 3,324 & \\
\hline Gross capacity factor & $\%$ & $48.0 \%$ & \multirow{2}{*}{ ORCA (based on Beiter et al. 2016) } \\
\hline Net capacity factor & $\%$ & $37.9 \%$ & \\
\hline \multicolumn{4}{|c|}{ CapEx } \\
\hline Total CapEx & $\$ / \mathrm{kW}$ & 5,355 & \multirow{14}{*}{ ORCA (based on Beiter et al. 2016) } \\
\hline Turbine & $\$ / \mathrm{kW}$ & 1,301 & \\
\hline Rotor nacelle assembly & $\$ / \mathrm{kW}$ & 1,119 & \\
\hline Tower & $\$ / \mathrm{kW}$ & 182 & \\
\hline Balance of System & $\$ / \mathrm{kW}$ & 3,263 & \\
\hline Development & $\$ / \mathrm{kW}$ & 165 & \\
\hline Project management & $\$ / \mathrm{kW}$ & 85 & \\
\hline Substructure and foundation & $\$ / \mathrm{kW}$ & 1,443 & \\
\hline Substructure & $\$ / \mathrm{kW}$ & 1,139 & \\
\hline Foundation & $\$ / \mathrm{kW}$ & 304 & \\
\hline $\begin{array}{l}\text { Port and staging, logistics, and } \\
\text { transportation }\end{array}$ & $\$ / \mathrm{kW}$ & 44 & \\
\hline Electrical infrastructure & $\$ / \mathrm{kW}$ & 999 & \\
\hline Array cable system & $\$ / \mathrm{kW}$ & 392 & \\
\hline Export cable system & $\$ / \mathrm{kW}$ & 487 & \\
\hline
\end{tabular}




\begin{tabular}{|c|c|c|c|}
\hline Assumption & Units & Value & Notes \\
\hline Grid connection & $\$ / \mathrm{kW}$ & 120 & \\
\hline Assembly and installation & $\$ / \mathrm{kW}$ & 440 & \\
\hline Turbine installation & $\$ / \mathrm{kW}$ & 318 & \\
\hline $\begin{array}{l}\text { Substructure and foundation } \\
\text { installation }\end{array}$ & $\$ / \mathrm{kW}$ & 122 & \\
\hline Soft Costs & $\$ / \mathrm{kW}$ & 790 & \\
\hline Insurance during construction & $\$ / \mathrm{kW}$ & 52 & \\
\hline Decommissioning bond & $\$ / \mathrm{kW}$ & 76 & \\
\hline Construction finance & $\$ / \mathrm{kW}$ & 221 & \\
\hline Sponsor contingency & $\$ / \mathrm{kW}$ & 389 & \\
\hline Procurement contingency & $\$ / \mathrm{kW}$ & 237 & \\
\hline Installation contingency & $\$ / \mathrm{kW}$ & 152 & \\
\hline $\begin{array}{l}\text { Project } \\
\text { completions/commissioning }\end{array}$ & $\$ / \mathrm{kW}$ & 52 & \\
\hline \multicolumn{4}{|c|}{ OpEx } \\
\hline Total OpEx & $\$ / \mathrm{kW} / \mathrm{yr}$ & 137 & \multirow{3}{*}{ ORCA (based on Beiter et al. 2016) } \\
\hline Operations (pretax) & $\$ / \mathrm{kW} / \mathrm{yr}$ & 30 & \\
\hline Maintenance & $\$ / \mathrm{kW} / \mathrm{yr}$ & 107 & \\
\hline \multicolumn{4}{|c|}{ Financials } \\
\hline Project design life & years & 25 & Offshore wind project life for GPRA reporting \\
\hline Tax rate (combined state and federal) & $\%$ & $26 \%$ & \multirow{7}{*}{$\begin{array}{l}\text { Offshore wind financing assumptions for GPRA } \\
\text { reporting }\end{array}$} \\
\hline Federal & $\%$ & $21 \%$ & \\
\hline State & $\%$ & $7.5 \%$ & \\
\hline Inflation rate & $\%$ & $2.5 \%$ & \\
\hline Debt fraction & $\%$ & $75 \%$ & \\
\hline Debt interest rate (nominal) & $\%$ & $4.5 \%$ & \\
\hline Return on equity (nominal) & $\%$ & $10.0 \%$ & \\
\hline WACC (nominal; after tax) & $\%$ & $5.0 \%$ & \multirow{4}{*}{ Calculation } \\
\hline WACC (real; after tax) & $\%$ & $2.4 \%$ & \\
\hline $\begin{array}{l}\text { Capital recovery factor (nominal; } \\
\text { after tax) }\end{array}$ & $\%$ & $7.1 \%$ & \\
\hline $\begin{array}{l}\text { Capital recovery factor (real; after } \\
\text { tax) }\end{array}$ & $\%$ & $5.4 \%$ & \\
\hline Depreciable basis & $\%$ & $100 \%$ & Simplified depreciation schedule \\
\hline Depreciation schedule & & 5-year MACRS & Standard for U.S. wind projects \\
\hline Depreciation adjustment (NPV) & $\%$ & $87.4 \%$ & \multirow{4}{*}{ Calculation } \\
\hline Project finance factor & $\%$ & $104 \%$ & \\
\hline FCR (nominal) & $\%$ & $7.4 \%$ & \\
\hline FCR (real) & $\%$ & $5.6 \%$ & \\
\hline Levelized cost of energy & $\$ / M W h$ & 132 & Calculation \\
\hline
\end{tabular}

